University of Louisville

ThinkIR: The University of Louisville's Institutional Repository

$12-2011$

\title{
A longitudinal view of the liberal arts curriculum a decade after merger : a multiple case study of community colleges in Connecticut, Kentucky, and Louisiana.
}

Ann E. Norton

University of Louisville

Follow this and additional works at: https://ir.library.louisville.edu/etd

\section{Recommended Citation}

Norton, Ann E., "A longitudinal view of the liberal arts curriculum a decade after merger : a multiple case study of community colleges in Connecticut, Kentucky, and Louisiana." (2011). Electronic Theses and Dissertations. Paper 1070.

https://doi.org/10.18297/etd/1070

This Doctoral Dissertation is brought to you for free and open access by ThinkIR: The University of Louisville's Institutional Repository. It has been accepted for inclusion in Electronic Theses and Dissertations by an authorized administrator of ThinkIR: The University of Louisville's Institutional Repository. This title appears here courtesy of the author, who has retained all other copyrights. For more information, please contact thinkir@louisville.edu. 


\title{
A LONGITUDINAL VIEW OF THE LIBERAL ARTS CURRICULUM A DECADE AFTER MERGER: A MULTIPLE CASE STUDY OF COMMUNITY COLLEGES IN CONNECTICUT, KENTUCKY, AND LOUISIANA
}

\author{
By \\ Ann E. Norton \\ M.A., Western Kentucky University, 1990

\begin{abstract}
A Dissertation
Submitted to the Faculty of the

College of Education of the University of Louisville

in Partial Fulfillment of the Requirements

for the Degree of
\end{abstract}

Doctor of Philosophy

Department of Leadership, Foundations and Human Resource Education

University of Louisville

December 2011 


\section{Copyright 2011 by Ann E. Norton}

All rights reserved 
A LONGITUDINAL VIEW OF THE LIBERAL ARTS CURRICULUM A DECADE AFTER MERGER: A MULTIPLE CASE STUDY OF COMMUNITY COLLEGES IN CONNECTICUT, KENTUCKY, AND LOUISIANA

\section{By}

Ann E. Norton

B.A. Western Kentucky University, 1988

M.A. Western Kentucky University, 1990

A Dissertation Approved on

November 4, 2011

By the following Dissertation Committee

Kristin Wilson

Dissertation Director

Rod Githens

Susan Edington

Joseph Petrosko 


\section{DEDICATION}

This dissertation is dedicated to my parents

\section{Joseph Sylvester Eaton III}

and

\section{Norma Jean Eaton}

Thank you for your constant encouragement and support throughout my educational pursuits. 


\section{ACKNOWLEDGEMENTS}

I would like to thank my dissertation director, Dr. Kristin Wilson, for her guidance, time and unwavering support over the past three years. Your willingness to assist me through the process when you did not know me as your student demonstrates your compassion for those in need. I will forever be grateful for your willingness to assist me when I felt like giving up on this dream. Also, I would like to thank my committee members, Dr. Rod Githens, Dr. Joseph Petrosko, and Dr. Susan Edington for their direction and support. I appreciate the time and attention you gave me and my work throughout this journey. Finally, I want to thank my family. To my loving and patient husband, Don, I thank you for encouraging me to continue when I felt like giving up. Your gentle nudging to write kept me moving toward my goal. Thank you for believing in me and being proud of me when I finished. To my daughter Madison, I thank you for understanding the time away from you while I attended classes and wrote the dissertation. You have been there with me since the beginning of this journey and I appreciate you for your patience and support over the years. To Kaiti and Lauren, I thank you for your support when my time was limited and your dad and I could not get away to visit as often. Also, I thank you for providing much welcome company to Madison when I was away working on this dissertation. To my sister, Laura, and brother, Joe, I thank you for helping to form the person I am today. Also, thank you mom and dad for instilling a strong education value in me and having faith that I would follow through to the Ph.D. 
TABLE OF CONTENTS

ACKNOWLEDGEMENTS
ABSTRACT
INTRODUCTION

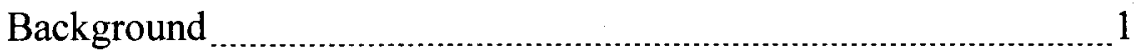

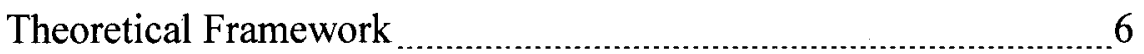

Purpose of the Study

Significance of the Study $\ldots$

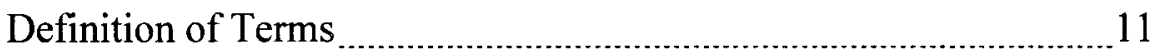

Study Limitations

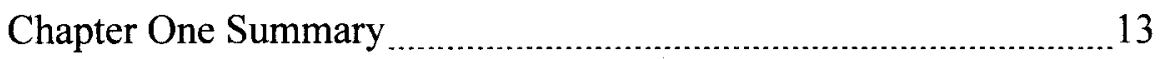

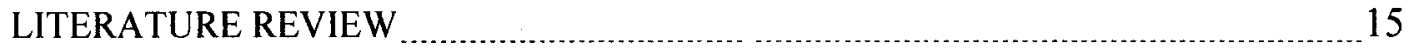

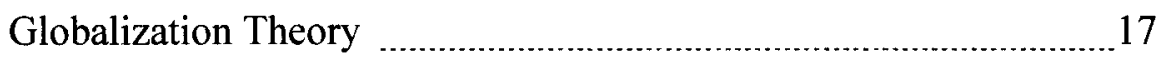

Mergers in Higher Education .............................................................. 24

Human Implications of Merger …………............................... 25

Summary

Increasing Emphasis on Workforce Development _.............................2 27

Summary $\ldots \ldots \ldots$

Diminishing Liberal Arts Curriculum …………………………....... 31

Trends in General Education ………............................................... 34

General Education Approaches _............................................36 
General Education Reform..

Trends in the Liberal Arts Curriculum ................................ 43

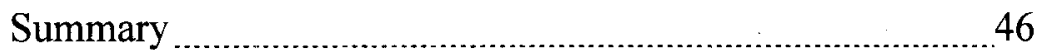

Historical and Political Contexts of the Colleges Under Study .............. 47

Connecticut

Three Rivers Community College

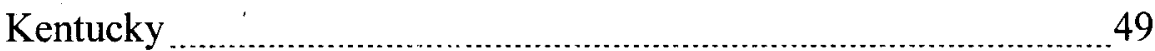

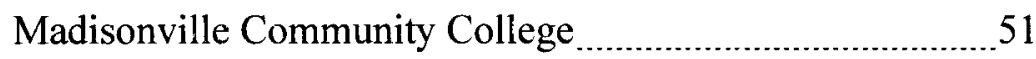

Louisiana

Nunez Community College .............................................. 54

Chapter Two Summary .................................................................... 55

METHODOLOGY

Introduction

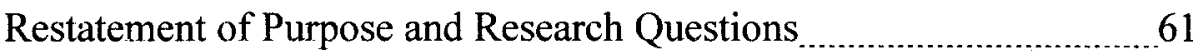

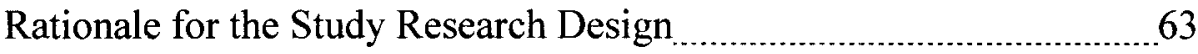

Qualitative Research Design .......................................................63

Multiple Case Study Methodology ………...................................... 64

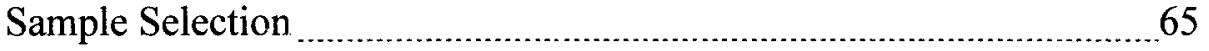

Data Collection Methods $\ldots \ldots$

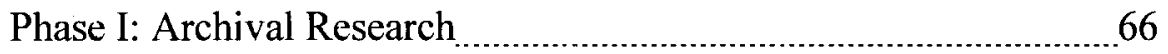

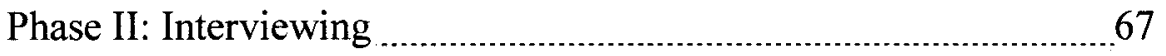

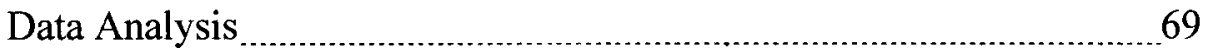

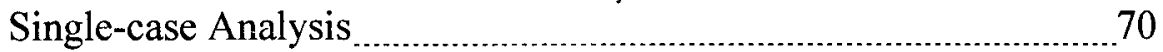


Cross-case Analysis

Ethical Considerations

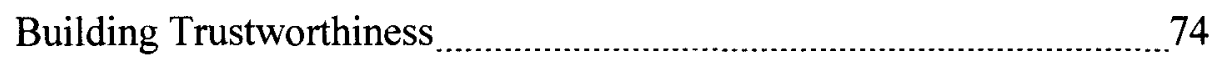

Study Limitations

Chapter Three Summary

FINDINGS

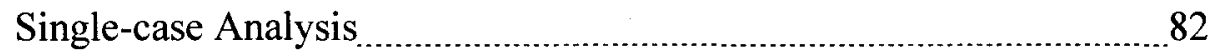

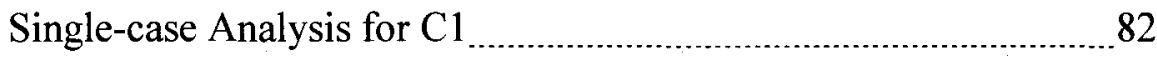

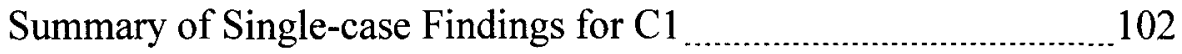

Single-case Analysis for C2

Summary of Single-case Findings for C2

Single-case Analysis for C3

Summary of Single-case Findings for C3

Cross-case Analysis

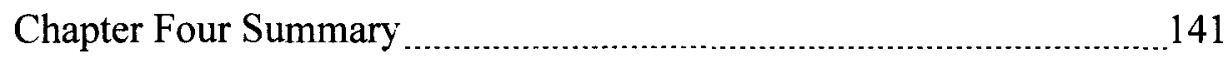

DISCUSSION

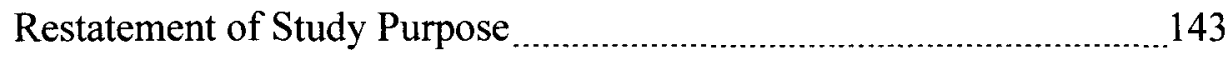

Research Questions and Findings

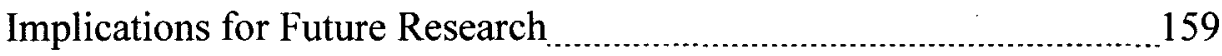

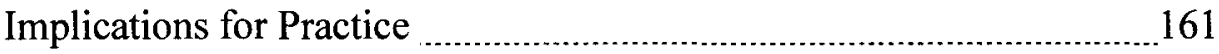

REFERENCES

APPENDICES 
Appendix A: Model of Multiple Case Study

Appendix B: Research Questions and Documents. 176

Appendix C: Interview Question Protocol

Appendix D: Trustworthiness Chart 182

Appendix E: Data Analysis Documents 183

Table 1: Ratings of Expected Utility for Each Theme 183

Table 2: Ratings of Case Study Findings 184

Table 3: Cross-case Themes 185 186 


\section{ABSTRACT \\ THE STATE OF THE LIBERAL ARTS CURRICULUM IN MERGED COMMUNITY COLLEGES}

Ann E. Norton

December 2011

This dissertation is an examination of the state of the liberal arts curriculum in community colleges in three geographic regions of the United States. From a constructivist paradigm and using globalization theory as a theoretical framework, this multiple case study examined faculty work life and administrative processes related to curriculum change in merged community and technical colleges. Through an examination of research on globalization, mergers, and trends in the general education and liberal arts curriculum, a gap in the literature emerged in the studies of community college curriculums after merger. This dissertation considers whether the focus on workforce development and decrease in the transfer mission has diminished the liberal arts courses in the college curriculum. Research on liberal arts courses identified them as courses that emphasize higher order thinking and the development of intellectual skills needed to engage in a democratic society. If students are not exposed to these skills, it may have a detrimental effect on a democratic society.

The first three chapters of the dissertation outline the problem, identify relevant literature, and provide the study methodology. Chapter one provides background information about the research problem and presents the argument that liberal arts 
curriculum may be diminishing in community colleges. Also, chapter one provides an overview of the theoretical framework which was based on the studies on globalization and community colleges by John Levin. Chapter two explores the research which provided the conceptual framework for the problem development. The research included studies on Globalization, Mergers in Higher Education, Increasing emphasis on Workforce Development, The Diminishing Liberal Arts Curriculum, and Trends in General Education. Chapter three offers a discussion about the constructivist approach to educational research and its application to the study. Chapter four includes the findings from the single-case analysis and cross-case analysis. Significant findings included a trend toward diminishing the liberal arts courses in AAS programs, especially as transfer is encouraged with these programs. Other significant findings revealed integration challenges between the general education and technical/occupational program faculty and their respective curriculums after merger. Additionally, study findings suggested that the changing demographics of today's community college students, as well as the ongoing budget constraints, create frustrations and challenges for faculty members.

Leaders of community colleges and technical colleges who plan to merge must reduce hierarchical communication during times of organizational change such as a merger and emphasize the positive outcomes of the mergers while minimizing the negative. Also, college leaders must recognize and respond to faculty members' frustrations with the amount of work required to teach students who require more remediation and present classroom management challenges. 


\section{CHAPTER 1 \\ INTRODUCTION}

\section{Background}

Globalization, particularly globalization empowered by technical innovation, has changed the way businesses, governments, and schools operate. Educators now see their mission as educating students for a global economy and global competitiveness (Levin, 2006). Economic development is often viewed as an educational problem, in that business leaders demand high levels of technical skills in workforce populations before they will invest in local economies. State policy-makers have responded by consolidating educational systems in order to standardize offerings and increase accountability, quicken the pace of program development, and operate more efficiently (Puyear, 2002). With an eye on the corporate merger context, several states, including Connecticut, Kentucky, and Louisiana, have merged their community colleges with their technical colleges (Puyear, 2002; Giroux, 1999; Levin, 2006). Both state policy-makers and educational leaders believe that these mergers have eliminated program duplication, removed transfer barriers, and reduced competition for state allocated dollars. However, government mandates and mergers have brought about changes in the missions of the community and technical colleges. The transfer mission, once the strongest part of the community college mission, is no longer the primary focus and the workforce development mission dominates the work of community colleges (Jacobs \& Dougherty, 2006). Some scholars have suggested that as the transfer mission diminishes, so does the emphasis on the 
liberal arts resulting in what may be a narrowing of curricular offerings (Grubb, 2005; Brint, Riddle, Turk-Bicakci., \& Levy, 2005). The outcome of this trend may be a graduate that has not been exposed to knowledge determined centuries ago to produce the “educated man" (Flannery, 1998).

The idea of liberal education in the west evolved from the life of Socrates through his pursuit of the questions "What is good?" and "How do we learn what is good and avoid what is evil?"(Flannery, 1998). Plato's Socrates suggested that education is deficient without the pursuit of the "study of that "for the sake of which' we do all that we do" (p. 2). These questions shaped the liberal arts curriculum through the middle ages to the present. In the middle ages, the "educated man" was a man who obtained knowledge through exposure to the trivium and the quadrivium disciplines in the medieval university. The trivium included knowledge in grammar, logic, and rhetoric while the quadrivium, considered a higher level of knowledge above the trivium, included geometry, music, astronomy, and arithmetic (Flannery, 1998). The purpose of these "seven pillars of wisdom" was to provide the basic content for an intellectual life. These disciplines are what comprised the "liberal arts", literally meaning the "arts of freedom" or the knowledge indicative of a "free" man (p. 4).

Today, the liberal arts curriculum and the general education curriculum are combined, especially in community colleges; therefore, the two topics are explored together. The purpose of general education is to provide the "breadth of knowledge" the graduate needs for engagement in today's societal issues. Recent general education studies in higher education revealed that there are varying approaches to the general education curriculum. Brint, Proctor, Murphy, Turk-Bicakci and Hanneman (2009) 
suggested four general education models existed between 1975 and 2000. The models included the traditional liberal arts model, which focused on offering courses in literature, philosophy, foreign languages and history; the core distribution model, which included course distributions from the humanities, social sciences, natural sciences, mathematics, and the arts; the culture and ethics model, which derived from forces of expansion and diversification and brought minority studies and ethics into the curriculum; and, the civic/utilitarian model which brought a focus on citizenship and preparing the student for work and civic responsibilities. Brint et al. suggested that the traditional liberal arts model is derived from status cultures; the core distribution model is derived from organizational compromises; and the civic/utilitarian model is derived from a political initiative and labor market incentives. Newton (2000), however, identified the great books model, the scholarly discourse model, and the effective citizen model as the models that provide the breadth and development that students need. The great books model provides a historical review of the most significant foundational works while the scholarly discourse model takes the opposite approach. It promotes a general introduction from multiple disciplines and the latest research about these ideas as the best approach to depth and breadth. The effective citizen model provides students with the best intellectual basis for their participation in society in the twenty-first century. It is evident through the research on general education that opinions vary about which approach is the best approach to depth and breadth of knowledge. One common idea that was emphasized in most approaches was the development of citizenship and civic responsibility in the curriculum. 
Research on general education requirements indicated that not all students experience the same breadth of knowledge exposure. Most baccalaureate colleges follow a distributional general education core curriculum model; although, at some liberal arts colleges the general education program was determined between the student and advisor (Bourke, Bray, and Horton, 2009). Higher ranking colleges, determined by a survey in the U.S. News and World Report annual rankings of the best colleges, offered the student greater choice in courses to meet his/her general education requirements. Although this approach gives the student more choice, it may prevent him/her from being exposed to new areas of knowledge because the student has "pre-determined" his/her interest in certain types of general education courses. Also, the student may experience a fragmented curriculum which lacks coherence. Zeszotarski (1999) gathered data from the 1998 Curriculum Project of the Center for the Study of Community Colleges and found discrepancies between general education requirements between transfer and non-transfer programs, indicating that non-transfer students may have less exposure to courses that develop ideas of civic issues. These studies revealed that discrepancies exist in general education requirements across baccalaureate and community colleges.

General education reform is a concern at all levels of higher education institutions. According to Johnson, Ratcliff, and Gaff (2004), eighty percent of Chief Academic Officers (CAOs) at 278 baccalaureate institutions indicated that they had engaged in general education reform in the previous six years. Most of the changes included course elective changes and the development of a more prescriptive course sequencing and course clustering to add coherence to the curriculum. The administrators indicated pressure from accrediting agencies led to some curricular change. 
CAOs at community colleges indicated major barriers to general education curriculum changes included resistant faculty members, transfer problems, inadequate funding and organizational issues (Path \& Hammons, 1999). The integration of occupational and academic curricula is difficult due to the extensive time it requires of community college faculty members who carry large teaching loads. Most integration efforts involved adding academic courses to occupational/technical program requirements, which lengthened their already comprehensive programs mandated by the program accrediting agencies. As state education boards and policy-makers demand a quick turn-around in degree completion, the occupational/technical program directors may strike the general education courses from their curriculum to meet this demand, but the students in those programs may lose exposure to the breadth of knowledge they need to engage in civic issues. Although faculty members may disagree about what specific courses to include in the general education requirements, the literature review on general education revealed an agreement from administrators and faculty members that the general education curriculum must remain responsive to students' needs, so it must be reviewed and changed often. Assessing the general education program continues to present a challenge for higher education institutions.

As noted previously, the idea of the liberal arts is longstanding in the historical development of the intellectual human. The critical thinking and reasoning learned in the trivium and quadrivium disciplines encouraged learning for "knowledge sake" to equip the individual with the logic and reasoning skills to be an active participant in a democratic society (Grubb, 2005; Flannery, 1998). These old ideas are still very much alive today and part of curriculum discussions at baccalaureate colleges, especially liberal 
arts colleges where many "elites" are educated (Bourke, Bray, \& Horton, 2009). Students at community colleges, however, are often the disadvantaged and underrepresented population who represent the "non-elites". Some scholars feel community colleges are directly responsible for social reproduction by "cooling out" (Burton, 1989) students or redirecting them into occupational/technical degrees rather than transfer degrees due to their perceived ability. These students then remain disadvantaged and do not advance in socio-economic status.

Today's globalized community college emphasizes skills training with a quick and flexible curriculum to prepare individuals to enter the workforce. Consequently, the graduate enters the workforce with a skill, but may lack the reasoning and logic to problem-solve and think critically in a globally competitive workforce, which puts him/her at a disadvantage because the community college did not provide adequate exposure to the higher order thinking skills found in the liberal arts curriculum. In the literature, community colleges have been called "democracy's college" (Diekhoff, 1950). If that is true then these colleges should be equally as responsible as the elite liberal arts colleges for developing curriculum that prepares students to become engaged participants in a democratic society rather than providing a functional curriculum preparing students for workforce development.

\section{Theoretical Framework}

Robertson (1991), the founder of globalization theory, defined globalization as "the compression of the world and the intensification of consciousness of the world as a whole" (p. 8). He suggested that the world is becoming a single place as technology advances, and national and international boundaries come down resulting in a globally 
competitive market. John Levin $(2001,2006)$, a leading researcher studying the effects of globalization on community colleges, completed a comprehensive study of seven community colleges in the United States and Canada. From this study he developed a report entitled Globalizing the Community College: Strategies of Change in the $21^{\text {st }}$ Century (2001). In this report he suggested that over the last two decades the role and mission of community colleges have evolved with external pressures from state governments, policy makers, and business and industry to become more efficient and accountable to remain competitive in a globalized market. The outcome is the globalization and vocationalization of education with a resulting emphasis on workforce development, deemphasizing transfer and liberal arts curriculum. Also, there is a growing emphasis on workforce preparation and retraining and less emphasis on individual development. Some scholars, such as Giroux (1999), suggested less exposure to the liberal arts can have larger implications on a democratic society because students will miss the exposure to higher order thinking and reasoning skills found in the liberal arts curriculum.

Through his studies, Levin (2006) found four categories of behavior present in a globalized community college: (a) oppositional culture, (b) values, (c) economic behaviors, and (d) labor behaviors. In his studies on community colleges, he placed his data into one of these four categories based on the interview statement content. Oppositional cultures suggested a critique of institutional practices, behaviors, and influences, or suggested factions within the institution that are opposed to institutional patterns and behaviors. Values reflected value statements relevant to both education and economic values or to institutional behaviors. Economic behaviors included statements 
that characterized institutional or individual behaviors associated with economic motives or goals. Statements describing or judging institutional or individual behaviors that pertained to the work of faculty were placed under labor behaviors. These four categories served as the analytical framework for the data collected in this study. The scope of Levin's community college research was broad, and not focused only on curriculum; however, the categories provide a structure to tie globalization and curriculum changes together through the data collected during interviews with faculty members and administrators and through document review. For this study, the researcher tracked oppositional factors, and values through faculty work-life and curricular changes and economic behaviors and labor behaviors through themes in administrative practices.

\section{Purpose of the Study}

The purpose of this qualitative multiple case study was to identify curricular changes in course offerings and in course content in the disciplines of English and communication in the years following state-wide mergers between community college and technical school systems in three states, Connecticut, Kentucky, and Louisiana; to understand how curricular changes are affecting organizational administration and faculty work life; and to understand whether curricular and organizational changes seem to reflect the globalization of the comprehensive community college mission. The English and communication (rhetoric) disciplines hold historical significance in the evolution of the liberal arts throughout the centuries so this study focused on these disciplines. The study had three major objectives: (a) To explore changes to the English and communication curriculum after the states' community colleges and technical schools were merged (b) to explore changes in faculty work life, particularly as it relates to 
curricular modifications, after the states' community colleges and technical schools were merged, and (c) to explore changes in organizational administration, especially related to curriculum development and modification, after the states' community colleges and technical schools were merged. Four issue questions drove the study:

1. Have or how have curricular offerings, course requirements and course content changed in English and communication since the merger between community colleges and technical colleges?

2. Has or how has the mission of preparing a workforce for a global economy been part of faculty curriculum discussions and changes?

3. Has the nature of work with students, colleagues, and/or administration changed since the merger? How so?

4. Have or how have the administrative process related to curriculum changed and what tensions surround curriculum discussions since the merger between community and technical colleges?

\section{Significance of the Study}

The presence of educational mergers in the literature is not new; however, the historic trend of mergers between small community colleges and small technical schools to become comprehensive community colleges has not been thoroughly studied. Researchers, such as Harmon (2003), conducting merger studies indicated that the effects of mergers are not fully evident for ten years after the merger occurs: therefore, the researcher chose to study community colleges whose mergers occurred over ten years ago. 
General education curriculum is well-studied at four-year institutions, but not at community colleges, although there are a few studies that date back to the early 1900s. These early studies revealed an emphasis on an academic curriculum. The 1950s brought more occupational/technical courses into the college curriculum. By the $1980 \mathrm{~s}$, the emphasis on workforce development led to growth in occupational courses and programs and a diminishing of the liberal arts courses (Schuyler, 1999).

Arthur Cohen (1992), a well known researcher of community college curriculum, conducted the most comprehensive curriculum studies over several decades to determine the state of the liberal arts curriculum. His most recent study was conducted in the 1990s. Through analyzing class schedules, course enrollment forms, and catalogs, he determined that a little over half of the curriculum was liberal arts. For the community colleges in this study, mergers with technical colleges were new or not yet completed at the time of Cohen's study; thus, the impact of the merger on the liberal arts curriculum could not be fully recognized if the effects of merger take nearly 10 years to develop. Also, Cohen did not conduct interviews with faculty members and administrators; therefore, a qualitative study, such as this study, can provide rich data to deeply explore the human side of the organizational change through eliciting the perspectives of administrators and faculty members affected by the curriculum changes ensued after the mergers. The study results may provide a voice for study participants, and inform policy makers and curriculum developers about the impact these organizational and curricular changes had on these study participants. 


\section{Definition of Terms}

Contextualization. "A diverse family of instructional strategies designed to more seamlessly link the learning of foundational skills and academic or occupational content by focusing teaching and learning squarely on concrete applications in a specific context that is of interest to the student" (Mazzeo, 2003; p.4).

Comprehensive community college. Community colleges offering (a) transfer education, (b) career education, (c) developmental education, (e) continuing training (non-credit), and (f) industry training (contracted) (Gale Encyclopedia of Education, 2010).

Globalization. "The compression of the world and the intensification of consciousness of the world as a whole" (Robertson, 1992; p. 8). In thought and action, it makes the world a single place. What it means to live in this place, and how it must be ordered, become universal questions (Robertson, 1992, p. 27).

General education. "...courses within a distributional schema that all students must pass in order to graduate" (Warner \& Koeppel, 2009).

Liberal arts. Those disciplines derived from the trivium (grammar, logic, and rhetoric) and quadrivium (geometry, music, astronomy, and arithmetic) in the middle ages providing the knowledge essential for an educated or free man in a democratic society. Today, the disciplines include the arts, humanities, social science and natural science (Flannery, 1998).

Modularization. "The breaking up of the curriculum into discrete and relatively short learning experiences" (Burke, 1995). 
Occupational/Technical Program. Programs designed to prepare students for employment and provide additional training to those already employed through skill development for the purpose of career advancement (Lohman \& Dingerson, 2005).

Technical college. Institutions offering occupational/technical skill development (Gale Encyclopedia of Education, 2010).

Terminal Degree. The end point of a student's education (O'Banion, 2010).

Vocationalization. Tendency to corporatize colleges toward a business model emphasizing workforce development and minimizing academic standards (Levin, 2001).

Workforce Development. Education and training for individuals seeking to change careers, incumbent workers or upgrade their skills (Bragg, 2001).

\section{Study Limitations}

This study has limitations which may affect its transferability. Stake (2006) stated that the benefits of multi-case study will be limited if fewer than four cases are chosen or more than 10 . Two or three cases may not show the interactivity between programs and their situations. Although the researcher included a research sample with geographic diversity, it would not reflect diversity across community colleges throughout the United States. Because qualitative research is subjective, the findings may not be reflective of faculty work issues and administrative processes related to curriculum at other merged community and technical colleges. For this study, many faculty members who experienced the merger had retired, so this limited the scope of interview information at some colleges. Also, the focus on the English and communication disciplines limits the scope of data findings. There are other academic disciplines and WAC programs that 
teach classic liberal arts, but in order to manage the scope of the study, the researcher limited it to the two oldest disciplines.

\section{Summary}

In sum, the mission of community colleges in the $21^{\text {st }}$ century has changed from the mission during their inception in the industrial era. Initially, the mission emphasized transfer, education and liberal arts courses. Today, state policy-makers, boards, and administrators, calling for more efficiency, accountability, and the development of a quick and responsive curriculum, promote a business model approach to running community colleges, including the curriculum (Levin, 2001; 2006). In the last two decades mergers between community and technical colleges became more prevalent to increase efficiency and eliminate duplication and competition for state dollars. With those mergers, attempts to marry community and technical college curriculums created challenges. As the mission changed to emphasize workforce development, faculty members worry about the narrowing of the curriculum and a shrinking liberal arts

curriculum. Scholars such as Giroux (1999), Grubb (2005), and Levin (2000) echoed these concerns and suggested that the curriculum narrowing may have larger implications on society. They asserted that as workforce development is emphasized, the higher order intellectual skills, those needed for an "educated human" (Flannery, 1998) for successful engagement in a democratic society, may be lost as the liberal arts curriculum diminishes. If community colleges continue to be "democracy's college" as they have been referred to since their inception, the curriculum should equip students with skills such as critical thinking, reasoning, ethics, and an appreciation for diversity. There are few curriculum studies, particularly qualitative studies, on the evolving nature of the curriculum, 
especially after the merger between community and technical colleges. Thus, this study sought to fill the gap of research in curriculum studies.

Chapter one introduces the research study, including its purpose, significance, theoretical framework, key definitions, and limitations. Chapter two provides an extensive review of literature providing information on globalization theory as the theoretical framework. Additional information on globalization and the vocationalization of community colleges, mergers in higher education, the growing emphasis on workforce development, the diminishing liberal arts curriculum, liberal arts and general education curricular trends provides contextual knowledge for the study. Chapter three outlines the rationale for the qualitative multiple-case study, an overview of the research design, data collection and analysis methods, and ethical considerations. Chapter four provides singlecase and cross-case findings. The final chapter offers a discussion of study findings and implications for research and practice. 


\section{CHAPTER 2}

\section{LITERATURE REVIEW}

Today, community colleges are bearing the burden of increased demands from external constituents to educate the masses with more accountability for learning outcomes and higher transfer rates, all while dealing with reduced funding from state and federal governments. In many states, the government demands for efficiency and accountability have led to educational reorganization. Although education reorganization began as early at the 1970s to meet the demands of external governmental forces, it has become more prevalent in the last two decades (Puyear, 2002). Education looked to corporate models of merger for direction (Puyear, 2002; Giroux, 1999; Levin, 2006). In several states, mergers between community colleges and technical colleges, that had very different missions, were driven by state legislative mandates.

As mergers occurred, the community college mission changed to accommodate the technical school mission. For community colleges, the transfer mission diminished while the workforce development mission dominated the work of community colleges, largely due to the tendency of state and federal legislatures to fund technical program initiatives (Jacobs \& Dougherty, 2006). Some scholars have suggested that as the transfer mission diminishes, so does the emphasis on liberal arts, which narrows the curriculum and denies students exposure to broader social concerns (Karabel, 1986; Goyette \& Mullen, 2006; Giroux, 1999; Sacks, 2009). For this reason, studying community college liberal arts curricular changes after mergers with technical schools is an important and 
underexplored topic, not only as means of understanding if, and why, decreases in the liberal arts enrollments are occurring in community colleges, but also what implications a diminishing liberal arts curriculum might have on the building a strong democratic society.

The overarching question the researcher intended to address was: Are community college curriculums sacrificing the development of critical thinking skills, including exposure to ethics, diversity, and a deeper understanding of a democratic society often found in the liberal arts courses for job skills training? Through a Constructivism paradigm and using globalization theory as the theoretical lens for this study, the researcher sought to understand the changes occurring over the last decade in merged community colleges' liberal arts curriculum, particularly the English and communication curriculum. Also, the researcher sought to understand, what, if any, the role globalization has played in the changes to the curriculum since community and technical colleges merged. Some scholars have suggested that the community college missions have become more vocationalized and workforce development focused and the liberal arts curriculum is shrinking, especially in colleges where community and technical colleges merged (Levin; 2001, 2006; Dougherty, 2004). If this is true, the result of this declining liberal arts curriculum and focus on workforce development found in a globalized community colleges, directly opposes what it means to be an "educated man". In the middle ages, the "educated man" was one with exposure to the trivium and the quadrivium disciplines in the medieval university. The trivium included knowledge in grammar, logic, and rhetoric. The quadrivium included geometry, music, astronomy, and arithmetic. These disciplines comprised the original liberal arts curriculum, which early 
scholars believed equipped man with the knowledge needed for engaged citizenship in a democratic society (Flannery, 1998).

There are few curriculum studies, particularly qualitative studies, on the evolving nature of community college curriculums given the evolving mission of the institution. Research has indicated that the effects of a merger are not evident for at least 10 years after a merger is complete (Harmon. 2003). The purpose of this qualitative multiple case study was to identify curricular changes in course offerings and in course content in the disciplines of English and communication in the years following state-wide mergers between community college and technical school systems in three states, Connecticut, Kentucky, and Louisiana; to understand how curricular changes are affecting organizational administration and faculty work life; and to understand whether curricular and organizational changes seem to reflect the globalization of the comprehensive community college mission.

To develop the framework for this study, literature on mergers, globalization and vocationalization of community colleges, the growing emphasis on the workforce development mission in community colleges, and curricular trends in the liberal arts are included. Specifically, topics in this chapter include (a) Globalization Theory, (b) mergers in higher education (c) emphasis on workforce development (d) diminishing liberal arts curriculum, and (e) liberal arts and general education curricular trends.

\section{Globalization Theory}

One outcome of the pressures created by globalization is described by some scholars (Giroux, 1999; Bragg, 2001) as the "vocationalization" of higher education. Giroux (1999) offered examples of the vocationalization of education in an article from the 
March 1998 issue of the Chronicle of Higher Education which highlighted the trend for colleges to offer business school deans jobs as college presidents as an example of higher education's trend toward corporatization. He noted that the dwindling fiscal resources from state budgets encourages hiring business leaders who work to establish business relationships with legislators and industry, and tailor curriculum to meet the needs of corporate interests. Levin (2000) stated that "...in the 1990s the mission of the community college had less emphasis on education and more on training, less emphasis upon community social needs and more on the economic needs of business and industry, less upon individual development and more upon workforce development" (p. 2). In their early inception, the community colleges' course offerings were largely academic, aimed at fulfilling transfer requirements. Transfer remained the mission emphasis through the 1960s even when technical programs began to evolve in community colleges (Cohen \& Brawer, 1996). Since that time the shift has slowly changed to today's emphasis on workforce development.

Levin (2002), a leading researcher in the field of globalization and community colleges, conducted a large international qualitative study, which included six community colleges from the United States and Canada. From this work, Levin found many changes in the community colleges due to the effects of globalization which were caused by social, economic, and political pressure. He determined that the community college is globalized with a focus on international and multicultural issues. The advance of technology and immigration, especially Asian immigration, contributed to this shift in focus of the community college mission. What used to mean "local" in relation to community colleges, no longer means the local community. Globalization forced a shift 
to a broader scope of service and new challenges for community colleges. Also, Levin (2006) studied faculty work and globalization through qualitative inquiry. Based on a literature review on globalization theory, institutional theory and cultural theory, Levin identified behaviors characteristic of globalized community colleges. The study purpose was to identify and explain faculty behaviors and values and their connection to institutional actions within the community college. He collected data through interviews with 171 faculty members from every discipline, including part-time faculty. He analyzed data based on four categories of behavior evident in a globalized community college which he determined through data collection: (a) oppositional culture, (b) values, (c) economic behaviors, and (d) labor behaviors. He then clustered themes under each of the four categories. Statements that were placed under the category of "oppositional culture" suggested a critique of institutional practices, behaviors, and influences, or suggested factions within the institution. Items placed under economic behaviors included statements that characterized institutional or individual behaviors associated with economic motives or goals. Statements from interviewees that either described or judged institutional or individual behaviors that pertained to the work of faculty were placed under the "labor behaviors" category. Items placed under the "values" category reflected value statements related to both education and economic values or institutional behaviors.

Levin (2006) concluded that faculty expressed conflicting values with that of the institution. He found results that supported the study hypothesis that government policies are requiring more accountability and that the institutions become more efficient and productive. Hierarchical decision-making, focus on training versus education, and economic behaviors and globalization comprise the institutional missions at community 
colleges in this study. The result of this shift in focus for faculty is a loss of identification and autonomy. Levin stated that faculty felt their work as educators-teaching, the development of curriculum, counseling and advising of students, and committee serviceis configured or framed within an economic and competitive context, even though their values may be based upon other principles and other goals, such as personal and cognitive development of students or the social advancement of their society (p. 84).

Thaxter and Graham (1999) surveyed 100 randomly selected community college faculty members from six community colleges in varying states about their perceived involvement in decision-making. They found that community college faculty members do not feel they are involved in important decision-making activities indicating an autocratic decision-making environment. The highest degree of participation was in instructional and student-centered activities. The researchers stated that one important finding of the study was that "failure to engage faculty and modify administrative approaches may result in community colleges that fail to respond to the demands of today's world" ( $p$. 673). Faculty members feel the emphasis is toward training and away from education, which Levin (2006) refers to as the corporatization of education.

These studies reveal aspects of globalization affecting community colleges. Faculty members have concerns about decision-making and the corporatization of the community college. Further, the studies inform community college administrators and external constituents about faculty oppositional issues surrounding the corporatization of education and their concern that the curriculum is being narrowed and eroded as the emphasis remains on workforce development. Throughout history there has been a distinct dissonance evident between scholars supporting the liberal arts who feel the 
decline in the liberal arts tradition will lead to a decline in the intellectual life of citizens and those scholars who feel educators must adapt to job-related needs of students in a global economy.

Dougherty (1994), suggested four categories to interpret of the role of community colleges, based on sociological frameworks, which can aid in understanding the historical creation of community colleges and the scholars who defend each view. These frameworks include (a) the Functionalists, (b) the Marxist Instrumentalists, (c) the Institutionalists, and (d) the State Relative Autonomy Theorists. The Functionalists defend community colleges and believe these colleges are an entry point for groups that otherwise might not have an opportunity to pursue higher education, which will lead to greater earning potential. The Marxist Instrumentalists believe the elite, with business interests, dominate and strive to secure taxpayer-subsidized worker training and to maintain an educational gap between the classes. Critics from the Marxist Instrumentalist faction believe community college students are deprived of the greater intellectual and economic benefits of obtaining a bachelor's degree because they experience a "cooling out"(Clark, 1980) or redirection from higher education aspirations into workplace training based on their perceived academic ability. Institutionalists, such as Brint and Karabel (1989) assert that institutional self-interest and competition have driven community colleges into contradictory missions and the structure of higher education encourages inequity. Finally, the State Relative Autonomy Theorists believe that government officials are the catalysts behind promoting community colleges to bring prestige to the community as well as an opportunity for citizens to access higher education; however, the government officials tend to put business and industry's needs 
first to support economic growth in their communities. The following studies support several of these sociological views.

Goyette and Mullens (2006) reported data to support the Marxist Instrumentalist groups that claim education is reproducing the class system. They indicated a positive relationship between social background and the selection of the arts and science fields. The authors identified two trends in education and society that may have shifted or altered this relationship over time. The first trend is the expansion of education post World War II when more non-elites obtained bachelor's degrees resulting in credential inflation. This inflation then led to a devaluation of the degree. High status occupations began to require more specialized training or graduate degrees. This meant that one now needed to have the name of a prestigious institution behind the degree for it to be viewed as valuable. The second trend is that higher socioeconomic students, having more exposure to high culture, are more likely to choose arts and science fields and later prestigious graduate programs. These students will enter the job market with stronger market value than those from vocational fields and will likely have more favorable longterm earnings. Kahlenberg (2004), (as cited in Ballinger, 2007), noted that the gap in education and socioeconomic status has not changed since the 1960 s. He stated that students in the lower socioeconomic levels make up only 3 percent of the enrollment at first-tier institutions while 74 percent of the enrollment is comprised of students from the highest socioeconomic level. Consequently, a larger percentage of higher socioeconomic status students graduate and migrate into the workforce perpetuating the class reproduction system. Conversely, the lower socioeconomic students gravitate toward community colleges, whose open access policy and lower tuition is appealing. 
Brint et. al. (2005) found a higher proportion of students with low test scores and from lower socioeconomic backgrounds enroll in institutions emphasizing occupational degrees which could lead to the student being "cooled out" (Clark, 1980) or redirected away from transfer degrees based on their perceived ability. These students graduate with terminal degrees which may leave them in the same socioeconomic setting. Sacks (2009) stated that "Four year colleges have become more exclusive domains for America's upper-middle class and above. In the early 1970s, public four-year institutions enrolled 40 percent of all Pell Grant recipients; by 2001, this figure had dropped to just 31 percent" (pg. 16). Dougherty (1994) noted that students who start their education at community colleges and transfer to four-year colleges are less likely to complete their bachelor's degree than students who begin their post-secondary education at a four-year college or university. These trends are important to this study, because as the community college mission changes toward economic communities and away from local communities, policy-makers and administrators view students as commodities and curriculums are narrowed, the historical concept of community colleges as "democracy's college" may be lost (Diekhoff, 1950; Dougherty, 2002).

Globalization brought about pressures for states to become more competitive in a global market. For many states, the call for efficiency and accountability in higher education resulted in educational reconstruction. Mergers are one form of educational restructuring, which affected the states in this study; therefore, understanding merger drivers and the human implications inherent in a radical organizational change, such as a merger, can illuminate key issues the community colleges in this study experienced through the merger process. 


\section{Mergers in Higher Education}

Although mergers are not new to higher education, the trend has gained momentum over the past two decades as a means of addressing issues of credit transfer, duplication, efficiency, and fiscal accountability; however, reasons for merger may vary from one situation to another. Several researchers offer key drivers for mergers (Harmon, 2003; Puyear, 2002; Rowley, 1997). Puyear (2002) identified merger drivers found in a twopart study. The first phase of a mission convergence study by the Community Center for Community College Policy Education Commission of the States surveyed states that offered community and technical colleges/vocational schools/technical institutes to determine if any had merged or were considering merger. The second phase, conducted in 2002, targeted state systems who indicated they had completed merger or were well into the merger process. The findings are based on material obtained from the colleges in the study and interviews with state directors of community colleges in Connecticut, Indiana, Kentucky, Louisiana, Minnesota, and Washington. He found that community and technical colleges merge because (a) maintaining two systems is costly to the state, (b) the separate systems create transfer and credit barriers for students, (c) workforce preparation is ineffective, (d) adults find it difficult to continue their education, and (e) existing turf battles between the two institutions who competed for state dollars and did not provide believable accountability measures to state legislators. These merger drivers are in line with Levin's Globalization theory and the corporate values now evident in community college organizational practices. Puyear's study included the three merged community colleges in this study; therefore, the merger drivers listed in his study have significance to the context of this study. 
Rowley (1997), a researcher studying college mergers, developed a survey from interviews with two university senior managers which he sent to 35 higher education institutions in England who had completed at least one merger. He found mergers occurred largely for academic and strategic reasons. Rowley identified culture mix, administration, and property as the three unexpected problems during mergers while enhanced academic quality and enrollment and growth were benefits of the merger. Harmon (2003), who has studied mergers extensively outside the United States, supported this finding. He stated that increased efficiency and effectiveness to deal with climbing enrollments was a key driver for merger. Increased course offerings to meet student diversity and greater governmental control to ensure colleges are directly meeting local and state objectives were additional merger drivers. Rowley found that over $90 \%$ of the mergers were successful and job losses occurred in only half of the mergers.

Although merger drivers are important to a broad understanding of the merger process, knowledge about the more intimate human implications of mergers can offer insight into the emotional aspects of the merger, which include the fears and concerns staff and faculty members experience before, during, and after a major organizational change over which they have little control. For this reason, studies on organizational change are included in this literature review.

\section{Human Implications of Merger.}

Harmon (2002) noted that mergers create organizational climates of confusion, fear, and frustration. Often, employees hunger for information and look to the wrong sources to gather information, which leads to confusion and induced spread of fear and misinformation. Faculty members on both sides of the merger fear losing their jobs, loss 
of academic freedom, loss of power, the decline in academic rigor, and increased workloads, especially in a merger like those between a technical and community college where academic standards and workloads vary due to the different college missions. Van Wagoner (2004) surveyed 510 professional staff in 12 community colleges, in a single state community college system, to examine the influence of certain factors on their perception of organizational change. He found that the longer individuals stay at one institution, the more likely that their experience and duration tends to negatively influence their perception of organizational change. Leaders must engage in clear, open communication programs to communicate the strategic plans regarding the change and involve employees in the decision-making process as much as possible (Miller \& Vacik, 1998; Pope \& Miller, 2005; Schweiger \& Denisi, 1991). Van Wagoner reinforced this research through his finding that the more individuals understand the mission and strategic goals of an institution, and the more they are involved in change, the better equipped they are to put change into context and view change in a positive manner. In their study of two-year college faculty satisfaction, using the 1999 National Study of Postsecondary Education Faculty (NSOPF) database, Hardy and Laanan (2006) determined that increased workloads created the greatest frustration. Faculty members were concerned about decreased time for professional development, a decrease in the quality of the education at their college, as well as a decrease in their autonomy. The older group has greater concern about the quality of education declining while faculty members age 35 and under were concerned about job security. 


\section{Summary.}

Mergers in higher education occur to increase efficiency and academic offerings, eliminate credit transfer barriers and turf battles, and to allow stronger governmental control for accountability. The human implications of mergers should not be overlooked by change agents. Employees of merging institutions seek open and clear communication about the changes and they want to be involved in the decision-making. Senior faculty members may have greater fear about the change process as well as academic erosion. Although workforce development is not new to missions of community colleges, as education is restructured to reflect a more business approach to education, and to meet demands for efficiency, accountability and flexibility, workforce development remains a dominant focus of the community college mission.

\section{Increasing Emphasis on Workforce Development}

In 2000, the American Association of Community Colleges, stated "Community colleges should view the preparation and development of the nation's workforce as a primary part of their mission and communicate to policymakers the uniqueness of the community college role" (p. 8). Jacobs and Dougherty (2006) suggested that as the workforce development mission grew in community colleges new tensions evolved. With contract training gaining popularity as a predominant part of the workforce mission, a competition within the colleges developed where non-credit course offerings began competing with traditional credit courses, which set up a distrust between teaching faculty and those training in the non-credit course. Traditional teachers questioned the quality of the non-credit courses. Furthermore, some faculty members feared that growth in the workforce education mission would diminish the transfer mission of the 
community college because more students were being recruited into the occupational education route.

According to Brint and Karabel (1989), community college transfer rates fell as focus on the expansion of vocational education and continuing education increased from 1960 to 1990 due to increased funding from the federal government after the Vocational Education Act of 1963 was passed (Cohen \& Brawer, 2003). More recently, occupational/technical degrees are not necessarily considered "terminal" because more students are transferring to four-year colleges to continue their education. Cohen and Brawer cited a national study by the Center for the Study of Community Colleges regarding the transfer of non-liberal arts courses to both research universities and comprehensive colleges and universities. They found that the flagship universities accepted fewer occupational courses than the four-year colleges that offered more careerrelated programs. Further, the researchers suggested that there is a blending between vocational and collegiate programs; more occupational program completers seek transfer to baccalaureate institutions and students who seek the collegiate program are undecided about a career choice or are taking classes for personal interest. Consequently, for these students the collegiate courses become the "terminal education" program (p. 32).

Community colleges are being pressured to strengthen their transfer programs to increase transfer rates. According to Townsend and Wilson (2006), community colleges are working more closely with four-year colleges to improve transferability through course and state level articulation agreements, and building career pathways for both transfer and occupational/technical programs. In an effort to improve transferability, Kentucky passed House Bill 160, which will create a statewide common course 
numbering system, a consistent evaluation of transfer credit for all Kentucky and Community College System courses, establishment of an appeals process to resolve issues between transferring students and the receiving institutions, priority admissions for KCTCS students, and a maximum credit hour limit for Bachelor's (120 hours) and Associate's degrees (60 hours) ("HB 160", 2010). Also, Louisiana passed SB 285 (Act 356), which mandates that the post secondary management boards, the State Board of Elementary and Secondary Education, and the local school boards work together to develop a comprehensive articulation and transfer program to provide a more seamless transition for students through the education system. This includes a common course numbering system for all general education and lower division courses and a requirement of 60 credit hour maximum for associate of arts and associate of science degrees, with 39 of those hours in general education and 21 hours of pre-requisite coursework for a bachelor's degree.

The implication of this push toward transfer of degrees, previously considered terminal, is that occupational/technical programs contain fewer general education courses than the transfer degrees; therefore, transfer students may lack the exposure to higher order skill development found in liberal arts courses which could put them in a disadvantaged position for success at the four-year college. Also, these programs may eliminate relevant courses to the program for courses that are more transferable to provide a seamless transition for the student. Consequently, the student may not receive the skills essential to their profession, but skills that fit the "transferable" category. This literature review illuminated two opposing positions about community college work and their emphasis on workforce development. One position, Jacobs and Dougherty (2006), 
referred to as a new vocationalism, which suggests that community colleges should be the gateway to job skills training and advanced technology training as a foundation for a career in their field. Those scholars with an opposing viewpoint suggest that the community colleges' role is to meet the needs of their local communities, which include low-income workers, immigrants and displaced workers, by providing a basic education and job skills training. Jacobs and Dougherty (2006) suggested that community college leaders are uncertain about the economy and future occupational job market, so they are unsure what their role should be.

If they promote transfer degree, which leads to higher paying jobs, and de-emphasize occupational training, will they lose the ability to reach out to the growing number of individuals in low-wage retail and commercial sectors? Yet, if community colleges promote education and training for lower-wage positions that may have higher rates of unemployment, will they actually reinforce social inequality? (p. 60)

This question reinforces the study concept which suggests that the influences of globalization are creating oppositional forces in today's community college missions. Emphasizing one path over another potentially leads to shortcomings for community college students. Those students interested in pursuing an occupational degree may shy away from an emphasis on transfer and the breadth of liberal arts/general education classes required for that degree. As Cohen and Brawer (2003) noted, students pursuing occupational training are risking more than the students pursuing liberal arts education because if there is not a job at the end of their training, then their money has been wasted. Students pursuing the liberal arts education have more options to continue their education. If community colleges emphasize occupational degrees and workforce training, resulting in the erosion of the liberal arts curriculum, community college occupational/technical students will lack the exposure to higher order intellectual skills 
historically developed in the liberal arts curriculum and determined as skills needed to become engaged citizens in a democratic society.

\section{Summary.}

The workforce development mission is central to community college missions today. This increased emphasis on workforce development creates tension between non-credit trainers and academic faculty in vocational fields who worry about the lack of rigor in non-credit courses. Moreover, academic faculty worry that the transfer mission is lost to the urgency for workforce training and meeting local business and industry needs. The emphasis on workforce development and the vocationalization of education leads to faculty concerns about the diminishing emphasis on liberal arts in the curriculum. Faculty concern for educational erosion and the narrowing of the curriculum through limiting the liberal arts courses in the curriculum was a common theme identified throughout merger and globalization studies; therefore it is explored further in this literature review.

\section{Diminishing Liberal Arts Curriculum}

The educational concept of the liberal arts began through the life of Socrates, the great Greek philosopher. His ideas, documented in his student Plato's dialogues, revolve around the humanistic questions he posed to the ancient Anthenians about "what is right?" and "what is good?" (Flannery, 1998, p. 2). Socrates' principles suggested that man has a desire to question human nature to pursue the source of goodness. Socrates' questions became the central questions to the liberal arts curriculum. In the middle ages, the liberal arts developed into seven disciplines comprising the trivium and quadrivium. It is from these disciplines that the liberal arts curriculum is defined today. 
Aristotle, Socrates' student and the author of Aristotle's Rhetoric, written in the fourth century B.C., is credited for developing the principles of persuasion (King, 1989), which guides argument development in both writing and speaking courses today. As a communication faculty member, the researcher teaches persuasion strategies through student exposure to Aristotle's Rhetorical Triangle of Persuasion which includes ethos (credibility), pathos (emotion), and logos (logic). Additionally, students learn the Twentieth Century British philosopher Stephen Toulmin's model of argument (Lucas, 2009). From discussions with her students, the researcher learned that they are exposed to this model in English when they are asked to write an argumentative essay; however, the consistency with which these ideas are taught from class to class may vary. This study may provide insights into faculty members' efforts to teach these concepts.

With the extensive educational restructuring occurring today based on business models (Levin 2001), the liberal arts curriculum may be diminishing as state policy makers cry for workforce training, and a quick and flexible curriculum. The long-term implications of the changes to the liberal arts curriculum are not yet known. Giroux (1999) stated "...the modeling of higher education after corporate principles and the partnerships they create with the business community do more than reorient the purpose and meaning of higher education; such reforms also instrumentalize the curricula and narrow what it means to extend knowledge to broader social concerns" (p.153). Changes are occurring that demonstrate increases in some liberal arts courses and decreases in others. As suggested earlier by Levin (2006), the emphasis on workforce development brings about tension between vocational and academic faculty about the quality of the education when more liberal arts classes are removed from program curriculum. In the 
proposed study, the researcher sought a greater understanding of this tension through Levin's oppositional issues and faculty values behaviors framework.

From a broader perspective, this literature review revealed a scholarly conflict over the removal of liberal arts courses from program curricula. In earlier research, Karabel (1986) said "the liberal arts programs, those that brought the community colleges into existence, are at risk of disappearing" (p. 27). Brint, Riddle, Turk-Bicakci, and Levy (2005) reinforced this concern by stating, "One of the most important changes in American higher education over the last 30 years has been the gradual shrinking of the old arts and sciences core of undergraduate education and the expansion of occupational and professional programs" (p. 150). These scholars suggested that the emphasis on workforce readiness and removal of the liberal arts curriculum create unequal footing for community college graduates. In comparison to graduates of four-year colleges and universities, community college graduates do not receive the breadth of skill development needed by a college graduate entering today's global workplace that a liberal arts curriculum can provide.

The literature suggested some essential skills the college graduate needs to be successful in today's globalized workplace. Milliron (2007) noted critical thinking, creativity, and courage as necessary skills for graduates to possess to better meet the challenges of a global workplace. Brewer (1996) who conducted a study with students, faculty and administrators in a community college system, found that all three groups identified communication skills and critical thinking as most important for the graduate to possess. This finding supports this study approach to understand to what extent students in community colleges are exposed to these concepts in their development. In his study, 
Zerkeri (2004) surveyed 291 graduates from Land-Grant universities to ask what skills they acquired in their college education that they felt improved their career experiences. Through a multi-variate analysis the researcher found that oral communication skills, public speaking, written communication, motivating and managing others, and effective group leadership were the skills students identified as most helpful in their careers. Although many vocational programs are working to develop methods to enhance critical thinking, problem-solving and reasoning activities, some liberal arts advocates see the liberal arts curriculum as the best source for developing these skills (Grubb, 2005; Giroux, 1999; Brint et al, 2005). As noted throughout this literature review, there is concern about the condition of the liberal arts curriculum as workforce development is emphasized; therefore, it would be remiss not to include studies about trends in the general education and liberal arts curriculum in this chapter.

\section{Trends in the General Education}

Following the principles of Socrates, Cohen and Brawer (2003) posited that the purpose of liberal arts education is to "...help people evaluate their society and gain a sense of what is right and what is important. This sense is not inborn; it is nourished through studies in which the relations among forms and ideas are explicated-the 'general education"” (pg. 317). Zeszotarski (1999) suggested that general education programs in community colleges combine elements of both liberal education and general education. Most community colleges follow distributional requirement systems for their general education requirements. This system provides a specific number of courses to be taken from major academic divisions such as humanities, social sciences, science, mathematics and fine arts or what otherwise might be labeled liberal arts curriculum. This is likely 
because college accreditation bodies mandate a number of general education hours for each degree.

The Kentucky and Louisiana colleges in this study are accredited by the Southern Association of Colleges and Schools (SACS), while the Connecticut colleges are accredited by the New England Association of Schools and Colleges (NEASC). SACS requires 15 hours of general education for the associate degree. One course must come from each of the following areas: (a) humanities/fine arts, (b) social/behavioral sciences, and (c) natural sciences and mathematics (Southern Association of Colleges and Schools, 2010). The NEASC requires that 20 hours of an associate degree program be completed in general education in the arts and humanities; science and mathematics, and the social sciences (NEASC, 2010).

Throughout this review, reference is made to the liberal arts curriculum. In the past, the distinction between liberal arts and general education was more evident, but today the two concepts are intertwined, especially in community colleges. Zeszotarski (1999), a scholar in the higher education and organizational change department at the University of California, Los Angeles, noted that traditionally, general education and liberal arts education were separate aspects of the community college curriculum, but the objectives of the two are now combined under the colleges' general education requirements.

Although community colleges utilize a distribution requirement general education model, in order to better understand the scope of approaches to general education in higher education, a review of general education literature is included in this chapter. Studies on general education in higher education revealed that the concept of general education is ever changing as scholars debate the inclusion and exclusion of approaches 
and courses in the general education curriculum. One point of agreement, however, is that general education programs must be under constant review (Bourke, Bray, \& Horton, 2009; Zekeri, 2004). Through this research review, several studies about general education approaches and general education reform efforts in higher education emerged. Although these studies are not exhaustive, their recent publication provides a contextual view of current concerns about general education.

\section{General Education Approaches}

General education studies revealed several models used in higher education institutions. Bourke, Bray, and Horton (2009) conducted a study of the top twenty-five higher education baccalaureate granting liberal arts institutions and doctorate granting research institutions to explore the context of their general education programs. They selected the colleges based on the rankings in the 2004 U.S. News and World Report magazine. Data gathered included philosophies guiding the general education models and requirements, as well as, course descriptions and listings. They found that the philosophies were representative of values that espouse lifelong learning, and preparation for life and citizenship. The most common model used in both types of institutions was the distribution requirement, which offers a knowledge base from whole disciplines rather than individual courses. Physical education was an added requirement at more liberal arts colleges while a foreign language requirement and the first semester seminar to meet the writing requirement were prevalent at both types of institutions. Quantitative reasoning was a requirement more often at the doctoral granting institutions. One interesting finding was that in three of the liberal arts colleges and one doctoral institution, general education was determined between the student and advisor, assuming 
that this abstract method of choosing general education courses would result in a more meaningful curriculum for the student. The researchers noted that the liberal arts tradition has transformed into today's general education and it resides in a core curriculum or distributional requirement models utilized in higher education.

In another study utilizing the 2007 edition of the U.S. News and World Report on college and university rankings, Warner and Koeppel (2009) selected seventy-two colleges and universities from national research universities, master's comprehensive schools, and liberal arts colleges among thirty-five states. Through a review of each college's website and online catalog, the researchers reviewed general education requirements. They gathered demographic information on each college through reviewing the 2007 online edition of the U.S. News and World Report. They found that students in colleges with higher rankings in the U.S. News and World Report have much greater choice in their general education program than lower ranked schools. For instance, students at Tier 1 colleges had an average of 49.8 choices of literature courses to meet that requirement versus 5.8 choices at Tier 4 colleges. To meet the philosophy requirement, students at Tier 1 colleges had an average of 105.7 philosophy courses from which to choose, while students at Tier 4 colleges had only 4 courses from which to choose (p. 254). Warner and Koeppel noted advantages to more course choice for students as (a) increased interest in the course, (b) increased ability for the school to attract a diverse student body, and (c) greater expansion of the students' perspective and understanding of the world (p. 254). Two potentially negative outcomes are students who have predetermined interests in courses might limit their ability to expand their perspective by only taking those courses with which they are most comfortable and more 
course choice brings the potential for the curriculum to become fragmented so the students have difficulty linking knowledge across disciplines.

Brint, Proctor, Murphy, Turk-Bicakci, and Hanneman (2009) affirmed the existence of the core distribution area and the traditional liberal arts models. Their study sought to describe and analyze the general education requirements at four-year colleges and universities from 1975-2000.They used the College Catalog Study (CCS) database and coded catalogs at five-year intervals over six years. Through factor analysis the researchers revealed four models that existed over the course of the study. The first model, the core distribution areas, grew out of Yale University in the 1860s as opposition to Harvard's free elective model. During the time of the study, the researchers found no decreases in requirements in natural or social sciences, but they did see decreases in humanities requirements. The second model, the traditional liberal arts model, originating in the colonial colleges focused on requirements in history, foreign language, literature, and philosophy while the culture and ethics models of general education requirements are more recent concepts initiated by educators in the elite secular universities who felt nonWestern culture should be represented in addition to Western culture in the civilization concept. The fourth model, the civic/utilitarian model, brought the concepts of citizenship and preparing students for business life into the general education curriculum. The researchers concluded that each college must tailor its general education to meet the institutions educational goals, resources and students (p. 257). They stated that assessing the general education program can be difficult and the assessment will depend on the general education approach. 
In an earlier study focused on community college general education curriculum requirements, Zeszotarski (1999) gathered data from the 1998 Curriculum Project of the Center for the Study of Community Colleges. She quantitatively assessed the content of 32 school catalogues to determine their general education purpose and core. She found a variety of themes throughout the sample's general education purpose, indicating an inconsistency between colleges in their definition of core knowledge and academic breadth necessary for the graduate to possess. In the distribution requirement at the sample colleges, differences existed in the transfer and non-transfer programs. The general education requirements in non-transfer programs varied from program to program. Math and composition requirements were highly represented in both transfer and non-transfer programs, but U. S. history and government courses were not required as often in occupational programs. Nearly fifty percent of the occupational programs, which may be a "terminal" degree for many of these students, offered exposure to knowledge about civic processes and issues. Zeszowarski stated "Knowledge of civic issues is a fundamental aspect of informed participation in a democracy. If occupational students are not at least introduced to the fundamental knowledge a general education provides, they may be excluded from full participation in significant social and political activities" (p. 47). The implications of the general education curriculum reach beyond the college walls. For this reason, general education curriculum must be reviewed often and reforms implemented to insure students get the broad knowledge base they need for engagement in society. The following studies discuss reform efforts and outcomes. 


\section{General Education Reform}

As indicated in the previous studies on general education, there are varying approaches to the general education curriculum in higher education and not all students experience the same "breadth of knowledge" across the disciplines. Liberal arts faculty members vie to include their courses in the general education requirements, while occupational faculty struggle to add the general education hours to their already lengthy curriculums. Administrators may approach the decision from a more economic point of view, leading to tensions and conflict between faculty members and administration.

In 2000, Johnson, Ratcliff, and Gaff (2004) surveyed chief academic officers (CAOs) in baccalaureate institutions who were members of the Association of American Colleges and Universities to gather their institutional views. Also, the researchers asked the CAOs to identify the contact person at their institution who was responsible for administering the general education program at their institution. These individuals were contacted and asked detailed questions about the policies and practices of their general education program. The survey yielded 278 responses. They compared data to a previously administered survey in 1990 . Over 80 percent of the CAOs surveyed reported that their general education programs had been changed in the past six years (p.10). Forty percent of the institutions were implementing changes that year. Thirty-one percent of the General Education Administrators (GEA) was conducting assessments of their general education programs (p.11). Most curricular changes included a reduction in student electives and an increase in prescribed course sequences and course clustering to add coherence to the varying fields of knowledge. These changes closely associated the general education program to the college mission. 
External factors played a modest role in general education change; however, accrediting agencies did influence changes to the curriculum. The respondents felt that the general education program needed to adjust and respond to the changes in students' needs, societal needs and the expanse of knowledge. Most of the changes during this decade-long study were structural to increase attention to diversity, global issues, interdisciplinary studies and course clustering to enhance coherence.

Through another administration survey, Path and Hammons (1999) sought to obtain information about the status of general education in community colleges. They randomly selected chief academic officers from all regionally accredited, two-year community and junior colleges listed in the American Association of Community Colleges 1994 membership directory. The researchers developed a survey including nine general education approach typologies. Four types were subject-centered approaches; two types were student-centered approaches; another two types were multi-disciplinary approaches; and one type was entitled infusion (i.e. writing across the curriculum). CAOs were asked to rate the approaches for the curricular areas including communication, arts and humanities, mathematics, natural sciences, social sciences, and health, physical and family education. They found a heavy dependence on subject-centered approaches. Also, all types of community colleges in the study offered general education in a similar manner. General education approaches used at the time of the survey were the same as those used ten years earlier. CAOs reported that community college students were likely to take an average of three communication courses and three arts and humanities courses. Students averaged taking two courses in each discipline of math, natural science and social science. Over half of the respondents indicated a desire for a different approach to 
general education than the one they were using in art and humanities; natural sciences; social sciences, and health, physical, and family education but they felt that there would not be a change at their college. Over 67percent of the chief academic officers felt general education programs were as important as transfer and occupational programs. Although the researchers did not go into detail about the major barriers to further program development, they presented a chart identifying the barriers. The top three barriers to further program development included resistant faculty members, transfer problems, inadequate funding to implement the change and difficulty organizing the new approach.

Dubrow (2004) confirmed the finding about faculty resistance to reform efforts in a qualitative study of the curriculum reform process at Western Protestant University, a pseudonym for a religiously affiliated liberal arts college in the western United States. The theoretical framework for the study derived from institutional culture and a typology of academic change developed by Larry Cuban (1999). Interviews were conducted with 18 faculty members and administrators involved in the general education reform process. He found that the reform process at WPU failed for several reasons. It took eight years to reach any consensus from the faculty when an alternative plan was prepared by an academic unit other than the committee charged with reform. First, the committee tried to make a fundamental change as mandated from administration. Even though the faculty agreed that the reform was necessary and they elected the committee to develop the process, in the end they rejected the process outcome and collegiality suffered. Once the committee presented the reform plan the provost did not offer proper support of the committee and discrepancies existed between faculty members and administrators about 
the level of religious interaction in the curriculum. Lessons learned were (a) committees charged with reform must have support from senior administration, (b) consensus and deliberation are important but it can slow the decision making process, and (c) when resources are limited the institution is not apolitical as members compete for available resources. In an earlier study on general education requirements, Brewer (1996) surveyed occupational faculty, general education faculty, and administrators in the Wisconsin Technical College System about the integration of academic and vocation education curricula. The conceptual framework and research questions were derived from a body of literature on integration. Respondents saw integration as a collaborative effort and they felt this integration would more effectively prepare students for the workforce. Brewer indicated that including required general education courses was the most common method of integration with occupational curriculum. Faculty respondents felt a barrier to effective curriculum revision was a lack of time to work together while administrators reported fewer perceived barriers to successful integration. Cohen and Brawer (2003) confirmed these study findings in their predictions about future community college issues and trends. "Integrated general education will make little headway....general education will continue being debated in the context of distribution requirements. It cannot become the guiding principle of an institution that is less dedicated to societal benefit than it is to each individual's immediate concerns" (p. 426).

\section{Trends in the Liberal Arts Curriculum}

Gwyer Schuyler (1999), author of, A Historical and Contemporary View of the Community College Curriculum, presented an overview of curriculum studies on community colleges since the early 1900s. He cited the work of W.C. Eell (1931) from 
his book The Junior College where Eell offered comparisons of curriculum studies dating back to 1918. In his book, he noted the first dissertation, which was completed in 1919 , about the community college movement. McDowell studied the curriculum offerings of nineteen community colleges and found that 82 percent of the course offerings were academic while 18 percent were vocational (p. 4). Eells also cited the work of Koos (1921), Whitney, (1928) and Hollingsworth-Eells (1930). Koos's study revealed that 76 percent of the curriculum was academic. Whitney and Hollingsworth found that 75 percent and 73 percent, respectively, of the course offerings were academic (p. 4). At the time of these studies, natural sciences made up the largest percent of the courses, followed by modern languages and social sciences running closely behind. Mathematics and English made up less than 10 percent of the curriculum. Koos's study revealed the emergence of remedial reading and the growth of occupational courses in the 1950s.

Curriculum studies in the 1960s were, according to Schuyler, focused on occupational offerings; however, the 1970s brought the beginning of a succession of studies conducted by Arthur M. Cohen through the Center for the Study of Community Colleges. Throughout the literature, his studies are the most commonly cited curriculum studies because they offer the most comprehensive approach to the study of curriculum trends. Cohen first studied community college curriculum in 1975, through a survey of catalogues and schedules. He continued to use the same study methods from the 1970s through his most recent study in 1998. One of his studies, conducted by Cohen and Ignash (1992) through the Center for the Study of Community Colleges sought to update curriculum and enrollment trends in the liberal arts. Through an analysis of catalogs, class schedules, and enrollment reports from 164 community colleges, they found that 
slightly more than half of the curriculum was liberal arts. Declines were noted in engineering and fine and performing arts courses. The researchers suggested that these declines may be due to shifts in the way these courses are categorized at the colleges. There have been significant increases in foreign language, philosophy and political science offerings. The researchers determined that the increase in foreign language was due to more ESL course offerings while the increase in philosophy and political science could be due to growth in certain programs. The humanities and social sciences courses had larger class sizes and the fine and performing arts had the lowest class size. English and math were the most populated courses, which is likely because they are required courses for all degrees. In looking back at the earliest curriculum studies, it is interesting that English and math represented the smallest percentage of the course offerings so there has been a significant increase on the emphasis of those two disciplines throughout the decades. Since this is the most recent study on the liberal arts curriculum at community colleges, it does inform this study by offering enrollment trends in the liberal arts. What is lacking from this study is that it does not provide a selective focus on curriculum changes occurring in community colleges and technical colleges after a merger. Also, it offers broad reasons for changes to the curriculum, but it lacks the intimate perspective of faculty members affected by those changes that interviews can provide. In Cohen and Brawer's (2003) most recent edition of The American Community College they provide 1998 data regarding curricula at the same 164 community colleges included in the previous study. They found only a slight change in the course offerings and student enrollments. 
In a more recent study, Portman and Stick (2003) sought information, through a quantitative study with faculty members throughout Washington State's Community and Technical Colleges in the 1999-2000 year, to examine the relationship between community college faculty members' departmental affiliation and their curricular choices. The Kruskal-Wallis analysis revealed differences among the academic departments. Faculty members in social science utilized the most concept learning while Developmental and Adult Education had the lowest use of concept learning. Humanities faculty had greater use of student intellectual development which included critical thinking and synthesis. Mathematics faculty members had the lowest student intellectual development use. Faculty members in the Vocational area and Business utilized the most vocational development, which was teaching job and technical skills. This study supports findings in previous research but it may not be transferable because only one community and technical college system was studied and systems vary across the United States. The study results support the argument that higher order thinking such as critical thinking, reasoning, and synthesis of information is more evident in disciplines encompassing liberal arts courses, particularly those in the humanities.

\section{Summary.}

These studies indicated that even though administrators desire reform they are reluctant to implement change initiatives. If undertaken, the reform process may be slow with extensive faculty involvement. Strong administrative leadership and support for the changes are necessary for such reform. As more state educational institutions are mandated to keep program hours to a minimum, such as those imposed by the Council on Postsecondary Education in Kentucky through the passage of House Bill 160 and 
Louisiana's SB 285 (Act 356), mentioned earlier, many academic and occupational programs may be forced to eliminate courses from their curriculum. For these programs, especially occupational programs, the cuts may occur in the general education courses which comprise a large portion of the liberal arts courses. Cohen and Brawer (1996) stated, "General education must not be optional, lest the gulf between the classes in America be accentuated as members of the elite group learn to control their environment, while the lower classes are given career education and training in basic skills" (p. 353). The long-term implications of mergers of community and technical colleges and the narrowing of the curriculum are not yet known; therefore, a study providing a longitudinal view of changes to the liberal arts curriculum since merger of community and technical colleges and the human implications surrounding the curricular changes, may provide policy makers and curriculum developers with important insights to consider before merging colleges and integrating curriculums. In order to have a better understanding of the community colleges in this study, the following section provides a historical and political context for each college system and individual community colleges.

\section{Historical and Political Contexts of the Colleges Under Study}

\section{Connecticut}

Prior to merger, community colleges, universities, and research universities were

all governed by different state-level coordinating boards which, in turn, was governed by a coordinating board. This coordinating board was responsible for planning and coordinating the system. Technical colleges were under the Board of Secondary and Elementary Education. In 1992, the Connecticut General Assembly enacted the Public 
Act 92-126 which merged community and technical colleges in five areas of Connecticut. In 1999 the colleges' names were changed from "community and technical colleges" to "community colleges" (Connecticut State Library, 2010). Today the system is comprised of 12 colleges offering associate degrees and certificates. Currently, their mission is: ...to make educational excellence and the opportunity for lifelong learning affordable and accessible to all Connecticut citizens. The colleges seek to enrich the intellectual, cultural and social environments of the communities they serve. The colleges support the economic growth of the state and its citizens through programs that supply business and industry with a skilled, well-trained work force (Connecticut Community Colleges, 2010).

The Board of Trustees oversees the governance of the community college system. This board is comprised of 16 governor appointees with six year terms and two elected student positions with alternating two-year terms. A system Chancellor leads the 12 college system.

Three Rivers Community and Technical College. Three Rivers Community College, now at a single location in Norwich, Connecticut since 2008, was formed from the merger of Mohegan Community College and Thames Valley State Technical College as mandated by the Connecticut General Assembly in 1992. According to the Three Rivers 2002-03 Self-Study, the separate physical campuses and differing unions created the greatest barriers to faculty unity after the merger. Although the governance merger occurred in the early 1990 's, the campuses only physically merged their facilities on the original Thames Valley State Technical College campus in 2008.

Norwich is home to approximately 39,000 residents and the college serves residents from the southeastern and eastern regions of the state. The college has three off-campus instructional sites. Current enrollment of part-time and full-time students in credit classes is over 3,500 and non-credit enrollment is approximately 2,400 each year (Three Rivers 
catalogue, 2010). The college's current mission is: "Three Rivers is an accessible, affordable, and culturally diverse community college that meets varied educational needs by creating an environment that stimulates learning" (Three Rivers Community and Technical College).To accomplish their mission, the college encourages lifelong learning, serves as a resource for organizations and people within the college's service area, emphasizes critical thinking, and contributes to the economic development of the region and state.

The college is accredited by the Connecticut Board of Governor's for Higher Education and the New England Association for Schools and Colleges, Inc. College academic departments include Business, Continuing Education, English, Humanities, Mathematics, Nursing and Allied Health, Sciences, Social Sciences, and Technology. There are 34 associate degree programs and 38 certificate programs. The English department at Three Rivers Community and Technical College houses English and communication faculty members. According to their website, they have approximately 10 full-time and 19 part-time English faculty members. The communication department is comprised of two full-time and five part-time communication instructors.

Since 2001, Dr. Grace Sawyer Jones has served the president of Three Rivers Community College. Her community college experience began in the late 70 s as a faculty member at Berkshire Community College in Pittsfield, Massachusetts.

\section{Kentucky}

In 1997, Kentucky Governor, Paul Patton, approved House Bill 1 legislation which created the Kentucky Postsecondary Education Improvement Act of 1997. The goals of the act included strengthening research programs at two state universities, providing 
programs of national distinction and access to baccalaureate programs at each of the eight regional universities. The bill further mandated that a comprehensive community and technical college system be established which would provide reasonable access to twoyear liberal arts and technical degrees, remedial instruction, workforce training, and continuing education courses ("HB1", 1997). At the time this bill passed, 14 community colleges were managed by the University of Kentucky and 25 technical colleges were managed through the Cabinet for Workforce Development. The University of Kentucky Community College System was governed by the Board of Trustees. The legislation transferred the governance of the system in the Kentucky Community and Technical College System (KCTCS) Board of Regents. Upon the mandate, 13 of the 14 community colleges consolidated with the 25 technical colleges to create 16 districts throughout the state. Initially, the KCTCS consisted of a community college branch and a technical college branch. After the governance transfer to KCTCS, conflict occurred over the different personnel systems for University of Kentucky employees and new employees hired under the Kentucky Community and Technical College System. Those previously employed under the University of Kentucky were provided an opportunity to move over to the Kentucky Community and Technical College System personnel system (Madisonville Community College Self-Study Report, 2000-01).

Prior to the merger, and as a result of the passage of Kentucky House Bill 814 in 1990, the Kentucky State Board for Adult and Technical Education became the governing board for Kentucky Tech. The board was composed of nine voting members serving four-year terms. The school director/principal established the annual budget and presented the Board members with annual plans to substantiate the budget requests 
The current KCTCS mission is to "...improve the quality of life and employability of the citizens of the Commonwealth by serving as the primary provider of College and Workforce Readiness, Transfer Education, Workforce Education and Training" (KCTCS.edu).

KCTCS offers certificates, diplomas, Associate of Arts, Associate of Science, and Associate of Applied Science degrees. Dr. Michael B. McCall is the founding KCTCS President. The system is governed by the Board of Regents, which includes elected and appointed members throughout the state and community college system. July 1, 2008 marked the $10^{\text {th }}$ anniversary of the consolidation of the community and technical colleges in Kentucky.

Madisonville Community College. Madisonville Community College is located in Madisonville, Kentucky, a city with approximately 20,000 residents, and it serves six surrounding counties. The college has been under the leadership of Dr. Judith Rhoads since July 1, 1998. In 2001, she led the consolidation of Madisonville Community College and Madisonville Technical College, which was the first consolidation effort in the state. Madisonville Community College is governed by a board of directors comprised of business leaders, professionals, and educators from the college's service area. Currently, the college employs over 200 staff and faculty. The college mission is as follows:

Madisonville Community College is a public comprehensive community college in the Kentucky Community and Technical College System. It is committed to establishing and nurturing a learning-centered, outcomes-based, culturally diverse organization. To offer curricula for the first two years of a baccalaureate program which lead to the awarding of the Associate of Arts or Associate of Science degree and which are transferable to all colleges and universities, public and private, in the Commonwealth (Madisonville Community College Mission, 2010). 
Madisonville Community College enrolled over 3400 students in the fall 2011 semester. Sixty percent of these students were part-time. Fifty-three percent of the student population was female. In addition to the main campus, the college has three other offcampus sites. In the 2009/2010 year Madisonville Community College awarded 491 degrees. One hundred sixty four of those degrees were AA/AS associate degrees, while 327 of the degrees awarded were AAS degrees. Also, there were 79 diplomas, and 709 certificates awarded (Board of Directors meeting minutes May, 2011). The college is accredited by the Southern Association of Colleges and Schools. Academic departments include, the Humanities, Social Science, Math and Natural Science, Allied Health, Applied Technology, and Nursing departments. Currently, they have eight full-time and five part-time English faculty members. There are three full-time and four part-time communication faculty members at MCC.

\section{Louisiana}

Prior to the educational reorganization in Louisiana, community colleges were affiliated with four-year colleges and they were a separate system from the state's vocational-technical college system. The 42 technical colleges were governed by the Board of Elementary and Secondary Education (BESE). Five community colleges were governed by the Board of Supervisors of the University of Louisiana. Baton Rouge community college, previously established by a Louisiana desegregation agreement was governed by the Louisiana State University governing board. The Louisiana legislative ACT 151 and ACT 170 in 1998, transferred governance of these institutions to the Boards of Supervisors for the Louisiana Community and Technical Colleges. 
Earlier in the decade, government leaders initiated the development of a statewide system (Manning, 2004). The attempt to restructure the system in 1990 failed, due to conflicts between four-year college leaders and vocational-technical college leaders. Instead of pushing a full-fledged restructuring, a pilot plan was developed to merge vocational and academic curricula at Nunez Community College in 1992. This merger was viewed a success and became a model for a statewide community college system. In 1993, the Senate passed the resolution authorizing the Board of Regents to create a community college system. The Board of Regents met with leaders from both educational systems to establish the feasibility of a merger. The college system was modeled after the three-tiered "California Model" where the state university has the most selective standards, the state regional universities a notch lower, and the community colleges are the bottom tier with open admission standards. Manning (2004) cited the State Relative Autonomy Theory (Dougherty, 1994), mentioned earlier in this chapter as the theoretical framework for the development of LCTCS. In 1998, the Louisiana Legislature passed ACT 151 and ACT 170, which approved the establishment of a separate board of the community colleges and the technical college campuses. The next year, the Louisiana Community and Technical College System Board of Supervisors was born. This board consists of 17 members, two of which are student members. Fifteen of the board members are appointed by the governor and two members are students elected from the system colleges. The board oversees 16 community and technical colleges throughout the state. In addition to this board, there is a Board of Regents for Higher Education which is a 16 member board responsible for coordinating higher education in the state (Louisiana Community and Technical College System). The community and technical college 
mission is to improve the life of citizens through educational programs at their colleges. Another aspect of their mission is to provide skills training for their area workforce (Louisiana Community and Technical College System).

Nunez Community College. Nunez Community College is located in Chalmette, Louisiana, which maintains a population of approximately 32,000 residents. In 1992 , the Louisiana Legislature passed ACT 341 which established Elaine P. Nunez Community College. This legislation mandated a merger between the Elaine P. Nunez Technical Institute and the St. Bernard Parish Community College to form a comprehensive community college; these colleges were the first merged community and technical colleges in the system. The college was under the Board of Trustees for State Colleges and Universities. The president of the Board of Trustees at that time, served as the college's first president. Nunez community college received accreditation from the Southern Association of Community Colleges in 1993 and reaccreditation in 1997 (Nunez Community College).

In 1999, management of the college was transferred to the newly established Board of Supervisors for the Louisiana Community and Technical College System. Nunez Community College is unique in that it was devastated by Hurricane Katrina. Prior to the hurricane, student enrollment in credit courses numbered near 2,400. Every building on campus was damaged or destroyed from the hurricane, but they were able to reopen the campus and resume classes in January of 2006. Since that time, the college has been working to rebuild facilities and enrollment. Reported enrollment for the spring 2010 semester was 1,848 (Louisiana Community and Technical College System). The college receives about 20 percent of its funding through grants and contracts. According to the 
2010-11 college catalog, Nunez Community College formed a partnership with the St. Bernard economic development council, now known as the Advisory Council to the Chancellor of Workforce Development, to strengthen the college mission to meet the local economic development and student career development needs (p. 12).

The college's academic departments include the Arts and Humanities, Business and Technology, Health and Natural Sciences, and Industrial Technology. Approximately 40 full-time faculty members teach among these divisions. Nunez Community College's English and communication faculty members reside in the Arts and Humanities Department. They have approximately six full-time English faculty members, including developmental English, and three part-time English faculty members. From a review of their website, there is only one full-time communication instructor, and two part-time communication instructors. The mission of the college is as follows:

Nunez Community College is a comprehensive community college offering a general education and occupational technologies curriculum that blends the arts, sciences, and humanities leading to associate degrees, certificates, and workforce development opportunities (Nunez Community College Catalog, 2010).

Dr. Thomas R. Warner, who has a lengthy history in both secondary and postsecondary education in Louisiana, was appointed Chancellor of Nunez Community College on September 14, 2000.

\section{Chapter Two Summary}

Since their evolution in the 1960 s, community colleges and technical colleges continue to morph to meet demographic, economic, and political changes. The call for increased accountability from federal and state governments to provide evidence of 
student learning outcomes and provide a more efficient and flexible curriculum to better accommodate business and industry needs, as well as a globalized workforce, has created an environment of constant change and chaos in community colleges (Harmon, 2002). Some state governments mandated mergers to address fiscal issues and curriculum duplication between community and technical colleges. Mergers create organizational climates of confusion, fear, and frustration (Harmon, 2002). In order to mitigate these fears, leaders must engage in clear, open communication programs to communicate the strategic plans of the change and involve employees in the decision-making process as much as possible (Miller \& Vacik, 1998; Pope \& Miller, 2005).

As community colleges become more vocationally oriented, the emphasis on transfer and the liberal arts curriculum diminished while workforce development and training activities gained considerable attention. In the literature, an ongoing debate exists about the importance of the liberal arts education versus the workforce skill development, especially in the community colleges, which enroll the greatest percentage of lower income and minority students. With the emphasis on workforce development and the vocational arts education in community colleges, many faculty members grow concerned about the narrowing of the curriculum through deletion of liberal arts requirements. In the larger picture, this narrowing can impact students who transfer to universities and enter a workforce requiring higher level thinking and reasoning skills. The literature review revealed differing views about the role of community colleges.

Today, liberal arts and general education co-exist in a core requirement for students at all levels of educational institutions. A review of current general education studies revealed varying models and approaches to develop a breadth and depth of knowledge for 
students. The most common model is the distributional core requirement. Students at Tier I colleges have a larger scope of general education courses from which to choose, while smaller college choices are limited. There is discrepancy between colleges about the definition of "breadth of knowledge" a general education core should provide. Socrates' founding definition of the "educated man" as one seeking knowledge of what is right and good for the sake of knowing became the questions guiding the liberal arts curriculum. Although these ideas are still actively discussed at baccalaureate institutions, community college students, especially those in occupational/technical programs, may not experience the full "breadth and depth" of knowledge that transfer students, and their baccalaureate counterparts may experience through exposure to liberal arts courses. Thus, the liberal arts may be losing footing in a society where a competitive global market drives educational offerings and student curricular choices. Community colleges, then, may not be fulfilling their missions as "democracy's college" as students lose exposure to critical thinking, the ability to develop effective arguments and the development of ethics and citizenship because of the narrowing curriculum. Consequently, these students may remain disadvantaged in comparison to their four-year counterparts and lack the ability to fully engage in a democratic society in a meaningful way.

A variety of theories and research methods evolved throughout the literature review. Globalization theory (Levin, 2002, 2006), organizational theory (Smart, 2003) and social reproduction theory were the most commonly referenced theories. Studies about community college curriculum date back to the early 1900s. Schuyler's (1999) historical account of the curriculum studies in community colleges and the cited work of Arthur Cohen, who has conducted periodic comprehensive reviews of the community college 
curriculum from 1975-1998, provided less than twenty comprehensive studies on the community college curriculum since the 1900s. The most common methodology for studying curriculum trends in community colleges, including the studies dating back to the early 1900s, was through the analysis of college catalogs (Schulyer, 1999). More recent studies by Cohen $(1991,2003)$ included the analysis of class schedules and enrollment reports. The studies on general education approaches were conducted through review of catalogs, college websites and demographic information provided on the U.S. News and World Report website. General education reform studies were conducted through surveys of chief academic officers and interviews with faculty members and administrators.

The gap in the research on curriculum and general education studies exists in the area of curriculum studies on merged community and technical colleges. Cohen's most recent comprehensive study was conducted in 1998 , which was either before the community colleges in this study had fully merged, or before the colleges could experience the impact of their merger on their curriculum. Also, the present research lacks the rich and intimate data from faculty members and administrators in these merged colleges about how curriculum is discussed and developed among faculty members, which is important to the understanding about how the institution and faculty values may differ or assimilate. These questions may best be answered through the intimate approach that interviewing in qualitative research offers. Thus, a study on the changes in the liberal arts curriculum, specifically in English and communication courses at three merged community colleges after their merger, can inform educational administrators, curriculum developers, and 
policymakers about curriculum trends that impact community colleges' ability to meet the demands of a globalized workforce.

The three community colleges in the study were merged with technical colleges in the 1990s to create comprehensive community colleges. State policy mandates drove these mergers, but their governing structures vary from cases to case. Currently, all three colleges have below 6000 students enrolled in credit courses and workforce development is emphasized in their missions. The academic departments, described earlier, also vary in structure and numbers of full and part-time faculty in the English and communication departments.

The next chapter describes the methodology for this qualitative, multiple case study of community colleges in Connecticut, Kentucky, and Louisiana. 


\section{CHAPTER 3}

\section{METHODOLOGY}

\section{Introduction}

The growth of the information age and the Internet created a world with no knowledge boundaries. For colleges, this means growing competition for student enrollment and state resources. Research has indicated that states are choosing to merge community colleges and technical colleges to achieve greater efficiency and accountability (Harmon, 2002; Rowley, 1997; Harmon \& Harmon, 2003; Arnolds \& Boshoff, 2004). Levin (2001) stated, "global forces, particularly economic ones, contributed to the organizational change in the 1990s and colleges in response to these forces altered their missions and structures" (p. 238).

The researcher approached this study through a constructivist paradigm utilizing globalization theory as the theoretical foundation because it provides the appropriate analytical lens to assess the structural and organizational changes in community and technical college mergers. Scholars debate the importance of maintaining the liberal arts in the college curricula (Cohen \& Ignash, 1992; Brawer, 1992; Brint, Riddle, TurkBicakci, \& Levy, 2005; Karabel, 1989). They feel that the liberal arts curriculum is diminishing in community colleges as workforce development is emphasized. If this is true, the globalization of community colleges and the resulting emphasis on workforce development is an oppositional force to the concept of the educated human derived from the middle ages as knowledge obtained through exposure to the trivium and the 
quadrivium disciplines in the medieval university. These disciplines developed the student's critical thinking and reasoning skills to become an active citizen in a democratic society (Flannery, 1998). Community college's originated as the "people's college or "democracy's college" (Diekhoff, 1950) whose purpose was to provide students with the knowledge base for effective engagement in democratic society. If the curriculum is narrowing, these colleges may be limiting students' exposure to higher order thinking skills often developed in the liberal arts courses. Through a case study approach, the researcher sought to understand how curricular changes are affecting organizational administration and faculty work life; and to understand whether curricular and organizational changes seem to reflect the globalization of the comprehensive community college mission.

This chapter is comprised of the study's research methodology and the following: (a) restatement of the purpose and research questions, (b) rationale for research design, (c) rationale for multiple case study methodology, (d) research sample, (e) methods of data collection, (f) data analysis, (g) ethical considerations, (h) issues of trustworthiness, (i) limitations of the study, and (j) a brief chapter summary.

\section{Restatement of the Purpose and Research Questions}

The purpose of this qualitative multiple case study was to identify curricular changes in course offerings and in course content in the disciplines of English and communication in the years following state-wide mergers between community college and technical school systems in three states, Connecticut, Kentucky, and Louisiana, and to understand how curricular changes are affecting organizational administration and faculty work life. The study had three major objectives: (a) to explore changes to the 
English and communication curriculum after the states' community colleges and technical schools were merged (b) to explore changes in faculty work life, particularly as it relates to curricular modifications, after the states' community colleges and technical schools were merged, and (c) to explore changes in organizational administration, especially related to curriculum development and modification, after the states' community colleges and technical schools were merged. Specifically, the study data collection focused on two of the oldest disciplines from the trivium, English and communication (rhetoric) courses. In order to better manage study data, the researcher focused on changes in these two longstanding liberal arts disciplines and provided a longitudinal view of curricular changes occurring in these disciplines since community and technical colleges merged in Connecticut, Kentucky, and Louisiana in the 1990s. A deeper understanding of the changes occurring in the liberal arts curriculum, such as those gained through qualitative inquiry, can inform policy makers and educators as they engage in curriculum planning and development activities. In order to explore this phenomenon, this study addressed the following four research questions that drove the study:

1. Have or how have curricular offerings, course requirements and course content changed in English and communication since the merger between community colleges and technical colleges?

2. Has or how has the mission of preparing a workforce for a global economy been part of faculty curriculum discussions and changes?

3. Has the nature of work with students, colleagues, and/or administration changed since the merger? How so? 
4. Have or how have the administrative processes related to curriculum changed and what tensions surround curriculum discussions since the merger between community and technical colleges?

\section{Rationale for the Study Research Design \\ Qualitative Research Design.}

A paradigm is defined as the "basic belief system or world view that guides the investigation" (Guba \& Lincoln, 1994, p. 105). Qualitative researchers hold different ontological assumptions about the world, seeing multiple realities rather than a single one. These world views are typically derived from individual experiences. Constructivist qualitative researchers view the world through relativism or constructed realities. The aim of the constructivist researcher is to understand and reconstruct mental constructs which are based on our social experiences. According to Guba and Lincoln (1994), the epistemology is transactional, subjective and meanings are created through the interaction between the researcher and study participants. Constructions can only be elicited and refined through this interaction between and among the investigator and the object of investigation. Constructions are interpreted through hermeneutical techniques and are compared and contrasted through a dialectical exchange. Values play a role in this form of inquiry and the researcher serves as a facilitator of the vocal reconstruction of the study participants. The ultimate aim of this research was to provide a more "informed and sophisticated reconstruction" (p. 112). It is through this approach that the researcher developed this qualitative multiple-case study. The researcher came to the study with great interest and she realized that perception plays a significant role in the interpretation of constructs. Through the transactional dialogue experienced in the interviews with 
faculty members about curricular issues, knowledge is co-created. Unlike surveys, the interview provides a more intimate approach to the object under study. Through the interaction with the study participants the researcher gained a deeper understanding of what the curricular changes they experienced meant to them on an individual level. It was the researcher's role to give these faculty members and administrators a voice and take mental constructs from different views and then reconstruct the meanings through the researcher's interpretations.

\section{Multiple Case Study Methodology}

According to Stake (2006), in a multiple-case study, the individual cases should be studied to learn about their self-centering, complexity, and situational uniqueness (pg. 6). Since the study involves more than one site, the researcher utilized multiple-case research methods. In his book Multiple Case Study Analysis, Stake provided a graphic design of a case study (p. 5). He stated that multiple-case research starts with the quintain or object or phenomenon to be studied. For this study, the quintain is curriculum changes occurring in communication and English disciplines since the merger of community and technical colleges. In the graphic, the quintain is the circular core of the case study, which includes the activity sites and data gathering methods. Outside the circle (quintain) are contexts which affect the researcher's understanding of the quintain, such as the educational, political, and cultural contexts, the history of the activity sites, and relevant research about the case study. Below the quintain core are issues and main information questions, which the researcher establishes about the quintain. Issue questions are not information questions; they are the deeper research questions which frame the study. An adapted copy of the graphic utilized for this study is located in Appendix A. 
Stake suggested that the multiple-case researcher starts with the quintain, arranges to study cases in terms of their own situational issues, interprets patterns within each case and then analyzes cross-case findings to make assertions about the concept which binds the cases together (pg. 10). For this study, the individual cases were merged community and technical colleges, now comprehensive community colleges, in Connecticut, Kentucky, and Louisiana. Once the cases are studied individually, the qualitative researcher conducts a cross-case analysis where assertions are made about the quintain by taking evidence from the case studies to show how uniformity or disparity characterizes the quintain. This study best fits Stake's multiple-case study approach because it sought to better understand the cases individually before making assertions about changes in the liberal arts curriculum.

\section{Sample Selection}

Stake (2006) offered three criteria for selecting cases: (a) Is the case relevant to the quintain? (b) Do the cases provide diversity across contexts? (c) Do the cases provide good opportunities to learn about the complexity and contexts? (p. 23). In the proposed study, the quintain represents changes to the English and communication liberal arts curriculum since state mergers between community and technical colleges. Before selecting cases for the study, the researcher established criteria to determine appropriate cases for consideration. The criteria used to determine case study participants were community colleges that merged with technical colleges within the same decade, colleges located in different geographical regions, and colleges that are now considered comprehensive community colleges. The three community college systems and community colleges identified for this case study meet Stake's criteria because all 
colleges are merged community and technical colleges and the geographical differences provide the opportunity to find diversity and complexity in the different contexts, and they are considered comprehensive community colleges offering transfer education and career education.

\section{Data Collection Methods}

Bogdan and Biklen (2003) suggested that many sources of data are better in a study than a single source because multiple sources lead to a deeper understanding of the phenomena under study. This study utilized multiple data collection methods and triangulation to enhance the understanding of the individual cases as well as the quintain of the study. According to Stake (2006), themes (research questions) indicate primary information about the quintain that the researcher seeks to obtain. Data collection methods included archival research and interviewing.

\section{Phase I: Archival Research.}

Bogdan \& Biklen (2003) stated qualitative researchers favor using documents as forms of data because they seek understanding how certain people define their organization through the documents. Through documents researchers can determine what people in the organization value. Also, official documents can be easy to obtain. The types of documents acquired may vary from college to college since faculty members and administrators may value documents differently. A list of documents the researcher gathered from each college included (a) most recent self-study, (b) course catalogs, (c) course enrollment reports if available, (d) curriculum guides, (e) class schedules, (f) course syllabi, and (g) curriculum committee minutes, if available. 
To acquire data addressing course requirement and enrollment changes in the English and communication curriculums, the researcher reviewed college catalogs, enrollment reports, course syllabi, and official college documents including policies and procedure manuals, college websites, accreditation materials including self-studies and/or quality enhancement plans, and committee processes with a focus on how curriculum changes are made. These sources of data provided information about mission changes, policy changes, curriculum changes, and enrollment changes since merger. To get relevant data about the faculty work changes and administrative process changes as it relates to curriculum, the researcher reviewed faculty handbooks, course schedules and enrollment reports. In addition to the interviews, the researcher requested assistance from the college contact to gather documents such as self-studies, enrollment reports, catalogs, faculty manuals, and any other documents that the contact felt could inform the study. At one college, historical documents were limited because many were destroyed during Hurricane Katrina. A table of documents reviewed and the research questions they informed is provided in Appendix B.

\section{Phase II: Interviewing.}

According to Bogdan and Biklen (2003), the purpose of the interview is "to gather descriptive data in the subjects' own words so that the researcher can develop insights on how subjects interpret some piece of the world" (pg. 95). In order to explore the perceptions of research participants, the researcher conducted open-ended, semistructured interviews. As a qualitative researcher, it is important to build rapport and trust early in the interview to set the participants at ease (Glesne, 2006). Once the researcher obtained IRB approval at the University of Louisville, she contacted the community 
colleges identified in the study proposal to gain entry to interview general education, technical/occupational faculty members, and Chief Academic Officers (CAOs) at the colleges. When permission was granted, the researcher contacted faculty members identified from a website search or faculty members identified by the college president or academic dean as having the historical perspective of the merger between the community and technical colleges. The researcher sent an e-mail to the identified faculty members requesting their participation in the study. Upon receiving each faculty member's agreement to participate, the researcher e-mailed the consent form so the participants could review the study objectives and understand their part in the data collection process. The researcher established interview dates and times through e-mail prior to the visit to the participants' college. Since the researcher is a faculty member at one of the colleges in the study, those interviews were conducted first in February and March 2011. The second and third college visits occurred in March and April 2011. Most interviews were conducted in participants' offices, with the exception of one college, which arranged a conference room for some interviews. The researcher conducted a total of 30 interviews throughout the three colleges. Each taped interview lasted approximately one hour. The researcher conducted interviews with liberal arts faculty members in the English and communication disciplines, occupational/technical faculty members, and academic deans at the respective colleges. Sampling of interview participants was criterion based. Faculty members of interest were those who taught for the community college or technical college prior to the merger because they offered insight from a broad perspective of change since the merger. The academic deans may not have the longevity in their roles as dean, but often they were faculty members before inhabiting their administrative 
positions, so their knowledge and perspective added richness to the data collected. For the interview, the researcher developed descriptive questions that sought to encourage the participant to talk about the cultural scene at their college by asking questions in language that they understood both culturally and personally through the use of example questions, experience questions, and native-language questions (Spradley, 1979). The researcher recorded participants' responses and transcribed them verbatim. Stake (2006) suggested that the interview is less about the interviewee than the case, but learning about the interviewee is important to understanding his/her interpretations. He suggested a series of interviewing questions to obtain data on various aspects of the case. He gave examples of basic research questions, questions to zero in on the main research issue, questions to obtain measurement data, and questions about immediate problems (p. 32). Additionally, he also noted that effective interviewing is "probe-based" (p. 31). Materials, such as artifacts, texts, and documents can be used to elicit comments or interpretations from the interviewee. While developing the interviewing protocol, the researcher kept the question structure and probe-based concept in mind. In addition to interviewing, the researcher consulted other sources of information to deepen her understanding of the college and participants (Bogden and Biklen, 2003). A copy of the interview protocol is included in Appendix C.

\section{Data Analysis}

Marshall and Rossman (1995) stated that qualitative data analysis is the process of bringing order, structure and meaning to the mass of collected data. It is a messy, ambiguous, time-consuming, creative, and fascinating process. It does not proceed in a 
linear fashion; it is not neat. Qualitative data analysis is a search for general statements about relationships among categories of data (p. 111).

\section{Single Case Analysis}

Stake (1995) stated that there are two strategic approaches for the researcher to find meaning in a case study. One is through the direct interpretation of the individual instance and through the aggregation of the instances until something is determined about them as a whole (p. 74). The case study researcher is trying to find patterns and understanding of the case through studying their contexts, issues, and behaviors (p.78). Stake (2006) suggested that multiple case analysis invokes a "case-quintain dialectic" which he defines as "a rhetorical, adversarial procedure, wherein attention to the local situations and attention to the program or phenomenon as a whole contend with each other for emphasis" (p. 46). People planning to study the quintain originate the themes while the findings originate with the people studying the cases. Both forces are different and the analyst must keep both alive while writing the assertions. The researcher undertakes the study to understand the commonalities and differences of the quintain across contexts. As noted earlier in the chapter, each individual case is studied to gain understanding of that particular case in its own situation. Stake posited that the complex meaning of the quintain can be better understood through knowledge of the activity and contexts of each case. For this study the political, historical, educational, and cultural contexts of each case were studied to aid in understanding each particular case.

To facilitate multiple case analysis Stake (2006) provides a pragmatic approach to data analysis through a series of seven templates. Each template serves a particular role in the analysis process including (a) assisting the analyst to outline the graphic design of the 
case study, (b) providing organizational structure to the study themes (research questions), (c) providing a structure for the analyst's notes while reading the case report, (d) assisting the analyst in determining the expected utility of each case for each theme, (e) providing an organizational matrix for generating theme-based assertions from case findings, (f) providing the multiple case assertions for the final report, and (g) providing organization for planning the multiple case final report. The last two steps provide a synthesis tool for data interpretation. The researcher utilized Stake's (2006) worksheets to provide an organizational matrix for generating theme-based assertions from case findings.

The first interaction with the interview data was through the transcription process. Although a transcriptionist assisted with the transcription process, the researcher transcribed several of the interviews. Field notes, documents and interview text were read and coded initially based on Levin's (2006) four behaviors evident in a globalized community college. The researcher began the analysis process by highlighting, in different colors, data relevant to the four areas of analysis from Levin's (2006) work which included (a) faculty work life (b) oppositional culture (c) economic behaviors, and (d) values. As other themes or repetitive phrases occurred the researcher highlighted those terms or ideas in red for further reflection.

Once this initial analysis was complete, the researcher then placed interview data from each participant under the respective interview question to read the multiple responses for each question. The researcher identified themes through the evaluation of the data which supported the study issue questions. Stake's (2006) theme generation worksheet served as a tool for organizing this step in the analysis process. When all 
responses were recorded under a theme, the researcher clustered related information under sub-themes. Themes and sub-themes were coded based on the four areas of analysis established in the theoretical framework. For instance, ideas related to oppositional culture were coded with OC. The researcher then numbered each code to distinguish it from other responses in that category for easy identification if needed later in the analysis write-up. After this step was complete, the researcher reviewed the information again to identify any further themes, as well as disconfirming responses within the interviews. The researcher clustered similar material under sub category headings within the larger category. As the researcher engaged in the analysis process, she was mindful of the study issue questions and the study quintain. This reflection allowed the researcher to not lose sight of the study objectives. Stake's (2006) matrix for generating theme based assertions from case findings helped the researcher to establish the level of importance of the ideas to the quintain. The researcher assigned items of high importance an $\mathrm{H}$, middle importance with an $\mathrm{M}$, and low importance with an $\mathrm{L}$. This worksheet is located in Appendix E (Table 1). After this step, the researcher then identified the findings from each case and themes associated with the findings. The researcher then rated each finding based on its importance to the study quintain. The step enabled the researcher to keep focusing on the information that was most relevant to the study. A table of this step is located in Appendix E (Table 2). Each college had subthemes unique to their college, but some sub-themes occurred across the cases.

\section{Cross-Case Analysis}

Stake (2006) suggested that the researcher resist the urge to merge the cases quickly with the established research questions. Instead the researcher must engage in a 
back and forth method of hearing the data so maximum attention is paid to the cases. $\mathrm{He}$ stated that the cross-case analysis consists of reading the case reports and applying the findings of each experience to the research questions of the quintain. Data analysis is an iterative, interpretive process as the researcher moves back and forth between themes, factors, assertions and findings to determine connections within the data. As discussed earlier in this section, the researcher must move back and forth with the data in order to "hear" it and fully understand it. Throughout this iterative process interpretation plays a significant role in the data analysis process. Thus, interpreting is looking for the meaning in the data and identifying what is important, why it is important, and what can be learned from it. After single-case analysis was complete and the researcher identified themes prevalent in each case, the cross-case analysis began. The researcher listed themes from each case and then identified the themes that occurred across the cases. A table reflecting these common themes can be found in Appendix E (Table 3).

\section{Ethical Considerations}

The qualitative researcher must be sensitive to the participants' willingness to give their time to participate in the study. The researcher must address any ethical issues to insure study participants are protected (Marshall \& Rossman, 1995). First, the researcher sent each participant an informed consent form to request their voluntary assistance in the study and to outline the purpose of the study. This form included a statement indicating that they may stop participation in the study at any time if they became uncomfortable. Second, the researcher kept study participants' names confidential and coded data in ways that protected their identity. Finally, the researcher 
secured the storage of all research materials to insure no one had access to the information.

\section{Building Trustworthiness}

The researcher approached this study from a constructivism paradigm. Constructivist researchers approach their study with the belief that there is a coconstruction of knowledge that occurs between the researcher and the study participants. Meanings are socially constructed through the interviews and data can be interpreted in many different ways. The major aim of this research approach is understanding and reconstruction of mental constructs, elicited and refined through the interaction of the researcher and the study participants and then interpreted through a hermeneutical/dialectical methodology (Guba \& Lincoln, 1994). In qualitative inquiry, the researcher is the instrument of research. Eisner (1998) stated "the self is the instrument that engages the situation and makes sense of it" (p. 34). He posited that the expert qualitative researcher understands the interplay of the sensibility and schema and uses this to understand a complex qualitative study. It is through sensibility that we notice the subtleties of the social world. Schema helps us to sort the significance of what we see. Eisner suggested that the way we see a situation, respond to it, and interpret it is based on our subjectivity or unique insight formed through our history. The researcher came to this research study with a rich history through her work as a community college communication faculty member in a division comprised largely of liberal arts faculty members. Additionally, the researcher supervised curriculum restructuring activities in technical programs, and served on curriculum review committees over the past twenty 
years. These professional work experiences led to the pursuit of knowledge about the study topic.

Trustworthiness of data in qualitative research is imperative to add validity to the study. Lincoln and Guba (1985) suggested four commonly referenced constructs used in qualitative research including (a) credibility, (b) transferability, (c) dependability, and (d) confirmability. Credibility means that there is confidence in the truth of the findings. To address credibility in this study the researcher triangulated data by comparing data from faculty and administrator interviews as well as archival documents to corroborate study findings. The researcher reviewed several sources of data and interviewed participants from multiple perspectives to look for agreement in order to corroborate the data. Additionally, the researcher engaged in peer debriefing and member checking so interview participants could review transcripts to verify her interpretation of the data. Transferability means showing that the findings have applicability in other contexts. To establish transferability the researcher established a document trail for data verification and engaged in thick description, or a detailed account of the phenomenon under study, so one can evaluate the extent to which the conclusions the researcher drew from the data can be transferred to other contexts. Dependability means showing that the findings are consistent and can be repeated. For this study, the researcher established dependability by having an external auditor review the study concepts and methods and findings to determine whether they are supported by the data. Last, to address confirmability, the researcher established an audit trail, triangulated data and engaged in reflexivity. Glesne (2006) stated that when engaging in reflexivity the qualitative researcher critically thinks about the research process as a whole and continuously monitors his/her own bias. Since 
the researcher is a general education faculty member in one of the colleges in the study, the researcher had more familiarity with the general education faculty members from the community college side of our merged college; thus, the researcher's situation as a faculty member could influence the data interpretation. To insure that researcher bias remained in check, the researcher utilized the constructs established by Lincoln and Guba (1985) throughout the study. A chart outlining the trustworthiness of the study can be found in Appendix D.

\section{Study Limitations}

This study has a few limitations which may affect its transferability. One limitation is the restricted research sample. Stake (2006) stated that the benefits of multiple case studies will be limited if fewer than four cases are chosen or more than 10 . Two or three cases may not show the interactivity between programs and their situations. Although the researcher included a research sample with geographic diversity, it would not reflect diversity across community colleges throughout the United States so generalization of study findings is not possible. Because qualitative research is subjective, the findings may not be reflective of reasons for changes in liberal arts courses in other community colleges. One limitation determined during data collection was that many faculty members who experienced the merger were retired, especially the technical program faculty, so this limited the number of participants who could speak about the merger. This limitation could affect the scope of perspective about the impact of the merger. Also, in qualitative research the potential for researcher's situational influence can impact the data analysis and interpretation process (Glesne, 2006). Since the researcher is a general education faculty member at a merged community college, the 
potential for situational influence is real; therefore, strategies identified in the trustworthiness section of this chapter assisted her in being subjective in the interpretation process. Also, the researcher's focus on the English and communication disciplines limits the scope of data findings. There are other academic disciplines and writing across the curriculum programs that teach classic liberal arts, but in order to manage the scope of the study, the researcher limited it to the two oldest disciplines; therefore, the study findings may not be transferable to other disciplines.

\section{Chapter Three Summary}

This chapter provides a view of the methodology and data analysis procedure utilized for this qualitative case study. The purpose of this qualitative multiple case study was to identify curricular changes in course offerings and in course content in the disciplines of English and communication in the years following state-wide mergers between community college and technical school systems in three states, Connecticut, Kentucky, and Louisiana, and to understand how curricular changes are affecting organizational administration and faculty work life. Four issue questions addressed important aspects of the case quintain.

Through a constructivist paradigm the researcher developed this multiple case study. The purpose of the multiple-case study is to understand the quintain of the cases. Each case must be understood through its situational contexts and issues that affect it. Stake (2006) offers a case study model which the researcher adapted for this study.

The sample selection was Three Rivers Community and Technical College in Norwich, Connecticut, Madisonville Community College in Madisonville, Kentucky, and Nunez Community College in Chalmette, Louisiana. These cases were determined for 
inclusion in the study based on three criteria. Each college experienced a merger between a technical and community college, each college is in a different geographical location, and each college is now considered a comprehensive community college.

Data collection methods included collecting archival documents, such as catalogs, curriculum committee minutes, enrollment reports, class schedules, and self-study reports. Other data collection occurred through interviews with general education, occupational/technical faculty members and academic administrators.

To analyze the data, the researcher utilized Stake's (2006) single-case and cross-case analysis to identify similarities and differences between the cases. Stake's (2006) seven data analysis templates provided structure for the data management.

With any research study there are ethical considerations to protect the study participants; therefore, the researcher sought permission for participation from the study participants through an informed consent form. The participants knew that their participation was voluntary and the researcher was diligent about keeping their identities and any information they shared confidential.

In qualitative research, issues of trustworthiness must be addressed. The researcher utilized Lincoln and Guba's (1985) four constructs to establish trustworthiness which included (a) credibility, (b) transferability, (c) dependability, and (d) confirmability. To address these constructs the researcher employed strategies such as triangulation, document trails, audit trails, peer audit of methods, provided thick descriptions, and engaged in reflexivity.

As a researcher it is important to recognize potential limitations of a study. For this study the limitations included the limited research sample, a selective focus on the 
English and communication disciplines, a limited number of participants who had experienced the merger, and potential for the researcher's position to influence the analysis and interpretation process. 


\section{CHAPTER 4}

\section{FINDINGS}

Over the past several decades, community college missions have changed in response to legislative, business and industry demands. State legislators cried for more accountability from community colleges and looked for ways to streamline education to eliminate curriculum duplication and make transfer easier between two and four-year colleges. During this time, economic factors influenced the work of community and technical colleges in their local communities. Mergers between community and technical colleges became one answer to state governments' demands for greater fiscal and academic accountability in higher education institutions. State governments mandated mergers as a way of addressing the growing duplication, transfer and fiscal issues. With the mergers came a marriage of the missions from community and technical colleges. The mission change brought greater focus on the workforce development mission in community colleges. Researchers, such as Levin (2001), have suggested this change in mission focus led to a diminishing of the liberal arts curriculum and a tendency for community colleges to run the colleges from a business model. The emphasis on workforce development has heightened the importance of occupational/technical programs, while the transfer programs, once a strong facet of the community college mission, is suffering (Grubb, 2005).

The purpose of this research study was to address the overarching research question: Are community college curriculums sacrificing the development of critical 
thinking skills, including exposure to ethics, diversity, and a deeper understanding of a democratic society often found in the liberal arts courses for job skills training? The study had three objectives: (a) to explore changes to the English and communication curriculum after the states' community colleges and technical colleges were merged (b) to explore changes in faculty work life, particularly as it relates to curricular modifications, and (c) to explore changes in organizational administration, especially related to curriculum development and modification after the merger of the states' community and technical colleges. The following issues questions drove the research study:

1. Have or how have curricular offerings, course requirements and course content changed in English and communication since the merger between community colleges and technical colleges?

2. Has or how has the mission of preparing a workforce for a global economy been part of faculty curriculum discussions and changes?

3. Has the nature of work with students, colleagues, and/or administration changed since the merger? How so?

4. Have or how have the administrative processes related to curriculum changed and what tensions surround curriculum discussions since the merger between community and technical colleges?

This chapter reviews the data analysis process and the study findings based on the study issue questions. Each individual case is discussed in a single-case analysis and then the results of the cross-case analysis are presented. The chapter concludes with a summary of the findings. 


\section{Single-case Analysis}

Each college is designated an acronym to provide anonymity of the college. $\mathrm{C} 1$ is the designation for the first college. $\mathrm{Cl}$ was created as a result of a state mandate in the late 1990 s to merge community and technical colleges. Prior to the merger the community colleges were governed by the Board of Trustees of a major state university. The technical colleges were governed by the state Cabinet for Workforce Development. The second college, $\mathrm{C} 2$, was formed through a pilot plan to merge the vocational and academic curricula in the state. Prior to the merger, community colleges in this state were affiliated with four-year colleges. Technical colleges were governed by the state Board for Elementary and Secondary Education. The third college, C3, merged in 1992. Prior to the merger the community colleges were governed by a state-level coordinating board. The technical colleges were under the Board of Secondary and Elementary Education. Today, the Board of Trustees oversees the college and a system and the 12 colleges are led by a system chancellor.

Each case analysis begins with a description of the case and highlights unique characteristics and findings from that case. The researcher reported the findings based on the major themes from the study issue questions.

\section{Single-case analysis for $\mathrm{C} 1$.}

C1 is a community college with a headcount enrollment of 3,224 as of August 31 , 2011. Of these students, the full-time equivalency is 2,534 . The college is governed by a Board of Directors. As of the fall 2011, there are eight full-time and five part-time English faculty members and three full-time and four part-time communication faculty members. C1 merged with their county technical college in 1998 as a result of a 
legislative mandate. The complete physical merger occurred in 1999-2000. The Humanities division, which houses the English and communication disciplines, is the lowest budgeted division in the college. The budget allocations are (a) Applied Technology, $\$ 24,000$ (b) Allied Health, $\$ 38,000$ (c) Nursing, 32,500 (d) Natural Sciences, $\$ 24,461$ (e) Social Sciences, $\$ 10,000$ and (f) Humanities, $\$ 7,000$ (Board of Directors meeting minutes May, 2011). Historically, the Humanities division has been the lowest funded academic division at the college. The larger budgets in the allied health and natural sciences divisions could be to accommodate program accreditation fees and lab materials.

Themel findings: Curriculum changes in English and communication after the merger

Curriculum changes encompassed trends in (a) course offerings (b) course content and (c) general education changes in the AAS curriculum since the merger. The researcher reviewed catalogs and class schedules from the year after merger and the current year. The 1999-2000 catalog noted that the AA and AS degrees required English I and II and a communication course. The AAS degree required 3-6 hours in writing/accessing information and three hours in communication. At that time there were no certificate or diplomas offered. A review of the 2010-11 catalog revealed that the English and communication requirements for the AA and AS degrees were the same, but the AAS degree reduced the writing/accessing requirement to 3 and removed the communication requirement. Diplomas and certificates are now offered.

The researcher also found diminishing variety in course offerings in English and communication. In the year after merger, the college offered five sections of literature, while there is only one section on the course schedule now. 
One faculty member (C110) stated:

At one time I was teaching 101, 102, a lit, women's studies. I had five preps. Now I have two preps. I think the more people you get in and the more people you serve the less variety you have in your own instructional decisions because those needs have to be met and you have got more people to meet them. You kind of get in a rut in your classroom instruction because you do not ever vary [your teaching] much.

In the communication discipline, the variety is diminishing as well. Just after merger, four different courses existed. Today, the offerings are limited to Basic Public Speaking (COM 181) and Interpersonal Communication (COM 252), with COM 181 being the more transferrable course. One communication faculty member (C132) stated:

I feel like we are all having to focus our attention on getting that course taught because I understand that it transfers and that we're not offering as many sections of the Interpersonal communication course, COM 252, as a result. So, I am feeling it is more narrow. We are really kind of tunneled as to what we are going to be able to teach and offer because of that transferability and it worries me a little bit. Just in terms of my own personal benefit, as well as, do we not need to be offering our students a little more variety in the discipline? So, that is my concern.

In addition to less course variety, in English and communication offerings, participants expressed concern over the diminishing general education in the Associate of Applied Science degrees, which were once considered terminal degrees, but today, these students often transfer to four-year colleges after completing the AAS.

(C135) stated:

Um, the only thing I would say is that I do think probably the biggest change since the merger, academically, has been some of the AAS programs, if not most of them, the ones that are degree programs, I think they have been watered down to an extent when it comes to gen ed so a lot of the programs have had English 102 taken out of them and a lot of them have had communications taken out of them. There is at least one, I think, that may have had English 101 taken out of it. I think the AAS degrees mean less than they did prior to the merger. 
The researcher also reviewed the AAS program curriculum plans and found that eight of the nine original programs removed ENG 102 from the curriculum. Also, of the nine original programs, two removed a communication requirement. Of the 11 new programs, six programs have ENG 101 (only) required and five programs have no communication course required.

Course content changes reflected a comprehensive course restructuring effort as a result of a Title III grant initiative. The focus of the grant was to restructure gateway courses, such as ENG 101,102, and COM 181 . The restructuring allowed faculty members in those divisions to break down their current courses and determine student outcomes, course requirements and assessments for each course. This restructuring brought coherence to each disciplines' curriculum.

(C135) stated:

When I first got here I thought they [English faculty members] were all over the place. I thought [name deleted] was doing his own thing, [name deleted] was doing her own thing, and [name deleted] was doing his own thing. I thought they were all over the place and then we started coming together and coming up with a common syllabus, common requirements and stuff. Since the merger, or since I've been here anyway, uh, we seem to have gotten closer and closer together in how we teach, what we teach, and the requirements we have for students.

Other curriculum related findings included a trend toward more active learning and less lecture. Critical thinking activities and problem-based learning were identified in many of the interviews as two prevalent teaching approaches. It should be noted here that critical thinking was the college's quality enhancement project for SACS reaccreditation.

(C133) said:

We were just doing more collaborative learning. We were doing more case studies and things of that nature. We were giving students a problem and they 
would work in groups to solve the problem. If we were talking about fallacies, for instance, in our basic public speaking course, we would go over a plethora of different types of fallacies and they would have to decide which fallacy it was and why it was a fallacy and they would have to reword it differently in order to make it a more truthful statement.

Although some faculty members indicated that they are teaching much differently since the colleges merged, one faculty member felt his teaching had not changed much.

(C133) said:

I've tried not to make a lot of changes. Because I see what I do as still being primarily transfer. You know the communication courses are part of the general education component curriculum. Now student's purposes in taking it may be different. Some just want to get that Associate of Science degree and transfer on or the Associate of Arts and transfer on. Obviously, our Applied Science students, which means they are going to go into the workforce typically when they graduate. So I try not to make any changes. Uh, there probably have been some subtle changes, but I hit the same content pretty much that I did all those years ago.

Another trend noted in the course content was the addition of more career-related

content. (C111) stated:

I think they have a little bit and it is partly restructuring that we have done as a result of Title III money, but we are focusing a lot less now on personal writing and narrative writing and that kind of thing and we are focusing a lot more on the kinds of writing that sort of are useful across the curriculum. We teach students a lot more about critical reading, summarizing, and analysis. We focus a lot more on argumentation now and in some of the developmental writing classes we have been focusing a lot on relevance so how is this writing going to be relevant either in my other classes or in my career. We are really getting away from you know the death of my grandmother paper or you know describing the best meal you ever ate paper and that kind of stuff and more into things like resumes and cover letters.

These findings indicate that course variety is diminishing, which supports Levin's (2006) argument that faculty members feel the emphasis is toward training and away from education supporting the idea of the corporatization of education. Course curriculum revision is a priority at the college but it has been focused on revising course 
competencies, learning outcomes, assessments, and incorporating critical thinking into the curriculum. The catalyst for the revisions is externally driven through grant initiatives and SACS re-accreditation requirements.

\section{Theme 2 findings: Mission change and curriculum changes after the merger}

The sub-themes identified under mission change reflected a perception that the community college was more transfer focused before the merger and more workforce development focused today. (C111) said:

I think it was more on transfer and on general education. It seemed like there was a little bit more emphasis on getting kind of a well-rounded education, getting some history and some science and some English and some communications, that kind of thing. People were more likely to take more diverse classes back then because they wanted to make sure that they had everything that they needed to go to the university.

Although, most general education faculty members interviewed felt the emphasis was more on transfer before the merger, one faculty member (C135), who was at the college prior to the merger said:

I want to say it was probably balanced. Neither. It wasn't exclusively transfer and it wasn't exclusively workforce development. I remember when I was teaching English composition before the merger I know that at any given...say 102 or 101 I would have students in or going into the nursing program and that is not transfer, that is workforce development.

One indication of the shift in focus may be due to the changing system mission after the merger. According to the college's SACS Self-Study (2000-2001), the system mission just after the merger read as follows:

The mission of the system is to provide:

A general two year academic curriculum with credits transferable to two year and four year colleges and universities; Technical and semiprofessional programs of two years or less; Within a two year college curriculum, courses in general education, including adult education, not necessarily intended for transfer nor technically oriented; and services to employers and the general public to 
provide continuing education and customized training for purposes of improving the knowledge and skills of [state name omitted for anonymity] workers and citizens in all regions of the state.

The Board of Regents supplemented this mission and approved the changes on April 30,

1999. The mission then read:

The mission of [state name omitted] is to improve the quality of life and employability of the citizens of the Commonwealth by serving as the primary provider of the following postsecondary education programs, training, and services: Certificate, diploma, technical degree, associate degree and transfer programs; Workforce training to meet the needs of existing and new businesses and industries; Remedial and continuing education, customized training for business and industry; Adult education, and associated services. (p. 6-7)

For previous technical college employees, their mission, prior to the merger, emphasized workforce development, but since the merger, they indicated that there is more focus on transfer for them. One nursing faculty member $(\mathrm{C} 130)$ stated:

You know we are still trying to put nurses at the bedside so workforce development is a big part, but we also see the need for more highly educated nurses so we do more of that from advising on day one with students about their interest in going on for a Bachelor's degree in Nursing and if they are going to take a gen ed. You know that's probably gone from doing an interpersonal communication to a COM 181 basic public speaking course which is more transferrable to the university level and that's what they need for a nursing program. I think some of our curriculum development has pushed in that direction. You know if they are not requiring a certain course then we kind of back off on it and we change to something else. So, I think we do our best to set students up to transfer on to that four-year setting and continue their education.

The curriculum change sub-themes related to the merger involved (a) the integration of general education courses into the AAS program curricula (b) streamlining curriculum toward transfer (c) the development of more certificates and diplomas (d) and the modularization of the curriculum. Prior to the merger technical/occupational programs required a technical writing course. According to technical faculty members' 
interviews, most soft skills, such as communication were taught within the program curriculum by the technical instructor or not taught at all. The integration of the curriculums after merger created scheduling issues for program faculty and they feel the students have difficulty making a connection between the general education classes and their careers. One previous technical college faculty member (C136) said:

Well, traditionally, and I'm talking about when I was with [state name omitted] Tech, there was a few academic classes that the students took. You know technical writing, technical math, um. Now there is a larger block of gen ed. And in recent years we've looked at ways to connect the gen ed with the technical program. Uh, something that makes sense. You know instead of teaching math and then teaching a technical class there is an initiative here at the college to bring the two together somehow. So the student can connect the math with the technical work and the technical work with the math, which is greatly needed because as you know traditionally there's been a big disconnect there.

The other previous technical college employee (C130) added:

I would like to see even a little bit more. Not particularly integrated but when they are doing general education courses that they have...like if they are doing English, they are working on writing that is more applicable to their discipline or at least in the interest of their discipline. You know, to write on something that they really don't have an interest in, but if there is a research paper required, make that research paper in the direction that has to do with their career goals.

General education faculty, on the other hand, expressed some resistance to the idea of contextualizing (technical/occupational faculty members teaching general education content toward their programs) or modularizing the curriculum. This resistance was noted in the response of one English faculty member (C110) who has extensive experience with curriculum development and approval both prior to the merger and after the merger.

There have been a lot of taking out and then going back and reevaluating and putting it back in, but initially it was kind of a dumbing down of the curriculum. I sat and listened with a smile on my face at the system when the plumbing people were saying they were meeting the communication competency in their program without offering communication. Everyone was trying to make up a little module 
that would cover what people who have master's degrees and years of experience were doing before that. They thought it was okay. I think what they found now is that as these people graduate and go out in the community and say they have these skills they do not have them, so they are coming back and it is a cycle from the community. The employers are demanding more general knowledge.

The chief academic officer at $\mathrm{C} 1$ added:

I do not think we have done a really good job with that [academic and technical/occupational integration]. I guess the direction I will take there is something that is happening a lot in academic circles and that is contextualization, and I think that is probably what you are referring to when we talk about integrating occupational and academic coursework. What people are usually talking about is contextualizing many general education competencies within technical coursework. That meets with resistance here, and I think some of that is really probably very sound honestly, but there are many colleges and programs that are taking those competencies, embedding them within their programs and teaching them as a part of how you learn radiography or machine tool or AIIT. There is a lot of research that shows that is really where the best learning takes place.

The findings under this theme indicated that both former technical college faculty members and former community college faculty members feel their mission focus changed after the merger. The community college members perceived a diminishing of the transfer focus and an emphasis on the focus on workforce development, while the technical college members perceived an increase in the emphasis on transfer. More technical programs are advising toward transfer. Successful integration of academic and occupational curriculum still eludes colleges that merged and faculty resistance may be one barrier to successful integration.

\section{Theme 3 findings: Curriculum administrative process after merger}

For this theme, the major sub-themes identified were (a) the curriculum process is more complex (b) it is more top-down (c) it is an overwhelming amount of work and (d) faculty value having input on local and system-wide curriculum committees. Prior to the merger, for the community college faculty, the process was faculty driven. If a faculty 
member wanted to create a new curriculum, revise a curriculum, create a new course or revise a current course or delete a course, that faculty member had to submit the appropriate paperwork, seek the support of their division members, gain the approval of the local curriculum development committee, get the local faculty approval and then submit the proposal to the system program development committee for approval. Once that body approved the program, it was sent to the system-wide Community College Faculty Council for approval. For the technical college, the curriculum process was more top-down and faculty members had less ownership of the curriculum generation development and approval process.

After the merger, the curriculum process changed to what interview participants describe as a much more complex process. It is faculty driven, but colleges have more individual control over programs and the approval process, which means that there may be multiple curricula for nursing if each college decides to develop its own program. The chief academic officer describes the local process at $\mathrm{C}$ :

You have a Curriculum Review Committee. And of course, following up on the $\mathrm{CRC}$ process you have an approval process, also, which is the $\mathrm{CAC}$, Curriculum Approval Committee. There work is not as in depth as the CRC because they vote on the recommendation of the $\mathrm{CRC}$, but you do have two bodies here. Now at some colleges they do not have two bodies. Some colleges the CRC also is the voting body. I kind of like having the checks and balances that we ended up with here, then there are some that send the vote to the full faculty and do that in a faculty meeting. There are a lot of complications there. You have got to have your faculty meeting when the cycles dictate which that would be kind of tricky to keep working with. And there are times with the $\mathrm{CAC}$, the voting body, has to call emergency meetings to deal with things that come through and we would have to call an emergency faculty meeting when that occurred, you know, if we went by that model. I think what we are doing now makes sense here but yet it is a really large amount of work for those people on the curriculum review.

Faculty members view the work as very time consuming, confusing, and top-down. A faculty member $(\mathrm{C} 110)$ described the previous curriculum process: 
Well the process was very straightforward. It was in our senate rules. Everybody knew the process for years and years and so we from the community college was always faculty driven. There were two standing committees that were faculty driven and one was the rules and the other was the curriculum, so faculty took great pride I think in trying to be involved in that. It was something that was controlled by faculty, they understood it, and they wanted to keep that power. After we merged the tech side had always been top-down. The state just told them the curriculum and so they were not accustomed to being involved in it and they did not understand why anybody would want to be involved in it, so it was this kind of difference in just the practice and the theory of it all. That was a big hurdle to get over, to try to convince them that it was important because it did mean jobs and you know all kinds of things.

A former technical college faculty member (C136) describes the new process in a more positive way.

You know we kind of did our own thing here. All these programs, technical programs were under, or the majority [of programs] were under, MIT. They were under the state umbrella. We broke away, which is good and bad. The good aspect is we have our own program, we call the shots now. It gave us some freedom. Before, everyone had to agree statewide what the curriculum would be. Now, since we have a unique program that's strictly unique to our college, we're not tied to that group anymore so it's given us the academic freedom we needed.

Unlike other committee work, faculty members who had experience on the system-wide curriculum committees perceived their work on that committee as valuable. They cited an appreciation for the broadened perspective that the experience provided regarding the curriculum needs across the system. Also, they felt pride in being asked to represent the voice of their college and to provide input on curriculum issues. (C134) said:

Well, I thought it was a good thing. I thought it gave our school a voice in the programs that we're going through. One thing I did learn at the system level was when there was a curriculum revision or a rule change, it seemed like I always learned a lot when I went up there because you get different points of view. You know you didn't always agree with the different points of view, but it seemed like things we might not have thought about here, someone at another school would have, so I thought it was good to have a lot of input from the different colleges.' (C136) said: 
It made me feel valued as an employee. That my input was valued and that I had a voice on how my program should look. It made me feel good being able to shape that curriculum.

The data under theme three illuminated a faculty perception that the curriculum administrative process, prior to merger, was straightforward but today it is much more complex. Further, the curriculum work is overwhelming not only to faculty members on the committee, but to the chief academic officer as well. Program faculty, on the other hand, viewed the process more positively than general education faculty members. In spite of the amount of work, faculty members who served on these committees valued having input and they appreciated the broadened perspective that the experience provided them. Additionally, faculty members felt like serving on the curriculum committee gave them a voice for their college and their input mattered.

\section{Theme 4 findings: Conflict}

Under the conflict theme, several data clustered under four areas: (a) loss and erosion (b) faculty/administration relations (c) integration and (d) anti-system. Subthemes of high significance to the quintain under loss and erosion were budget constraints affecting professional development and resources, loss of focus on teaching due to other responsibilities of the job, the loss of variety in courses to teach, and a decline in the student quality.

Budget constraints impact every area of the college. Where participants perceive that it most impacts them is through the administration's decision to cancel classes due to low enrollment, and through limited resources for professional development. As mentioned earlier, the Humanities division has the lowest budget. Each faculty member is allotted $\$ 175.00$ for travel per year for professional development. The college does, 
however, have a professional development program which provides local weekly workshop opportunities for faculty. Divisions with Perkins allocations, those with technical programs, or those in disciplines supported by Title III grant initiatives have more funding for professional development.

A general education faculty member (C132) stated:

It is my sense that maybe faculty are not traveling and doing as much of that professional development as they once were. I think, again, it has to do with budget constraints and things of that nature. But I felt like a couple of years ago there was this big push in professional development and my sense is, just from chatting with colleagues, that maybe there's been a change in the way that that is being done. Maybe folks are not getting as many opportunities as they were.

The other way faculty see changes affected by the budget is through courses being cancelled, which often reduces the variety in teaching load. Faculty members, such as (C135) expressed his perception:

I used to teach creative writing and I had quite a bit, well I would usually make the class, but the classes would no longer make and I think part of that is the economy and what is going on there. People want courses that are going to count for something and creative writing doesn't really fit that bill.

Another oppositional finding was that faculty members feel they are unable to focus on teaching due to the growing responsibilities in other areas of their job. The researcher sensed a frustration that administrators are detached from the work of faculty and they lose sight of the work in which faculty are engaged. (C110) stated:

My work has tripled; but I just think we are larger, everything is faster, and we are recruiting people at a lower level so it takes more remediation. It takes more office. I may not be talking to them one on one but I am e-mailing and answering questions and doing all of this stuff. What I do now is so different than what I did when I started because at one time I felt like I was interacting with people more and now I feel kind of like a rat in a maze.

A program faculty member $(\mathrm{C} 126)$ stated: 
Before we merged my primary responsibility was teaching. I was in the classroom from like 8:00 in the morning until 3:30 in the afternoon. A lot of student time. Um, so much student time that in some cases it became more personal, you know, I got to know the students as friends. Uh, but now, the instructional hours have been cut. Um, especially with this last round of reducing hours to 67 credit hours, 67 or 68 , whatever it is. There's a lot more responsibility since we merged that is taking me outside of the classroom.

The researcher identified another sub-theme related to the growing work of faculty members. Respondents perceive that their work is growing due to the influx of underprepared students who require more remedial work. Also, faculty members suggested the change in the student demographics as playing a role in their frustration. According to interview data, students are younger and less invested in their education than students several decades ago. Classroom management issues appear to be more prevalent now due to the maturity level of the incoming students. (C129) said:

I think that even when I was teaching English, I felt a greater connection with the students at that point and time than perhaps I do now. It may be due to demographic changes of the students as opposed to merger. We are getting younger students now. Younger students are either underprepared for the community college experience or younger students who see the community college as two years before I go to the university. And of course, being younger, they are somehow more connected with their peers than say other adults.

Under the second sub-theme, faculty/administration relations, the most significant finding was related to the participants' perception that they are working much harder now and the administration is detached from the work of faculty. Although the college has gained opportunities from securing grants, it has created more work for faculty in committee work and paperwork. Another issue creating more work for faculty members is the amount of remediation they are required to do because students come to college underprepared. Also, faculty members felt the influx of technology is creating more work in several ways. Now, students expect faculty members to be available to answer 
questions around the clock. Another growing expectation is that faculty members take on a more administrative role. Today, faculty members are expected to register students in their offices, report student drop out dates online, and print their own student rosters, and enter grades, all of which was previously done by the admissions office. (C110) summed these issues up:

With the merger there were all kind of curriculum changes but at the same time there was also a new push toward technology, so we had to learn all kinds of new software packages and it just appears to me that since the merger that faculty has been expected to do so much more for the institution. An example would be when I came here 30 years ago we had an admission office that admitted students, that is where we turned our grades in, and it was done by pencil. We had about 2,000 people then, and we had two people in admissions and they handled it. Now we have about twice that many students and there are probably 20 people in admission and I am registering students in my office and I am putting grades in the software, so it appears to me that even though we get more support staff that to justify those positions they have to send something for me to fill out. With every grant I get more paperwork to do, with every new support person I get more paperwork to do and that takes away from interacting with students.

A second finding related to faculty/administrative relations revealed that faculty members perceive that the administration is cut off from faculty work. One faculty member ( $\mathrm{Cl10})$ elaborated on her perceptions about the administrators' detachment:

I do think probably they are perceived as cutoff from the heartbeat of the college, that they are more in an isolated bubble and they do not really get the whole view of everything which I am sure is true just by being an administrator.

The chief academic officer, who previously served as the social science division chair,

offered a similar perspective to substantiate the faculty member's perception:

I really miss that role of chair [division chair] because it is a much more intimate relationship with faculty. I like working with faculty in terms of what they are doing in their courses. I like to learn what they are doing in their courses, the new things that they are doing with regard to improving student learning, creating greater challenge, things like that that I am more distanced from now. 
Another sub-theme identified under the conflict theme was integration. Items of high significance to the quintain in this theme included curriculum integration between general education faculty members and technical/occupational faculty members and the addition and reduction of general education courses in the AAS program curricula. Initially, after the merger, the technical/occupational faculty members had to convert their clock hour time with students into credit hours. Also, they were used to teaching the general education portion of the program in addition to their program content. For some, the addition of the general education courses, taught by general education faculty members, disrupted the flow of their program. One program faculty member (C130) stated:

When I first started teaching LPN we taught the anatomy and physiology and those courses. There wasn't a lot taught outside. You know we did the human growth and development, psychology aspects of it and everything was what you need to know for this profession. It was not a lot of gen ed. I think probably starting in that I had that philosophy that the gen ed kind of got in the way of our scheduling and you know during the merger and being pushed into pushing classes into credit hours and specific times and that sort of thing took what I thought was our flexibility away.

Two major conflicts occurred during the merger for the nursing program. The first conflict emerged as the LPN program [previously affiliated the technical college] and the $\mathrm{RN}$ program [previously affiliated with the community college] merged together. Initially, there was a distinction between the LPN and $\mathrm{RN}$ faculty due to their educational level differences. (C130) described the experience:

Oh yeah (laugh). Integrated was controversial because it was putting two different faculties together and two different programs together and to shape the whole world of the college change in the gen eds. That not only shook it here, but it shook it across the state because science departments were involved due to the changes and it shook communications world and social science because we have so many students, whatever we do impacts everybody else and we know that. Sometimes we forge forward and do it anyway (laugh). 
One major conflict identified through the interviews with nursing faculty members related to a change in the nursing program requirement from anatomy and physiology I and II to a new course specifically developed for nursing students (BIO 135). Natural science faculty members felt the science course was watering down the biology content of the course in taking it from a two course requirement to one course. This disagreement created great conflict between nursing faculty members and biology faculty members. Curriculum minutes confirmed this finding of conflict between science and nursing faculty members.

The final sub-theme under the conflict theme derived from participants' statements indicating a resistance to the system office and its initiatives. Faculty members expressed a frustration over the top-down initiatives and perceived bloated system office, which now has over 200 employees. Some participants perceived that there is a lack of coherence between the system needs versus the faculty and students' needs.

(C133) noted:

I think one possibility is again the bureaucracy, um, you know when [college system name] started there were only a handful of administrators. And I think the last time, and I may have to double check this, but the last time we were talking about hundreds of people being employed by the systems office. And all of them have their own little niche. Some people are pushing technology, some people are pushing teaching and learning, some people are pushing professional development. Uh, and of course, the whole aspect of the accountability that faculty has, not only to staff and students, but to those administrators, makes you want to do all those things.

Although faculty members expressed frustration with the system office and felt there was a loss when they lost the connection to a major state university after the merger, there were some participants who felt the college's affiliation with the system, 
opposed to its previous association with a major university, brought some positive attributes to the college.

The college chief academic officer said:

I think the university gave us that sense of who we are in higher education. It is really very important; however, we also had our place within that university and it was not a prominent place. I think we knew that. We knew where we fit in and where we were. In a way without any kind of formal constraints, it constrained us or maybe we did it to ourselves. I am not sure, but either way I feel like we were more confined. We did not reach out as much. We did not push ourselves as much. We did not think outside the box as much, none of that. I think that has been the major change since we moved in to [system name removed].

The findings under theme four indicated that conflict existed due to loss and erosion of budget, course variety, and professional development. Also, faculty members perceive they are working harder and administration is detached from the work of faculty. Conflict existed in relation to the integration of the general education and technical/occupational faculty and the curriculums. Finally, data indicated a conflict between the work of faculty and the system office initiatives and work. Theme 5 findings: Faculty work changes related to student, colleague, and administration interactions since the merger

For the final theme, the researcher identified the following sub-themes with high significance to the quintain: (a) More administrative work to job now (b) less time for teaching students (c) more committee work from outside influences and (d) more emphasis on professional development. As mentioned previously, under the conflict theme, participants perceived that their role held a stronger administrative component to it. This is reflected again in the final theme. One previous technical college faculty member indicated that his work with the pursuit of grants to support programs in his division, created much more work for him. He describes his experience: 
It seems like there is always a grant on my back door. I am always meeting with [name removed] about a new grant initiative. I think I've taken more of an administrative role, myself. You know there's a business aspect to teaching. Teaching is no longer teaching. There's a strong administrative component to it, you know, there's a lot of paperwork. Uh, there's a lot of community service. I am constantly making contact with community facilities that I use for clinical sites. There's a lot more documentation with this system than it was with the old system. Uh, annual plans, um, diversity plans, uh, so I spend a lot of my time working on those aspects, those administrative aspects.

Another major sub-theme related to faculty work was the amount of committee work related to external influences such as the Quality Enhancement Project (QEP) which is a component of the reaccreditation process for SACS. Also, the college has received three Title III grants over the last eight years, so the implementation of those grants increased the committee load. Both external influences related to curriculum restructuring so they have high significance to the study quintain. The QEP focused on implementing critical thinking across the curriculum. The QEP initiative coincided with the first Title III grant which focused on restructuring general education courses to add coherence to learning outcomes, assignments, and assessments. Faculty members received course releases to meet each week for one semester to restructure courses. The second Title III grant supported program restructuring efforts for technical and occupational programs to strengthen their learning outcomes and assessment measures. Also, a QEP committee met regularly to develop strategies for implementing critical thinking into the curricula across the college. All of these initiatives created more committee work for faculty.

One faculty member (C135) noted:

Well, it has increased but I don't know if it is the merger. I think it is because of my role has changed. So, there were a lot of committees that grew out of the first Title III that I have been on and stayed on like the English 101 course restructuring committee still stays pretty active. 
There were several faculty members who felt that committees were not meeting as often over the last two years. One faculty member noted an e-mail he received, sent to all faculty members, from the president which stated that she was limiting committee work because faculty were complaining about not having enough time to focus on their teaching:

Judging from the e-mail we just saw, it's probably going to decrease even more. Basically it said that they wanted us to focus less on committee work and more on teaching, I believe it was. But uh, when I got here we were doing a lot of committee work.

The final sub-theme under the work of faculty is the increased emphasis on professional development. Faculty members perceived that the Title III grants provided them more opportunities to travel to conferences that would previously were not possible due to the cost. The grant work, coupled with the QEP initiative brought not only external professional development opportunities, but many more local workshops as well. One such workshop is a critical thinking seminar for faculty, which enables faculty to come together and discuss important topics in education and engage in critical thinking activities themselves. This workshop is offered in the evenings. A meal is provided and faculty members read assignments prior to class. New faculty members are required to attend this series for a year.

One faculty member (C111) shared the following about the emphasis on professional development:

I think it is emphasized more now especially since we are focusing a lot more on teaching and learning. I think more people are being encouraged to go to some of the big teaching and learning conferences like NISOD or the League for Innovation in the Community Colleges. 


\section{Summary of Single-case Findings for $\mathrm{Cl}$}

In summary, for $\mathrm{Cl}$ the interview data indicated that the course variety in English and communication has diminished since the merger, which creates some frustration for faculty members in those disciplines. General education faculty members expressed concern over the diminishing general education requirements in the Associate of Applied Science degrees. The catalyst for curriculum revision was Title III grants and SACS reaccreditation. The revisions included developing course competencies, student learning outcomes, and assessment measures. While some participants indicated a major shift in their instructional approach, some indicated that their teaching has not changed.

General education faculty members felt the mission prior to merger was more transfer focused, but emphasizes workforce development now. Conversely, faculty members under the previous technical system feel there is more emphasis on transfer for their programs since the merger. Although after the merger general education courses were added to technical/occupational programs, the program faculty members expressed a need to make the general education courses more applicable to the technical program students' careers. General education faculty members resist the idea of contextualizing and modularizing their curriculum for technical/occupational degrees. Faculty members perceive that the curriculum administrative process is more complex and top-down oriented since the merger. Also, the work on the curriculum committees is more timeconsuming and overwhelming.

Faculty sense losses due to budget constraints, which make it more difficult to engage in meaningful professional development and impacts the administrations' decision to limit course offerings. Both technical/occupational faculty members 
expressed frustration about the increased work due to increased technology, more administrative work, committee work created from external sources, and the amount of remediation students need. Also, faculty members perceive that the administration is detached from the work of faculty.

\section{Single case analysis for $\mathrm{C} 2$}

The second college, C2, merged with the technical college in 1992. It was the first community and technical college in the state to merge. It was considered a model merger in the state. Currently, the headcount enrollment is approximately 2,000 students. Over the past two years the college has seen significant enrollment growth due to an influx of students coming from a nearby major city. There is a large community college within 10 miles of C2's community, which is described by several faculty members as "the competition" or "the big gorilla". Many residents from that nearby major city are choosing the smaller community college environment and enrolling at $\mathrm{C} 2$, which has increased student diversity. The local residents of the community where $\mathrm{C} 2$ is located value having access to an education in their town. Student mobility is an issue for many students in the area. Budget cuts and other losses significantly impact the work of faculty

at C2. Currently, there are five full-time English instructors and one full-time communication instructor.

A distinguishing characteristic of this college is its strong, charismatic leadership, which emanates through the school from the voices of faculty, staff, and students. Findings with major significance to this college included the reduction of general education class offerings in English and communication, declining student ability, budget constraint issues, and the impact of leadership on the organization after a major disaster. 
The researcher presents the findings from each theme, which evolved from the study issue questions.

Theme 1 findings: Curriculum changes in English and communication after the merger

Much like the findings of the previous case study, findings under theme one revealed a perception that course offerings in English and communication have diminished. Also, the general education courses are diminishing in the AAS curriculum. Further, faculty are preparing students for a globalized workforce through enhancing critical thinking, problem-solving and hands-on experience. The course content for the Composition I course has little literature, but several essay assignments. (C220) describes the course content: "Well with grading it is holistic grammar, content, everything. We do writing modes so we will do narration, cause and effect, compare and contrast, things like that." When asked about the last time the English faculty revised their curriculum one faculty member said:

We actually just started doing changes to the 101 and the second level of developmental English writing. Last fall we started talking about it and we are trying to make changes for this fall coming, changing books, you know changing some of our methods. Last semester we put a rubric together. You know, we had one but we revised it for portfolio grading and things like that, so we try to do stuff like that every semester, make revisions to rubric and things like that.

The researcher reviewed catalogs from the year after the merger and the most current catalog to determine programs offered and changes in the general education requirements in English and communication. According to a review of the 1992-93 college catalog, C2 offered one AA degree, three AS degrees, an AGS (Associate of General Studies) degree, five AAS degrees and two ABS degrees. At that time, 15 certificates were available. English Composition I and II were requirements for the AA and AS degrees. Communication could be taken as a Humanities course to meet the three 
hour Humanities requirement for the AA or AS degrees. Certificates generally required an applied writing course. A review of the 2010-11 catalog showed four degrees (a) the Associate, designed for preparatory education for transfer (b) the AA, designed for transfer in advanced standing for a four-year college (c) the AS, designed as a transfer degree (d) the AAS (e) the Certificate of Applied Science (30-42 hrs.) (f) the Certificate of General Studies ( $30 \mathrm{hrs}$. of general education courses) (g) the Certificate of Technical Studies (21-33 hrs.) (h) a Technical Competency Area (1-12 hrs.) and (i) a Technical Diploma (45-60 hrs.).

The researcher reviewed the 1992-93 catalog to determine the number of courses listed for English and communication. At that time, there were 11 English courses to potentially offer on the schedule. For communication, the analysis revealed eight potential courses to offer on the schedule. A review of the current catalog (2010-11) showed six potential offerings in English and five in communication, indicating a decrease in the variety of offerings in each area. Interviews with English and communication faculty members reflected a perception that course offerings are diminishing. One faculty member (C125) stated:

Now since then, slowly but surely over the time I have been here, speech has been eliminated from certain programs. It used to be that everybody here who used to graduate in paralegal in two years they had to take my argument and debate course beside the one speech course. Now they do not have to take debate anymore.

The second major finding indicated that the general education courses in the AAS programs have diminished since the merger. The Associate degree requires English Composition I and II and a speech course. The AA and AS degrees require Composition I and II and nine hours of Humanities, which means a student may or may not choose a 
communication course to fulfill that requirement. Of the five AAS degrees, four require a communication course. The fifth program, currently pending approval, does not require a communication course. One of the Certificate of Applied Science requires a communication general education course. For those certificate programs, only Composition I is required. The Certificate of General Studies requires Composition I and II, but no communication course. The Certificate of Technical Studies requires an applied writing course or Composition I and no communication requirement. The technical diploma, which the college practical nursing program offers, requires Composition I and no communication course. The $\mathrm{C} 2$ chief academic officer, whose background is teaching English, indicated a need to broaden the general education courses in the AAS programs.

My take on it would be that some of our career programs are not strong enough in their gen ed components and so what they require for let's say levels of English. If they require anything, is not in my view, what it should be to really turn out people for the workforce because every time anybody studies...like 10 years ago the Department of Labor issued this huge report that came up with what were called scan skills, but they basically convened people from higher education industry and said what are the skills that people need to have to be successful in the workplace. They were almost all general education, liberal art skills, written communication, critical thinking, problem solving, analytical reasoning and so on. And so, if you only teach people how to operate equipment and machinery and not give them that broader perspective, I think yeah there are often entry level jobs that they can get but in terms of their longer career they should have more of a base of general education.

Theme one data support the findings that offerings in English and communication courses have diminished since 1992-93. Furthermore, the general education courses have diminished in the AAS programs.

Theme 2 findings: Mission change and curriculum changes after merger

The majority of the responses to interview questions under this theme, indicated that the community college grew out of the technical emphasis on the $13^{\text {th }}$ and $14^{\text {th }}$ grade 
at a local high school, therefore, the primary emphasis is, and has been, workforce development. Respondents said that they do emphasize transfer as well, but the cultural background is technical in nature. One program faculty member said:

I see both [areas of emphasis] and it really kind of depends on, like for my program, my program does both. We put our students out in the workforce within a year once they start our program, so that is definitely workforce development, but it also provides a platform for them to transfer if they want to become an RN.

The researcher identified another dominant sub-theme related to the changing student demographics and the growing need for more emphasis on multi-cultural issues. In the last year, African-American student enrollment has significantly grown creating a greater need for a focus on diversity issues. The college administrator offers his perspective.

We are getting an increasing number of students from [name removed] ...and most of those are African-American students coming from the public schools mainly... so I think as of this spring our African-American student population is over $40 \%$ or around $40 \%$ which is a big change from pre-[hurricane] and previous years, so we are learning that culture and having to try to make sure that we are providing the resources again for 2,400 students as opposed to a much smaller number three or four years ago.

An English faculty member (C220) said:

We have had to kind of lower our expectations in our courses because of our student population. Some students are just, you know, we had a student last semester who was repeating an English 101 class for like the third and fourth time, and it is kind of like what do you do? I mean I had him take it again. That is all you can do. Others, who do not teach English by the way, well we cannot have this student unhappy. The student has taken the class four times. We need to find a solution.

When the researcher asked faculty members how they were preparing students for the globalized workforce they identified some ways they felt they were preparing students (a) through critical thinking exercises (b) through problem-solving activities (c) by making connections with current events and (d) by teaching work ethics. The college's 
SACS Quality Enhancement Project has influenced the addition of problem-solving and critical thinking activities in the general education courses and program curricula so several interview responses indicated an emphasis on critical thinking in their course assignments. The nursing program coordinator indicated that she was working with the student success coordinator to develop one of the student success courses specifically for nursing students with an emphasis on critical thinking in the course.

\section{Theme 3 findings: Curriculum administrative process change after merger}

For several years, the Chancellor for Academic Affairs was responsible for the curriculum. When it became too much work, the Chancellor formed a curriculum committee. According to the college administrator, curriculum changes can come from faculty members, the department, or from him. One sub-theme identified related to curriculum was that the process is intended to be bottom-up, but it is more top-down. The college administrator and a faculty member with extensive experience on the committee cited the reason for this as largely due to faculty members coming from a high school background and not having a comfort level in taking ownership of the curriculum development process.

The chief academic officer at $\mathrm{C} 2$ said:

I do feel that it is the culture here both with faculty and with the division deans had been much too passive about looking at the curriculum, so I have been trying to push that and give them models again from longer established, comprehensive community colleges.

A faculty member (C219), who has extensive experience on the curriculum committee added:

We make changes when it is kind of thrown in our face that we need to make a change rather than us looking at it and saying well we need to make this change 
because it will affect this way. So in that respect, it [curriculum change initiatives] come kind of top-down rather than bottom-up.

The interview data revealed that faculty members who served on curriculum committees valued that experience. They felt they gained a greater awareness of what is going on and how changes occur. Some faculty members felt resistance to new curriculum ideas. One faculty member stated, "I think that they are kind of resistant to new things. I think they are kind of resistant especially to new ideas for the humanities."

\section{Theme 4 findings: Conflict}

The researcher identified several sub-themes under the major conflict theme and they included (a) student body (b) loss or erosion (c) faculty/ administration tension (d) integration and (e) governance. The student body sub-theme was a prominent theme throughout the interviews. Faculty members indicated a frustration with the low skill level of the current student population, as well as their apathy toward learning. Another issue related to the student body was classroom management issues, which seem to be more problematic for many faculty members. The college chief academic officer commented on this issue:

Our faculty really felt a difference this year. Our student population got younger. It got more diverse. I think they noticed a lot of classroom management issues and classroom dynamics that were somewhat different than they had been and that has been an adjustment.

A general education faculty member (C220) said:

Our students have taken kind of a turn for the worse. You know, each semester it just gets worse. We have populations of students who are coming in with naturally little academic preparation, but even worse than academic preparation it is just basic life skills like manners, how to behave in a classroom setting, how to deal with other people's opinions, how to respect authority, how to follow rules. And that has really what I have noticed really in the past two or three years I have noticed that students have become each semester more immature, more, you know, in this mindset of disregarding anything but their own little worlds, more 
close minded, more rebellious. I kind of feel like sometimes I am dealing with high school kids, but they are actually a little worse than high school kids because the high school kids that I have taught in the past you tell them once and that is it.

When the researcher asked faculty members whether they taught Plato in their courses, they indicated that those ideas would be too complex for their student population. One English faculty member stated "My students would think you are saying play dough." Another faculty member stated:

I think most students now days in our time they are really interested in practical things. They want to do something that is going to help them get a job. Anything that is just overly intellectual there is a lot of resistance to it.

Another significant sub-theme under conflict is the perception of loss or erosion related to budget cuts, course teaching variety, and general loss due to Hurricane Katrina, which was referred to often by study participants as "the storm". Loss was not associated with merger as much as the impact of Hurricane Katrina. Throughout the interviews, budget constraints surfaced as a major concern for faculty. Budget issues eliminated some student resources, such as tutoring, and faculty members felt they needed to provide those services to their students. Consequently, they are giving their time to tutor their students. Also, when they were asked about professional development, most faculty members responded that there was no money for professional development. One faculty member said he had to cancel two conference presentations he had been accepted to because there was no money to travel. The college administrator stated:

I think because community colleges in [state name deleted] in general are much newer than they are in most of the country and because there really have not been the resources in the system our faculty have not had as many opportunities for professional development as they should have had, and we still do not really have the funding to do that. I am trying to apply for grants that will give us some of those resources. 
Several faculty members were teaching overloads or teaching part-time at four-year colleges to supplement their incomes, which are quite low in comparison to other community colleges in the state according to interview data.

Another factor affecting the budget and teaching was the destruction from the hurricane. Each interview revealed a reference to before the storm or after the storm as a way to determine a time period in the college's history. The college lost its administration building when the hurricane tore through the community. Although they had makeshift facilities and opened the following fall, they lost a major portion of their enrollment. Prior to the hurricane the enrollment was 2400 and after the storm it was 800 students. The major building on campus today was flooded in the storm and was only reopened in 2009. The campus is still recovering from the storm, but enrollment is back up close to the pre-hurricane enrollment. One consequence of Hurricane Katrina was that the college had to furlough some faculty. One faculty member, (C225), described the situation:

Right after Katrina, about half, especially the humanities faculty, half of them were furloughed and if you were furloughed you did not get the raise. Some people got a $\$ 3,000$ to $\$ 4,000$ year raise and some people did not.

Another loss associated with the hurricane was the loss of faculty members whose homes were destroyed which forced them to move away. The storm displaced faculty and staff, and some have never returned to the state after relocating. This loss has impacted the academic work of faculty as noted by one faculty member (C221) below:

After Katrina we lost our political science instructor so I volunteered to teach that, so I teach introduction to American government. I have the graduate hours. It is not what I had focused on, but I had the graduate hours and I volunteered to teach this one class that we really needed. I have been teaching it ever since.

The pressure of budget constraints keeps administrators and faculty burdened about the future. Faculty members worry about their jobs being cut and administrators 
worry about pressures from governing bodies to eliminate programs. The college chief academic officer stated:

Obviously we overlap [programs with a nearby community college] and we try to cooperate and there are some cases I suppose where you would not want the same program at the two institutions, but you know we really only want the ones we feel will be viable and will meet the needs of our service area but sometimes that does not get through the Board of Regents, and 460 programs in the public two and four year schools of the state that we think maybe need to be cut, so now we are all having to try to keep the ones we want to keep and justify that so we have four programs under the gun at the moment that we are trying to keep that they are trying to get rid of.

Another sub-theme for the conflict theme was faculty/administration tension.

Faculty members revealed tension related to a perception that administrators demonstrated a resistance to new curriculum ideas and a lack of support for broadening cultural activities. When the researcher probed for more information about the source of the resistance, it seemed that the resistance was not from the president. The researcher sensed that faculty members felt some resistance, both in class, and within the college faculty and staff, about discussing diversity issues. One faculty member (C224) said:

I think, I do not know, there is like a, I do not know what you would call it, a resistance to it to some degree but somebody else could say no there is not...We have a very diverse student body and I think that would be something that we should have, and of on issues like that and just I do not know get people comfortable talking...but there is a resistance in talking about issues of race, ethnicity, diversity can be kind of prickly.

Also under the conflict theme is the sub-theme the researcher labeled Integration which addresses conflict experienced as a result of integrating the community and technical college personnel after the merger. Further, integration addresses curriculum issues when academic and technical/occupational curriculums were combined after the merger. As mentioned earlier, the technical culture was the dominant culture. After the merger there was geographic segregation of the Humanities division from the main 
building. The Humanities faculty members were put in trailers behind the technical school building. A faculty member (C225) described the experience:

They actually had trailers out here, but they still sort of had the entire, the technical school was still in its same building but the humanities faculty was in trailers. When I came here, they were just building the back building. It was in process so it looked like Barney Miller Humanities. We were kind of the red haired little bastard kids at a family reunion, and we all had a room like this. Everybody was piled in to one room. It looked like Barney Miller. We were all piled in one room, and I even had to teach a course outside.

The initial integration of the curriculums created tension between the academic and technical faculty members after the merger. A faculty member (C219) stated:

But dealing with the technical faculty has not really been I would not call it a problem, but there have been some issues along the way. For instance, we have had technical people that in some cases did not want us as math people to do as much as we did because they were used to being at a voc tech school. They were used to teaching the math required for them within the context of their own curriculum for their students, so to turn that over to us some people, you know, kind of balked against that and did not want us to do so much. Some people were happy to just turn it over and did not care what we did, but then might complain about the fact that like we were not teaching their students what they needed to know. But again, we had a technical math class that was going to cover electrical, heat and air conditioning, welding, machine tool technology, you know, as well as nurses and culinary.

In addition to issues related to curriculum integration, the technical faculty members, who were accustomed to teaching in clock hours, had to convert their curriculums into credit hours for lectures and labs. This effort required more work on their part than it did for community college faculty members. According to (C219), technical faculty members were resistant to this at first.

Another issue related to integration which was mentioned earlier, is that the historical culture of the technical institute merging with a $13^{\text {th }}$ and $14^{\text {th }}$ grade at a local high school affected the faculty's ability to take ownership of the curriculum. It seems 
that culture has changed slightly, but some programs may need to be upgraded. The college chief academic affairs officer said:

Some things that we offer as technical diplomas or AAS degrees I feel should be upgraded to AS and AA degrees, so that is some of my agenda. I think we need to be offering courses and programs that we are not at this point, but a lot of that is at the mercy of the Board of Regents, whether they let us do that. I think there has not been as much of a culture of faculty actively initiating curriculum proposals as I would like to see.

When the researcher asked the college chief academic affairs officer about whether or not integration of curricula has been successful, he indicated that he would like to see more general education in the career programs. He cites a broader educational context as limiting the successful integration of technical and general education. He said:

We are facing the national challenge that every other community college is facing that two-thirds of our students come in not ready to do college level work. So then if you say to be an electrician you are going to have to pass college level algebra or, you know, composition I and II a lot of them are just going to go away or not successfully complete. And you really have to try to find the right balance for that. I mean sometimes it is going to keep somebody from developing a successful career credential. On the other hand, if an electrician cannot read a schematic well that would make you nervous. So that is a challenge.

Another way the broader educational context is impacting community colleges is through state legislation making it easier for students to transfer from two-year to fouryear colleges. The college chief academic officer described this legislation:

This fall we had a $31 \%$ enrollment growth, and I think two main reasons: One is there has finally been some state legislation to try to get [state name omitted] I think more in line with sort of patterns of the rest of the country in terms of who goes to community colleges as opposed to four years. Our percentage of students in community colleges has been much smaller than the rest of the country. A year or two ago only $29 \%$ of the students in college in [state name omitted] were in two years and nationally it was at $47 \%$. Also, because [state name removed] has been way behind on the ease of transferring from two-year to four-year schools and legislation the year before last kind of forced that issue and created a transfer council which resulted in community colleges creating designated transfer degrees associate arts and associate science and then the four years are required to accept all 60 credits. Before then we had been having to negotiate course by 
course and fight the battles that the rest of the country fought about 25 years ago, so that is another draw that students know that they can come and get an associate degree here and it will all transfer. So, we are having huge enrollment growth.

Another sub-theme the researcher identified under conflict related to understanding the broader educational and political context s of the case, which impacts the study quintain. The governance structure in the state is described (by C219) as "topheavy" in boards of education since the merger. Initially, the college was governed by the state K-12 board of education, which also governed the technical schools. From there the college was under the governance of the University of [state name omitted] group. From that governance system, they then moved under their own community and technical college system board. (C219) said, "It has been an extreme political ride." The college chief academic officer stated, "We have five [boards] for higher education, which most of us would say is at least three too many, so that makes that a little cumbersome."

Findings under this theme revealed that faculty members perceive a change in the quality of the student body, which is impacting their ability to advance the curriculum in some courses. The sense of loss and erosion is strongly tied to the mounting budget constraints, which impact the work of faculty in many ways. Faculty/administration tension surrounds issues of broadening diversity programs and curriculum. Integration of academic and technical faculty was difficult at first, but today it is not a conflict issue. Integrating the curriculums is still difficult and some programs need a stronger general education component. The broader educational context in the state creates barriers to successful integration.

Theme 5 findings: Faculty work changes related to student, colleague and administration interaction since the merger 
For the faculty work life theme, the researcher found that English faculty members experience some frustration with the large composition classes and the fact that students seem more job-oriented. Also, a curriculum issue related to advising is that there is no standard course numbering system. The community colleges share a system-wide matrix of courses which faculty members use to determine course equivalency and transferability.

The first sub-theme the researcher identified was that English faculty members find the large composition classes challenging. They expressed frustration over the amount of grading involved in their courses compared to other disciplines. (C221) said, "Sometimes we have 30 people in a class. That is 30 papers. I teach five of them. I assign a paper I have got at least 100 papers to grade, 100 essays written by people who do not know how to use an apostrophe."

From an administration perspective, the growing enrollment creates concern for administrators in keeping the class load manageable while still considering the budget. The college administrator stated:

Our average class size, which we look at carefully each semester, has been moving up steadily which is good financially but also it is still at a level that works in terms of the load on instructors. It is about 18 students a class now which means we can run some classes with 10 in them as long as we have got other classes with 30 in them. The challenge is, you know, for the faculty one of the things that is really hard to do is to really make sure to hold the line on enrollment particularly in English and math courses and particularly in ones where students are still at the developmental or introductory stages so that the faculty have a manageable number of students to work with. And that is tough. I mean, we keep them at decent levels but I would like those levels and those courses to be a little lower than they are under the pressures of enrollment within budgets.

In addition to the class size issue, the interview data revealed a few curriculum issues. One issue is that the community college system does not have a common course 
numbering system, which makes advising and transfer challenging. They have a course matrix which is a guide for faculty members to use to determine if a course is equivalent to another community college course or four-year college course. The faculty member most experienced with curriculum indicated that there is faculty resistance to adopting a course numbering system with a state university. He suggested that until the common course numbering is mandated, it is not likely to occur.

When asked about the communication with colleagues about curriculum issues, the curriculum faculty member with the most experience on the curriculum committee, said that in the first few years after the merger curriculum was discussed often, but since then it is talked about much less unless an issue arises. As mentioned earlier, there is a general lack of ownership of curriculum development in this college's historical culture, which makes curriculum change a passive pursuit.

Although the faculty members have challenges regarding budget issues and the student population, there was a strong commitment to the community college student. The researcher sensed an overall strong student/faculty relationship. One faculty member (C220) said

I think my students are the reason why I do my job, which is the case for most educators. I always say that there are things here that I cannot stand, but once I walk in to my classroom and see my students I do not care about all that stuff. I just care about my students. That is the driving force behind what I do.

Theme five findings indicated English composition faculty members desire lower caps in their courses due to the grading workload. The lack of a common course numbering system creates some difficulties in advising students for transfer, but faculty are resistant to a common numbering system with a state university. Curriculum revision is not an active process on the campus, which the administrator contributes to the 
historical background of the faculty members. There is a strong teacher/student relationship at the college.

\section{Theme 6 findings: Leadership}

For this college, the researcher added an additional theme because it was so prominent in the interview data. The $\mathrm{CEO} / \mathrm{Chancellor}$ of this community college has had a positive and lasting impact on the faculty and staff at his institution. He is credited for bringing the college back after the storm and the researcher discerned that he is loved and respected by faculty members, even those who might be labeled anti-administration. He has a political background in the state. Faculty members used words like "love [name removed]", and "patriarch" to describe him. The Chancellor is described as "studentfocused" and "hands-on" with students. He serves as a mentor to students in the student mentoring program. One staff member (C226) stated:

As far as the students are concerned, they love [name removed]. I mean he is one of the few chancellors I have ever seen that walks the halls during registration. You know, how are you doing? How are your classes? He knows some of them by name within the first few days. I mean he does not know everybody, but he knows a good bit of them. Those that he does not know by name he recognizes their faces. If they have ever come to him with a problem, he remembers them. How are you doing in that class? Are you doing okay in that class? Is everything going okay with Ms. Jones or whatever? He remembers everything, and they love him. They always say who is that old man, that nice old man. That is the chancellor. That is the chancellor, you know they are very surprised that he interacts with them the way that he does, and they love him. He mentors students.

The researcher noted this warmth in her field notes during the visit. He made a point to introduce himself to the researcher during the visit and inquire about the study, as well as other personal information about the researcher. This interaction was significantly different from other presidents at the other sites the researcher visited. It is evident that the chancellor is a strong leader and respected by many at the college. 


\section{Summary of Single-case Findings for C2}

In summary, $\mathrm{C} 2$ findings suggested that offerings in English and communication have diminished in both the variety of course offerings and in the AAS program curriculums. Faculty members perceive the mission has shifted to emphasize workforce development, even though the college culture is technically dominant. The growing diversity in the student population is creating a need for more emphasis on global and multi-cultural issues. Findings related to the curriculum administrative process illuminated that faculty members are hesitant to take control of the curriculum due to a lack of comfort, which could be based on the historical culture of the faculty. Thus, the process tends to be more top-down than bottom up. Some college curriculums and programs need to be upgraded but the college is struggling to hang on to some programs that are currently under consideration for elimination due to the statewide budget constraints. Conflict sub-themes surrounded issues related to the changing student body, loss and erosion due to budget cuts, the storm, and the curriculum. Other conflict data clustered under the faculty/administration tension, integration, and governance subthemes. For faculty work life, large composition classes, and a lack of a standard course numbering system, emerged as relevant sub-themes under this major theme. Finally, the interview data revealed a strong leadership presence at $\mathrm{C} 2$, which the researcher identified as a sixth theme for the college.

\section{Single Case Analysis for $\mathrm{C} 3$}

The final case, C3, is the largest of the three colleges in a statewide system of 12 community colleges. The college total enrollment was approximately 5,000 students. Of these 5,000 students, 4722 students were credit-seeking students. In the fall $2010,88.4 \%$ 
of the students enrolled were seeking an Associate Degree, while 3.1\% were seeking certificates and $8.5 \%$ were non-degree seeking (2010 fact sheet). One distinguishing characteristic about the merger between the technical college and community college is that the actual paper merger occurred 12 years ago, but the physical merger only occurred in the last three years. Thus, some aspects of the merger were not realized until the physical merger occurred. Another unique characteristic about this college is that the faculty members are divided by two unions which were initially separated by technical college faculty and community college faculty. However, as new faculty members are hired, they may be placed randomly into a one of the two unions. Unions determine the work of faculty in the college. This union separation was the source of great conflict after the merger and some aspects of the conflict linger today because the differing contracts create differences in workload issues. Also, the union contracts create a barrier between administration and faculty. Through interviews with faculty members and administration, the researcher concluded that the cultural difference between the two campuses was a significant barrier to integration between the two cultures.

Theme 1 findings: Curriculum changes in English and communication since the merger

Prior to the merger, all technical degrees at the technical college required HUM 1100-English Comp, HUM 1104-technical writing, and HUM 1105-oral communications (Technical college 1992-93 catalog). Prior to the merger on the community college campus, communication courses were embedded in the English department and taught by English instructors. The general studies degree required nine hours of Humanities (three ENG 11 and three LIT were two of the requirements). The remaining three hours could 
be met with a Humanities course. Thus, the student could graduate with an associate's degree without any speech course. In 1993, just after the merger, the general studies program required ENG 131: Speech class. Also prior to the merger, the community college offered 13 English courses and one speech course in the catalog.

A review of the 2010 catalog revealed that there are 15 English courses and three speech courses in the college catalog. Thus, it appears from the catalog review that English and speech offerings have grown. The researcher noted that the additional English courses in the catalog could be to meet the intercultural requirement, which was not there in the 1993 catalog. This could also be the case for the Intercultural communication course, which was added to the communication course options. Perhaps these were added to meet a diversity outcome. After meeting with the only full-time communication instructor, the researcher learned that he was only hired last year. Until this time, English faculty members, or adjuncts were teaching the communication courses.

From the interview data, one overarching sub-theme the researcher identified was that both the English and communication disciplines are working to develop more coherence in their disciplines. The new faculty member indicated that he was hired to bring a sense of coherence to the speech curriculum. (C343) said:

I am the first person who has formally had a communication role here. So, I was brought in to standardize the curriculum, decide on a common text, because we didn't have one. Just certain things like that. Work on the learning outcomes, so I have been working on that as well. That's been a very large project and taking up a lot of time doing that and we hit a few of the milestones we were looking for so far but there is definitely more work to go over the years.

From his comments, it seems that the college is behind other colleges in distinguishing communication as a stand-alone discipline. Although, it should be noted, that the 
communication instructor is teaching English courses in addition to communication courses.

The English division chair indicated that there was great disparity in what was taught, particularly due to the large number of adjunct teachers in English. Both English and communication taskforces met over the last year and developed a common course syllabus and limited the text options from six to three. (C344) described the experience:

We are hard at work on making sure that all of our sections at the composition level are more coherent because so many of them are taught by part-timers we were seeing some slippage in terms of how our students from individual sections were fairing when they moved on to literature so we're working on that course, just providing some coherence, but we are not changing the outcomes at all and we are not changing the content of the courses per say. We changed the text. We shortened the list of options, for example, that our faculty use. We used to have a list of six texts that our faculty members could choose from and we cut it in half. It wasn't easy (laugh). But we did it. We went from none actually when I first started here you could teach pretty much whatever you wanted to. So that is a major change.

One unique characteristic about the English I and II sequence at this college is that the

English II course curriculum is poetry, drama, and fiction. (C344) said:

We only have one semester of composition and then our students take literature and composition. They take one semester of comp and then a second semester, these are our liberal arts and sciences program requires that. The English 102 is a course where the students read and write about poetry, drama, and fiction. It is different from a lot of other schools because it has been my experience that in most places, certainly in places I taught before here, is that students study composition for a full year, two semesters that is, and then if they require to or desire to they take additional English courses. But, we don't do that here. Our college is different from others in the system. But, we're [school name removed]...we're unique.

When the researcher asked participants about the general education outcomes, the use of critical thinking emerged as a common concept. The communication faculty member discussed his concern about maintaining a deeper level of thinking in the general education courses as opposed to skill development: 
That is one thing that I tried to push more is having critical thinking and maybe responsible citizenship. [I wanted] the idea of democracy and the democratic citizen to be more a part of that class. We are not there yet, necessarily, but that is something that we are trying to work toward. And because it does speak to our general education outcomes, it seems like institutionally there is a lot of support for that. I have been very happy to see that because I was very worried, frankly, about people wanting to go too far in the direction of skills while leaving out the critical thinking, the information literacy, learning how to do research, learning how to write, you know different things like that were really, really important parts of the a class like this because it's not about just winging it or thinking off the top of your head.

This faculty member shared rubrics created by the general education taskforce, of which he is a member. In their effort to determine if general education courses are meeting those general education outcomes, the committee members are gathering artifacts from general education faculty members to determine if they are meeting those outcomes. He indicated that some faculty members are resistant to provide artifacts because they are worried that they might be perceived as not doing their jobs. (C343) had the following to say about the process:

What we are doing is we have three different groups of faculty members who we give piles of artifacts and we say "Ok we want you to test this against the information literacy rubric". The people who gave us these samples of student work say this has something to do with information literacy so we go through and test whether or not it is meeting the outcomes or at least some of the outcomes of information literacy and then on what level is it meeting it. You know a low level or a high performing level. All of that is spelled out in the rubrics. Our next round of evaluation, our information literacy and scientific inquiry and responsible citizenship and we have spent a lot of time soliciting donations of artifacts and we make the copies and everything so that ends up being really time consuming trying to convince people to participate, you know because it is voluntary, of course, and then making duplications, collecting the artifacts. Then we have the separate groups go out and they actually do the assessment and then we bring back and collect the data trying to figure out what does this all mean? Are we actually doing what scientific inquiry says? Are the courses that say they are meeting scientific inquiry meeting scientific inquiry and at what level are they? If they are not, then, why are they saying they are? You know we're trying to figure out. What are we doing and are we really meeting these general education outcomes that we've said that we need to meet? Then we figure out 
why or why not. Then we determine whether we need to revise the rubric or the process.

\section{Summary.}

The findings under this theme indicated that the English and communication offerings have grown since right after the merger. Also, there is more recognition of communication as a discipline, as evidenced by the first and recent hire of communication faculty member. Data revealed that faculty members have recently engaged in dialogue about coherency in their courses. Further, the college is looking at general education outcomes through the work of a taskforce. The participants perceive critical thinking as an important skill for students to possess when they leave college.

\section{Theme 2: Mission change and curriculum changes after merger}

The theme two findings revealed that most faculty members see workforce and transfer as equally important to their mission. Most participants did not indicate that one was emphasized over another. Even program faculty indicated that they are advising toward transfer. One program faculty member (C339) said:

Within my degree program, I have lots of ors, this course or that course, and then I have that broken up into advising tools for terminal and transfer. If a student's intent is "hey, I just want to get my associate's degree and go get a job and I really do not want to do anything more", or they are already working in the field and they just need that degree to get promoted or something like that I put in to the terminal option which has a lower math requirement than some other kinds of things. But if they say, I think I may be going on some day to transfer to a university I put them in the transfer option where they are going to get their science lab, they are going to get their higher math and other kinds, lit and comp, writing that are going to be better transferred for them.

Another sub-theme was that the mission of the college may be changing with state legislation. Some participants viewed the changes with some trepidation indicating that they did not really know what the future held for them. (C344) expressed: 
Well the community college system has its own board and that may change in the next six months or a year because our new governor is proposing that we merge the boards of the four-year colleges and the board of the community colleges into a single board; and so with that, we have no idea how that will affect us directly. We do know that we won't have our own community college board that is looking out for our specific best interest. There will be a big board and we'll be another layer removed in terms of the attention we might receive. We are all very anxious about what that will mean to our future. Because of budget issues, it is actually up in the air right now about whether to continue it. No one has said it's not going to but, you know, everything is on the table. So, I mean honestly, what are mission currently is, we don't know what the mission a year or two from now will be.

The academic dean at $\mathrm{C} 3$ elaborated on the change:

The bill calls for the elimination of the board of trustees for various different components of organizations of higher ed except [state college name removed] which will remain separate, so the state universities, community colleges and [college name removed] which is an online state college will all be under one board. They are going to call it the Board of Regents and essentially our college will then report directly to what is right now the level of department of higher ed, so it will really eliminate some of that sort of duplication of effort if that goes through. We are apt to experience a change in the way the programs curriculum approval goes on.

From the two quotes above, it appears that there is uncertainty about what the governance change will mean for this college and the impact the change will have on the college's mission and curriculum process. A final finding under the mission theme was that $\mathrm{C} 3 \mathrm{~s}$ faculty members appear dedicated to the mission of their college. One newer faculty member coming to the college from a liberal arts college commented:

I've found that, now this is only my first year and so I am still meeting people and learning a lot of things. But there are a lot of faculty here that are very dedicated to the mission of the community college and it seems to me that it takes a certain type of teacher to be dedicated to the mission of the community college.

\section{Summary.}

The major findings under the mission and curriculum change were that faculty members see transfer and workforce development as an equally important part of their mission and they feel both are emphasized at C3. As the state legislature restructures 
governing boards in the state, the way curriculum is done may change, which is creating some fears in faculty and administration about the future mission of their college. Faculty members feel a strong dedication to the community college mission and value the work they do.

Theme 3: Curriculum administrative process change after merger

When the researcher interviewed faculty members from the original community college, she learned that the curriculum process very early on in the college's existence, was not representative of all divisions. (C337) said that the positions on the committee were voted positions by the general faculty so you might have five or six members of the committee from the same division. He described the early curriculum committee structure:

People would be voted in to the curriculum committee because I remember the first time that I was on it there were over twenty-something people on the curriculum committee. It was not a representative of the school because it was a popular vote, so you could have six or seven people from one department and one or two or sometimes none from another department, so we changed all of that with organization because that was not fair. That was not a fair representation of the needs of the school and the students.

Later, that process changed to be more inclusive of all divisions. (C337) described the change:

The curriculum committee consists of department chairs and people from student services, so that is where we are now. That is where we have been for a very long time now and, of course, the academic dean is the chair of that particular committee. We meet once a month and we go over all the curriculum issues.

Curriculum changes originate with faculty members or a division. Course proposals must get approval from the department before going to the curriculum committee. Once approved by the curriculum committee, the course is then part of the catalog. Degree program approval is a much more involved process. (C344) describes it: 
A degree program is also developed by individual faculty members or perhaps a collaboration of faculty members who want a new program. Right now we are looking at whether we want a video production program. Once the degree program is developed then the faculty member who is writing the proposal might have a course release or it might be their additional responsibilities solely devoted to that. Then it comes to the department and the department says...this is missing. That is missing, this is a great idea, and then it goes to the curriculum committee for approval. The curriculum committee adds whatever they want to add and then once it is approved at that level, it goes to the board, the college board level.

Faculty members on the curriculum committee felt the experience benefited them in their teaching.

(C343), a new faculty member, stated:

I think that this is something that I can't even claim as my own thought, it was actually a colleague, who keeps saying "I think I was doing a lot of these things already, but it makes me see why I do it". It makes me figure out what do I need to do better? And then maybe there are a few things that I could eliminate that I do in the classroom, like an assignment that either could be tweaked or eliminated, or maybe it would end up being the centerpiece of the class. Once I really start looking at the outcomes, I can see what really needs to be done and it makes everything a little bit clearer.

(C339) added:

I am on the curriculum committee which is one that I think is particularly interesting because it gives you a much broader understanding of curriculum and what goes on because it does not matter whether it is a technology program or an arts or science program or a career program everything has to come to curriculum. Whether it is a course or a change to the plan of study or something like that. I enjoy that because I can get a broader view of what is going on, and it is a very good committee.

A more senior faculty member (C341) had a different view about what he perceives is happening with curriculum. He said:

When I was on curriculum, it was a vigorous and vibrant committee. There was a lot of debate. It was not uncommon for people to get mad at each other. But I always thought that people were really, not unlike Hamilton and Jefferson, had different perspectives on which way to go. But both sides firmly believed it was the best way to go for the college. And they would vigorously debate that. That doesn't happen anymore. I think that is a part of governance that is falling. It's part of the whole larger responsibility that we are all involved in governance. 
This faculty member elaborated on his story indicating that he felt the curriculum process was more of a top-down approach and faculty members on that committee tend to passively agree with the academic dean, which minimizes the importance of faculty ownership of the curriculum.

\section{Theme 4: Conflict}

Throughout the interviews, the researcher noted the recurrent themes related to the merger, which still create frustration for faculty members. Several of these issues clustered under a merger issues sub-theme. A second prominent sub-theme was student characteristics which create another source of frustration. The third sub-theme included clusters of issues related to management.

Data clustered under the merger issues sub-theme included: (a) cultural differences (b) different union contracts (c) separate campuses (d) different physical environments. First, the cultural differences between the technical and community college faculty created conflict after the merger. One aspect of cultural conflict is the differing union contracts. Although the union leaders are working together to bridge the differences now, right after the merger, the contract differences created tension between the two groups. As mentioned earlier, this college is unique because the physical merger occurred twelve years after the actual merger. Consequently, some merger issues were not as evident with the initial merger because the campuses stayed about the same until they were physically merged in 2008 . The academic dean described the cultural differences:

Looking back on the culture of the merger that evolved at the time, there was a culture at the community college campus and a different culture at the technical college campus. The way I envision them is that it was a much more feminine culture on the community college and a much more masculine male culture, and 
that is my own personal take on it, in that it was a much more structured, much more hierarchical, much more sort of top down kind of traditional, much more traditional hierarchical structure in the technical college campuses in many regards. The sort of ethic was much more male and the ethic in the community colleges was for lack of better words or a better way to describe it to me it was much more female. It was much more collaborative. The basic premise to everything was that everything had to be democratic. It had to be discussed. There are even still some remnants of that I think in some ways. It is a little bit of a combination of both things as you might imagine now, but it did take a very long time for that to sort of morph into what it is right now.

One faculty member suggested that the retirement of some of the "old-timers" has helped to change the culture in a positive way as new faculty members integrate into the college faculty.

The physical differences in the two campuses affected scheduling and interaction with colleagues and students. The community college building was described as having space issues. (C337) said:

The last year we were there we were in cubicles out in a garage and before that we were in an office that was smaller than this and we shared it with another person, so you really could not have private conversations with people.

Although this faculty member saw disadvantages to being overcrowded, another faculty member perceived the layout of the previous building as more conducive to interaction between colleagues than the new building. He said he likes having his own office now, but the physical locations of the offices decrease his interaction with students due to the noise factor.

When we were in the old [campus name removed] campus, we had a rectangular sized floor with offices all around it and a hallway. [It was] internal rectangular with a meeting room in the center. So, if I wanted to go see so and so over here, I just left my office door open. I'd walk by and people would say "hey, how are you" and we would talk. Sometimes just to go ask two questions would take me a half an hour because I'd be talking all the time. But it was like that. Um, this is a main corridor now. I don't want to leave my door open because other people who do, students just walk right in. Excuse me, I've got somebody here. "Oh". There is no sense of decorum, there is no sense of what is acceptable or not. Um, so we 
keep our doors shut. I got tired of going out and telling people you can't use words like that in the hall. Their social language is awful. I was going out all the time going "You can't say that...what makes you think you can say that?" Then they look at me like I'm weird. So I keep my door shut all the time. It's nice having a private office, because we used to have to share.

The second most prominent sub-theme was student oriented. Faculty members perceive that students are apathetic toward their education. Students' lack of preparedness for college, both academically and socially, was a source of frustration and concern for faculty members.

(C341) said:

We're getting more and more traditional age students right out of high school. They are not prepared to do the college level work that I require. Speaking for others there too, I think, but I'll only speak for myself. They are not prepared to do college level work. Their study habits are awful. They don't want to do the work. And I was just sitting in my classroom going over what I think is a very exciting lecture about art and history and there was a young man in the back and he was texting something. I said "That's good, you got a 34 on your first test, and a 42 on the last one...you keep going boy". They don't care. I seem to be spoon feeding them a lot more than I ever did in the past. Um, and while I hope that I am maintaining the same standards, I am not seeing as many students meeting them as I used to.

Another faculty member (C343) commented on the growing need for more classroom management skills with the changing nature of the student body:

I've noticed at times, in the younger classes, especially, that there is a lower level of maturity then there was at the previous school that I taught at. I am not exactly sure why that is. I could do all kinds of conjecture but I don't know. It seems like it is kind of like $13^{\text {th }}$ grade at times with the younger classes, not the older classes where maybe 20 year olds are, but the 18 and 19 year olds require a lot of classroom management, keeping in control, a lot of things like that that I definitely didn't expect. Every so often I find myself saying ok this is college, we don't do this (laugh).

The third sub-theme dealt with management issues. Issues clustered here were faculty/administration related. Several participants perceive the administration negatively citing specific instances where they did not feel supported by administration. The 
administration is perceived as more top-down. One faculty member indicated that this college had the most one-year hires in the system, which appeared to frustrate faculty members. The data revealed that new faculty members (those there less than five years) tended to have a more favorable perception of administration than senior faculty members interviewed. (C343), a new faculty member, described his experience with administration:

It's been really good. I was fortunate that I was thrown into a college-wide committee where we are doing curriculum work for the general education curriculum, which actually has a lot to do with I think what the research that you are doing. So that has been really good. There are some people from administration on that committee and it's very collegial and they are very nice. They have been very willing to introduce me and help me and work with me. That's really been nice as far as on a professional level.

However, a senior faculty member (C339) suggested a different relationship with administration. He alluded to the union contracts creating a barrier between administration and faculty members:

I would be comfortable in saying at least I do not think faculty look to administration for leadership or mentoring. If that is the kind of tact you are looking for, we do not have that type of relationship with the administration. Part of it is structural. Part of it is personalities. We are heavily unionized here, so part of it I think as a practical matter neither the president nor the academic dean can be really in a role of mentoring people which is unfortunate because then it would be seen as giving people preferential treatment over other people. That brings up grievances and contractual issues and all that other stuff, but personality wise I do not think that is their personality either.

The academic dean commented on her frustration with union contracts. She said: "You know we [administrators] have a lot of limitations because of our union contracts and things that I cannot enforce." Another senior faculty member (C244) said:

Well, I would say, generally, especially faculty, I wouldn't say so much staff, that there is more distance than is good between the administration and the faculty and staff, particularly the faculty. I think there might be some, no I think generally, 
you might pick up on the sense that there is too much space or more space than might be good in terms of communication.

\section{Summary.}

The major sub-themes under the conflict theme related to the cultural differences between the technical and community college faculty members after the merger, the different union contracts after the merger, as well as issues related to the two separate campuses which existed for 12 years after the merger occurred. The second prominent source of conflict was related to the student body, which is more diverse, younger, and underprepared for college. Interview data revealed conflict between the faculty members and the administration, which may be largely due to the college being strongly unionized. Theme 5 findings: Faculty work changes related to students, colleague, and administration interactions since the merger

Major sub-themes under the faculty work theme were (a) student body changes and (b) teaching issues related to professional development, committee work, and curriculum.

According to a fall 2010 enrollment fact sheet, C3 has seen a steep enrollment growth since 2008, which is the year they moved into their new building. Besides the steep enrollment growth the composition of the student body has changed. C3 is seeing a more diverse student body. In the fall $2010,37.3 \%$ of the student population was AfricanAmerican, $22.2 \%$ was Hispanic, $31.8 \%$ was Asian, and $16.2 \%$ was American Indian while $15.3 \%$ was white (2010 fact sheet). While C2 had the largest African-American student population, C3 had the highest Asian and American Indian populations. C3 is near several casinos on Indian Reservations, a major industry in the area, which accounts for the growing American Indian student enrollment. Additionally, the student 
demographics have changed so the student body is comprised of younger students just out of high school. Information from the college 2010 fact sheet indicated that of the $83.9 \%$ of students attending on the main campus only were 24 years old or younger. These changing demographics lead to needs and issues in the classroom, some of which were mentioned under the conflict theme.

Professional development opportunities are available on a weekly basis at C3. However, conferences and other outside professional development opportunities are reimbursed through the union. Again, there are differences between the two unions, so reimbursement may not be equal for all. (C339) described the process:

If you are doing independent professional development that is funded through the union so what you do is you go to the seminar, do the course, do whatever that you are doing, and then you submit that paperwork to the union professional development committee. They determine whether it was actually job related or not. If the answer is yes then they reimburse you for it. And again, that varies between the two unions. The CCCC for quite a number of years has not had any money for that, so they have not been reimbursing people. The AFT, the union I am in and the professional development committee I was on, we allotted I want to say $\$ 1200$ per person per year and if they did not use it we would give the balance to somebody else who did, but we were guaranteed a minimum amount for professional development.

The researcher identified another sub-theme related to committee work.

Committee work is heavy for those newer faculty members going up for tenure. For other faculty members, upcoming accreditation visits contributes to more committee work.

(C344) said, "We have had a spike because we are going to have NEACS coming in the next couple of years (laugh). That has caused a spike in our engagement in committee work." One active committee formed for the upcoming accreditation visit is the general education committee which is working on outcomes, assessments, and rubrics for the general education courses. When the researcher asked the academic dean about general 
education she noted that general education discussions only recently occurred at the college. She said:

In fact, when you say gen ed, it was only until recently and for the first time ever in the history of either of the two colleges within the last five years in the time that I have been dean within the last five years we have now for the first time ever even had a conversation about what gen ed is. People did not even know what gen ed was. They said well these are basic courses you have to take. These are the core courses, they are the core curriculum, but they never really talked about gen ed. What is gen ed? So that is a new discussion that we have had even within the last five years.

When asked about the integration of general education content into the technical

curriculum she indicated that discussions were taking place between general education

and technical faculty members as the technical faculty members developed rubrics for

assessing general education competencies in their program curriculum. She stated:

As an example, in our technologies, we were recently going through a tech accreditation. It is causing them to have to pay really a lot of attention to how they do their assessments in their course and how they assess various different things, so they have had to develop a rubric for instance for grading writing communication, written communication, and oral communication. These guys are engineers, so they have had to go over to the English department and work with them, and some of them have joined the gen ed task force and figured out how you measure ethics in a curriculum by working with humanities faculty. So it has really caused them to work together differently and to also pay more attention to how they structure their curriculum and where these things appear in their curriculum, so it has been a really great sort of integration, a great integrative experience for faculty.

When the researcher asked participants how they are preparing students for a globalized workforce, critical thinking, effective writing, teaching the idea of citizenship, and teaching students the ability to adapt were mentioned. The work of the general education taskforce is to create assessment measures to determine that this type of learning is taking place in the curriculum. (C344) said:

So I really see the work that I do and the work that I help and support my colleagues in doing as essential because if students cannot express themselves 
both orally and in writing, then they are going to be lost in navigating the world that they are facing in this century, so it is really essential, and we work hard at it, and we are doing more and more also with oral communication as well in helping our students and I hope I am developing them to be lifelong learners and thinkers because...preparing them for a job is short sighted. Because whatever career they leave us with is going to be so different if it exists down the road, that if they are not critical thinkers and learners they are going to hit a wall. That is what we try to do.

Another faculty member (C343) stated:

I think that if we take the critical thinking part really seriously and we take the idea of responsible citizenship seriously, then hopefully students will come out being able to adapt to whatever the job market is. I have no idea what it is going to look like in 10 years, much less 30 years, whenever people are at the peak or about to retire from whatever it is that they are doing. But hopefully, through some of those core things that we are trying to teach through critical thinking and analysis they will be able to adapt.

Faculty work change issues clustered under student body changes, committee work and curriculum. The younger, more diverse student body is creating a need for change in the classroom environment. Committee work increases in preparation for an upcoming accreditation visit. Specifically, the general education committee is working to create assessment measures for general education competencies in all courses and programs. Integration of the general education and technical faculty members is one outcome of the recent discussions about general education at $\mathrm{C} 3$.

\section{Summary of Single-case Findings for C3}

The findings at $\mathrm{C} 3$ indicated that the English and communication faculty are working to bring coherence to courses in their disciplines. $\mathrm{C} 3$ is unique in the fact that they recently hired their first full-time communication faculty member. Previously, these courses were taught by English faculty members and adjuncts. C3 is also unique because the English II course is comprised of poetry, fiction and drama, which is unlike other colleges. Faculty members perceive that the mission emphasizes transfer and workforce 
development. The faculty is perceived as being dedicated to the community college mission, despite frustration with the changing student demographics. The current college mission may be questionable due to upcoming legislation to restructure education boards in the state. Also, budget cuts may reduce certain parts of the mission, such as continuing education, which may change the college mission. For now, the curriculum committee is comprised of division chairs and the academic dean. This is an improved process from an earlier committee structure that was not representative of divisions. Curriculum is faculty driven. Clusters of conflict issues surrounded merger issues, students, and management. Faculty work changes were related to student demographics and curriculum. The college is highly unionized; these union contracts impact faculty work and limit the administration's authority with faculty.

\section{Cross-Case Analysis}

After completing the single-case analysis for each college, the researcher reviewed the findings from each case to determine similarities and differences between the cases. The review of the individual case findings revealed seven similar themes under (a) curriculum (b) budget constraints and faculty work and (c) student issues. A table summarizing the similar themes across the cases can be found in Appendix E (Table 3).

The first three themes involved curriculum, so they hold the most significance to the study quintain. The study participants perceived that the curriculum process is supposed to be faculty driven, based on SACS guidelines; however, they indicated a perception that the process is more top-down since the merger. The reasons for these participants' perceptions may vary from case to case. As noted in the single-case study, the historical background of teachers coming from a high school teaching background 
may be a factor contributing to the lack of ownership of the curriculum. A faculty member at $\mathrm{Cl}$ said that after the merger there were attempts from the system office to make the local and system curriculum committees recommending bodies only. She described the process:

Somewhere in the first few years they really wanted to stop that and they started having everything just recommended, so you could be adamantly, as a faculty member, opposed to a curriculum but you did not have a vote. Ultimately it was all recommended. That worked for a few years until the accrediting agencies came in and began to ask faculty. They had no idea how the curriculum was done.

The third case, $\mathrm{C} 3$, interview data revealed that newer faculty members saw the process as more faculty driven, but faculty members who experienced the merger felt the curriculum process was more top-down to represent the influence of the technical college approach to curriculum. One faculty member who experienced the merger said:

My sense is that the dean says "Here look at this and we're going to go for this". They all just raise their hand and move on. It wasn't like that before. The two deans I worked with before the current one sort of liked debate. They were comfortable with it and I think they didn't have a problem saying "Ok, that makes sense." My sense is that this one doesn't want to do that. It's her way. That's my perspective.

The second common theme the researcher identified across the cases was that there are still barriers to the successful integration of academic and technical program curriculums. A state legislative mandate to reduce program hours led to the omission of general education hours in the technical and occupational program curriculums at $\mathrm{Cl}$. Program directors feel forced to reduce hours, but their discipline accrediting bodies require the inclusion of so many competencies that the faculty members are forced to reduce the general education hours. Program directors and faculty members see value in the general education courses for their students, but they are seeking ways to embed the general education courses into the technical curriculums through modularizing or 
contextualizing the general education courses. General education faculty members resist this trend, feeling that technical faculty members do not have the specialization in the general education to teach those elements.

At $\mathrm{C} 2$, the academic dean expressed a need for more general education in technical and occupational programs. He attributed the state culture toward education as a major barrier to successful integration. As mentioned before, the college mission evolved from a $13^{\text {th }}$ and $14^{\text {th }}$ grade at an area technical high school. Although the culture has changed some over the years, the technical culture remains the dominant culture. The researcher found that there are efforts to contextualize courses for the nursing department. One math faculty member indicated that they are developing a math class specifically for the nurses. Also, a nursing faculty member stated that she is working with the student success coordinator to create a study skills class, which emphasizes critical thinking, for the nursing students. She said:

What we are looking to develop to assist with that would be an opportunity with our college success class that we have on campus now. [name removed], again with the teaching department, has put together one just for teachers that would be specific to them, so we thought it would be very beneficial if we could have a college success just for nursing so that we can teach those very different approaches to test taking and studying and those skills that are so different because it is so much critical thinking.

Faculty members at all three colleges indicated that critical thinking is a skill their students needed to be successful in the global workplace. $\mathrm{C} 1$ and $\mathrm{C} 2$ are emphasizing critical thinking and problem-based learning as a result of their Quality Enhancement Project for SACS reaccreditation so faculty members appeared committed to developing critical thinking skills in their curriculum. The researcher felt the initiative was strongest 
at $\mathrm{C} 1 . \mathrm{C} 3$ also emphasized the need for students to possess critical thinking. One English faculty member, (C346) said:

Critical thinking, the majority have no idea what it is and I use an analogy of an egg. Their minds are like the egg and you have to open it with a slight tap on the shell. When you get a little crack you can feed them nourishment through that little crack. You have to be careful not to crack it wide open and spill the yoke all over the place. So to prepare them for a globalized society, with my pedagogy and my teaching style is to tap into something that you're passionate about or prepare yourself to be receptive to that passion when it comes and to keep a critical, open mind of the various societal issues we have locally, nationally, and globally, as well.

$\mathrm{C} 1$ and $\mathrm{C} 2$ shared two themes related to curriculum. First, there is a diminishing variety of course offerings in the English and communication disciplines since the merger. Also, general education courses are diminishing in the Associate of Science Degree programs at those colleges. (C225) said:

We are offering less and less in the humanities and I feel like we are becoming more technical and more just giving them right now what they need in the factories when we should be expanding. Right now everybody is fussing about budget. When we should be really expanding it seems like we are shrinking in selection and course offerings.

$\mathrm{C} 1$ and $\mathrm{C} 3$ interview data revealed more curriculum revision to align competencies, student learning outcomes, and assessment measures. External influences, such as a Title III grant and the SACS Quality Enhancement Projects, were catalysts for the changes. C2 was doing some curriculum work with their QEP, but it was not embedded in the institution like at $\mathrm{C} 1$ and $\mathrm{C} 3$.

The other dominant themes to cross each case were student-related themes.

Faculty members expressed frustration with the growing younger student population. The term "immature" was mentioned more than once during the interviews. Coinciding with this student immaturity was the classroom management issue, which resulted from having 
a more immature student body. Faculty members felt students' behaviors were more consistent with what one might imagine occurring in a high school class. Additionally, study participants felt frustration over the increasing numbers of students coming to college academically underprepared. Several faculty members indicated that the remediation involved in working with these students is increasing their already heavy workloads. At C.2 faculty members were providing tutoring outside of class. One English faculty member even held a Saturday session to focus on grammar skills because it was such a problem in her classes. Colleges $\mathrm{C} 2$ and $\mathrm{C} 3$ shared a common theme of a more diverse student body. These two colleges have experienced an influx of multi-cultural students. C2 has seen growth in the African-American population, while C3 is seeing larger numbers of American Indian students due to the growing casino industry in the area, which are run by American Indians.

Most $\mathrm{C} 1$ and $\mathrm{C} 2$ general education faculty members in the study felt that the mission emphasis has shifted from transfer before the merger, to more emphasis on workforce development today. C3 was different, in that for most of the faculty members interviewed, they felt their previous institution emphasized both transfer and workforce development.

The faculty/administration relations themes emerged at $\mathrm{C} 1$ and $\mathrm{C} 3$, but for different reasons. Faculty members at $\mathrm{C} 1$ indicated that their administration was distant from the work of faculty because the communication is largely top-down. Division chairs are the liaisons between administration and faculty. The chief academic officer at $\mathrm{C} 1$ indicated that she communicates to faculty through the division chairs. At C3 faculty 
members indicated that the distance is largely due to personalities and the fact that the college is highly unionized.

A final cross-case theme was that cultural differences between community and technical colleges created difficulties in the integration of the two cultures. This tension seemed more apparent at $\mathrm{C} 2$ and $\mathrm{C} 3$, which came from a technically dominant background. Academic faculty members felt physically isolated from technical faculty members. One academic faculty member at $\mathrm{C} 2$ described his perception of the Humanities division as the "Barney Miller" division because they were crammed into a small space. C3 faculty members who experienced the merger described some interaction between the two cultures, but the cultures were not physically merged for 12 years after the merger, so each culture could maintain a sense of their own culture. For C3, some of the integration experiences were delayed for this college. For $\mathrm{C}$ 1, there were initial feelings of fear, but the integration of the two cultures seemed less difficult. This campus did maintain three separate campuses after the merger. The technical college just located on the main campus this year, but in its own building. Perhaps the impact of the integration is lessened due to the late date of the physical merger of the technical college to the community college campus.

\section{Chapter Four Summary}

In summary, the study findings illuminated that the curriculum revisions have been to create more coherence from course to course through reducing textbook options, creating grading rubrics and identifying student learning outcomes and assessments. Critical thinking and problem-based learning are techniques faculty members are using to prepare students for a globalized workforce. The curriculum process, while stated by 
many participants as faculty-driven, is perceived by faculty members as top-down. So faculty members feel some frustration that the governance process may be failing because faculty will not take ownership, or feel they do not have ownership of the curriculum. Faculty members did express positive feelings about serving on the curriculum committee. They said it made them feel valued and it helped them to see a broader curriculum picture.

One area of curriculum that continues to present tension between academic and technical/occupational faculty members is the integration of the two curriculums. There are still barriers to the successful integration of the two curriculums. Since the merger, general education courses have been added to the AAS curriculums and are more recently being removed again. This diminishing of the general education in the AAS programs is a concern for academic faculty members. Another concern these faculty members have is the narrowing of the curriculum in the English and communication disciplines where literature sections and communication sections have been reduced over the years. Most faculty members felt the mission emphasis is less transfer focused and more workforce development focused although previous technical college faculty members felt the emphasis was more on transfer since the merger. Faculty/administration tension exists at all of the colleges, but it was more prominent in $\mathrm{C} 1$ and $\mathrm{C} 3$. In those colleges, faculty members felt the administration was distant from the work of faculty and has adopted a more technical college approach to management. Finally, the study findings illuminated cultural differences as a significant factor affecting the successful integration of academic and technical/occupational faculty members after the merger. Retirements and hiring new faculty members assisted with cultural change. 


\section{CHAPTER 5}

\section{DISCUSSION}

\section{Restatement of Study Purpose}

The purpose of this qualitative multiple case study was to identify curricular changes in course offerings and in course content in the disciplines of English and communication in the years following state-wide mergers between community college and technical school systems in three states, Connecticut, Kentucky, and Louisiana, and to understand how curricular changes are affecting organizational administration and faculty work life. The study had three major objectives: (a) to explore changes to the English and communication curriculum after the states' community colleges and technical schools were merged (b) to explore changes in faculty work life, particularly as it relates to curricular modifications, after the states' community colleges and technical schools were merged, and (c) to explore changes in organizational administration, especially related to curriculum development and modification, after the states' community colleges and technical schools were merged. The researcher focused on changes in these two longstanding liberal arts disciplines and provided a longitudinal view of curricular changes occurring in these disciplines since community and technical colleges merged in Connecticut, Kentucky, and Louisiana in the 1990s. In order to explore this phenomenon, this study addressed the following four research questions: 
1. Have or how have curricular offerings, course requirements and course content changed in English and communication since the merger between community colleges and technical colleges?

2. Has or how has the mission of preparing a workforce for a global economy been part of faculty curriculum discussions and changes?

3. Has the nature of work with students, colleagues, and/or administration changed since the merger? How so?

4. Have or how have the administrative processes related to curriculum changed and what tensions surround curriculum discussions since the merger between community and technical colleges?

The study theoretical framework was based on John Levin's (2006) work on the globalization of community colleges. He identified four categories of behavior present in a globalized community college: (a) oppositional culture, (b) values, (c) economic behaviors, and (d) labor behaviors. In his studies on community colleges, he placed his interview data into one of these four categories. Oppositional cultures suggested a critique of institutional practices, behaviors, and influences, or suggested factions within the institution that are opposed to institutional patterns and behaviors. For instance, in this study, oppositional cultures were evident through interview data about the integration of the academic and occupational faculty at the time of the merger. Some cultural opposition continues with the attempts to integrate the academic and technical/occupational curriculums. Other data indicated oppositional cultures in faculty and administrator relations. The second category, values, reflected value statements relevant to both education and economic values or to institutional behaviors. One 
dominant finding related to values was that faculty members who served on curriculum committees valued that experience. Also, at one college, value statements surrounded their college leadership. The third category, economic behaviors, included statements that characterized institutional or individual behaviors associated with economic motives or goals. For this study, economic behaviors were identified through decision-making based on budget constraints, grant-writing for more resources, limiting the variety of course offerings, and the growing emphasis on the workforce development aspect of the community college mission. Statements describing or judging institutional or individual behaviors that pertained to the work of faculty were placed under labor behaviors. Comments related to curriculum revision, course content, faculty workload, and the student body reflected labor behaviors. The researcher tracked oppositional factors, and values through faculty work-life and curricular changes and economic behaviors and labor behaviors through themes in administrative practices.

\section{Research Questions and Findings}

Research Question 1: Have or how have curricular offerings, course requirements and course content changed in English and communication since the merger between community colleges and technical colleges?

Finding. One common finding in the literature was that general education programs must be under constant review (Bourke, Bray, \& Horton, 2009; Zekeri, (2004). Based on the study findings, the researcher determined that this constant review is not happening at all the community colleges to the extent it should, but for different reasons. One college had a passive approach to curriculum revision due to the historical background of its faculty members coming from a secondary education teaching 
background. Another reason was that faculty members lacked the time required to discuss changes. Also, at two of the three colleges there were limited resources for curriculum revision. For one college, the lack of faculty initiative to revise the curriculum was a source of frustration for the chief academic officer. Although he was only in his second year at the college, he described the cultural influence of state governing boards and the historical background of the faculty as being barriers to active faculty participation in this form of governance. Another barrier to constant revision is the amount of time it takes for faculty to engage in academic dialogue. For one college, where the English and communication curriculum revisions occurred, the college utilized the funds of aTitle III Strengthening Institutions Grant which provided course releases for faculty members involved in the revision process. The time away from the classroom enabled them to meet weekly to discuss revisions. Colleges that do not have these financial resources might be less likely to grant course releases for revision work due to the ongoing budget constraints these colleges face. Another interesting finding, from one college chief academic officer, was that general education discussions were very new to the faculty members of the college. She indicated that general education discussions had only occurred for the first time at the college in the last five years. Although this college had a general education taskforce reviewing general education competencies and outcomes, it was to prepare for an upcoming accreditation visit. The researcher found that reaccreditation preparation involved curriculum revision at all schools.

Although English and communication course requirements in the Associate of Arts and Associate of Science degrees remain largely the same as before merger in terms of their content; there has been a growing focus on developing consistency to the required 
books, student learning outcomes and assessments. This effort could be due to college accrediting agencies requiring this sort of curriculum revision. The study finding that reaccreditation drives curriculum revision supports the work of Johnson, Ratcliff, and Gaff (2004), who found that accrediting agencies did influence changes to the curriculum. For the two southern colleges in the study, reaccreditation requires the development of a Quality Enhancement Project. For two of the three colleges, this QEP project influenced the attention to curriculum revision at the college.

Finding. Another study finding indicated that one college seems to be behind the two other colleges in recognizing communication as a discipline. Just in the past year C3 hired their first ever communication instructor. He indicated that he was hired to bring coherence to that curriculum. Interestingly, he also is required to teach English courses. Prior to his hiring, the communication/speech courses were taught by English faculty members, which appears to be more of the traditional secondary education approach to instruction where the instructor teaches more than one core subject.

The study finding was interesting because there appears to be an assumption that if a faculty member is qualified to teach English, they should be qualified to teach communication courses. The training for these two disciplines is not the same so there still seems to be some "old school thinking" about these two disciplines at this college. The concern would be whether or not faculty members in English and communication discuss assessment tools and student outcomes to ensure there is consistency from courses assessed by the English faculty members to courses assessed by the communication faculty member. The expansion of the course offerings in communication could be because they have a full-time instructor now. Also, new requirements for 
diversity and multi-cultural components in the curriculum brought more expansion in the curriculum offerings in English and communication.

Finding. Another study finding was that technical/occupational faculty members are advising their students toward transfer to a four-year college. They are developing career pathways to make this process easier. These career pathway curriculums include general education courses that are more transferrable. For instance, the nursing program at one college in the study changed the communication requirement to a Basic Public Speaking course rather than an Interpersonal Communication course. When this happened the enrollment in Interpersonal Communication courses took a plunge. So, it seems that the choices program faculty members make to include general education courses in the technical/occupational programs drive enrollment in the general education courses. If you remove the English II or communication requirement, the course enrollments drop and this impacts the teaching variety for instructors.

An extenuating effect of the shrinking variety in course offerings was expressed by faculty members as a fear of burn-out with such a limited variety of courses to teach. This burn-out could lead to instructional apathy, which could negatively impact the instructional programs at the college. For community college faculty members this burnout could lead to more discontent with teaching and the desire to leave their job. If they chose to stay, the faculty members, lacking the challenge of new preparations and content, may become less effective teachers in the classroom and negatively impact morale at the college. For community college leaders, the implications of this burn-out mean more hiring due to increased turn-over rates, or the development of a significant morale issue and increased tension between faculty and administration. 
In addition to the negative impact of the diminishing course variety on the instructional program, Warner and Koeppel (2009) noted advantages to more course choice for students as (a) increased interest in the course, (b) increased ability for the school to attract a diverse student body, and (c) greater expansion of the students' perspective and understanding of the world (p. 254). If course offerings are narrowing, students limit their exposure to broadened perspectives that those courses offer, which could put them at a disadvantage in comparison to graduates with a broader exposure to the liberal arts. This finding supports research by Brint, Riddle, Turk-Bicakci, and Levy (2005) who suggested that the emphasis on workforce readiness and removal of the liberal arts curriculum create unequal footing for community college graduates.

Finding. Study findings indicated that transfer is being emphasized more at the colleges. Although the general education components of the Associate of Arts and Associate of Science, traditionally transfer degrees, have remained about the same, the diminishing appears to be in the Associate of Applied Science degrees, which are the technical/occupational degrees at community colleges. With a growing emphasis on these degrees, which promote workforce development, the concern becomes whether colleges are equipping these students with enough general education to consider them generally "educated". One chief academic officer in this study indicated that their college did not require enough general education in his perspective. If this is so, what consequences does this minimal general education have for students who transfer or for students who enter the workforce after obtaining the AAS degree? For students who transfer, they may be at a disadvantage, academically, over four-year college students in the amount of general education they need to be successful. These students must take more general education to 
meet the four-year college general education program requirements, which could be a diversion for degree completion. Also, these students may be academically underprepared and contribute to an increased attrition rate in four-year colleges.

Finding. Based on the interview data regarding course content, it appears that community college students have difficulty understanding concepts and ideas that require a deeper level of thinking. The interview data indicated that there is not much literature in the Composition I course. Also, the researcher noted a decrease in literature offerings. Faculty members expressed frustration in their students' ability to "get it". They indicated that basic grammar skills are a major problem, so they spend a great deal of time on remedial grammar issues. Although English faculty members at all the colleges indicated that they teach argument development, very few English faculty members taught the classical Toulmin Model of Argument Development. Faculty members indicated that the concept might be too difficult for students to understand. They teach argument development, but in a more general manner. However, communication faculty members indicated teaching the Toulmin Model of Argument Development when they teach persuasive speaking, although they too indicated that students find it difficult to understand. As one faculty member noted in her interview, she feels she has to lower her expectations of students now because of their increasingly lower skill level. Perhaps the open access admission policy at community colleges and the financial incentives for more people to come to college through government incentives is contributing to the growing number of academically and socially underprepared students enrolling at community colleges. One such initiative which created larger enrollments at community colleges is the Workforce Investment Act, which is a federally funded program to provide 
workforce development training/education to laid-off workers, veterans, incumbent workers, youth, and the disabled. These types of initiatives, and the growing number of high school students who are graduating, but still placing in developmental courses upon entering college may be increasing the amount of remediation required in community colleges.

Finding. As the researcher reflected on Levin's (2006) analytical framework of behaviors associated with globalized community colleges, two prominent themes reflected oppositional factors related to English and communication. Faculty members expressed concern about the diminishing general education in the AAS programs. Also, academic faculty members resist the idea of contextualizing or modularizing their curriculums for inclusion in the AAS program curriculums because they feel technical/occupational faculty members are not as well qualified to teach the contents of their curriculum as someone who has a Master's degree in the discipline. Technical/occupational faculty members expressed frustration with the "disconnect" between the students' ability to integrate the academic and AAS program curriculums. They would like to see greater career application to academic curriculum content. A shared value expressed at all three colleges, by faculty members who had served on curriculum committees, was that although it involved a great deal of work, they valued being able to have input on curriculum decisions and they saw that work as important.

Research Question 2: Has or how has the mission of preparing a workforce for a global economy been part of faculty curriculum discussions and changes? 
Finding. The majority of general education faculty members at the colleges felt that the colleges' mission became more workforce oriented after the merger. This finding supports Levin's $(2000,2006)$ study findings which indicated that faculty members feel the emphasis is toward training and away from education, which Levin refers to as the corporatization of higher education.

However, the faculty members who worked at the technical college prior to the merger felt the opposite. They indicated that they advise students more toward transfer now than before the merger. This finding supports the work of Townsend and Wilson (2006) who established that community colleges are working more closely with four-year colleges to improve transferability through course and state level articulation agreements, and building career pathways for both transfer and occupational/technical programs.

Finding. When the researcher asked faculty members about how they are preparing students for a globalized workforce, the dominant answer was through effective writing and the development of critical thinking skills. Faculty members indicated that they were creating case studies, applying information to current events, developing effective writing skills, creating problem-based learning exercises, and promoting hands-on experience to develop critical thinking skills. This finding supports the work of Brewer, (1996) Zekeri (2004), and Milliron (2007), who named critical thinking, communication skills, and effective group leadership as important skills for graduates to possess to be effective in the workplace. However, if communication and a course emphasizing writing skills are eliminated from the AAS curriculum, as evidenced from this study, the AAS graduates may be at a disadvantage when they transfer to four-year colleges, or migrate into the workforce. As the chief academic officer at one college mentioned, a SCANS study done 
by the Department of Labor about ten years ago, indicated that skills found in liberal arts classes, such as written communication and critical thinking, were the skills employers wanted their employees to possess. If the development of those skills is minimized through the removal of liberal arts courses from the curriculums, these graduates will not have the skills employers say they most need in an employee. The lack of these skills could impact the longevity of their employment.

Also, a study by Portman and Stick (2003) indicated that Humanities faculty had greater use of student intellectual development which included critical thinking and synthesis. If this is true then eliminating those courses from the AAS curriculum creates a disadvantage to students graduating with an AAS degree from the community college. Zeszotarski (1999) stated, "Knowledge of civic issues is a fundamental aspect of informed participation in a democracy. If occupational students are not at least introduced to the fundamental knowledge a general education provides, they may be excluded from full participation in significant social and political activities" (p. 47). The implications of the general education curriculum reach beyond the college walls. For this reason, general education curriculums must be reviewed often and reforms implemented to insure students get the broad knowledge base they need for full engagement in society.

Research Question 3: Has the nature of work with students, colleagues, and/or administration changed since the merger? How so?

Finding. As cited in the literature review, Harmon (2002) noted that mergers create organizational climates of confusion, fear, and frustration. Faculty members on both sides of the merger fear losing their jobs, loss of academic freedom, loss of power, the decline in academic rigor, and increased workloads, especially in a merger like those 
between a technical and community college where academic standards and workloads vary due to the different college missions. For the general education faculty interviewed they do feel there is a decline in the academic rigor in the AAS curriculum and this would be a result of the merger. It also reflects the fact that academic and technical curriculum integration is still a problem. Most faculty members did indicate heavier workloads but they attributed that more to growing enrollment, the increase in technology use, the growing administrative aspect to their job, and the increased time required in the remediation of their students. English faculty members at all three colleges said grammar skills are a constant struggle with their students. Perhaps community college faculty members are experiencing the results of a technology dependent generation, where communicating in full sentences with appropriate capitalization and punctuation is not necessary for understanding to occur in the texting and Twitter worlds.

Most respondents indicated that many of these fears were not realized. Initially, there was a distrust and tension between both sides of the merger. Although that tension has subsided to a large degree, some concerns remain, such as those associated with faculty workload and academic standards. Many study participants felt all other demands of the job were taking attention away from teaching. These findings support Hardy and Laanans' (2006) work which suggested that increased workloads created the greatest frustration for faculty members. Further, these findings support Levin's (2006) work suggesting that there is a contradiction between faculty work which is framed within an economic context and faculty values which are based on the cognitive development of students and the advancement of society. 
Finding. One consistent and dominant theme throughout the colleges was the impact of the changing student demographic which is bringing younger students to the community college. The younger, more "immature" student is creating frustration and a stronger need for classroom management. More than one faculty member referred to their teaching as "the $13^{\text {th }}$ grade", indicating the incoming students had no idea about how to behave in a college classroom. The researcher heard stories of students arriving as much as 45 minutes late to class and leaving class early without any explanation.

Other issues the participants mentioned were the students' inappropriate social language, intolerance toward other's ideas, and general apathy toward learning. At a time when attention to diversity is emphasized in education, it seems there is a need for more emphasis on diversity and classroom management training for faculty members and attention to diversity in the community college curriculum. One college in the study indicated a resistance to the expansion of multi-cultural activities and discussions in the classroom. A study participant from that college said although diversity was part of the college mission, it needed more attention. This perceived reluctance to support cultural activities seemed to put some tension between administration and faculty members interested in broadening cultural activities.

Finding. All three colleges in the study indicated tension between administration and faculty to varying degrees; however, the gap seemed to be greater in $\mathrm{Cl}$ and $\mathrm{C} 3$. The researcher concluded that budget constraints are contributing to some tension, which would fall under Levin's (2006) economic behavior of globalized community college analysis. Most study participants had not seen raises in the past several years. At C2 these budget constraints seemed more apparent. At that college, student resources, such as 
tutoring, and monies for faculty professional development opportunities were significantly reduced, which had a deeper impact of the work of faculty at that college. At all three colleges, grant writing for external sources of income to support faculty work was an active pursuit; however, grants created more work for faculty members in administrative duties and committee responsibilities.

Another influencing factor of the administration/faculty divide was that the flow of communication appeared to be top-down at all three institutions; however, it was most evident at $\mathrm{C} 1$ and $\mathrm{C} 3$, where there was a mid-management level of division chairs, which relayed information from faculty to administration and from administration to faculty. At $\mathrm{C} 3$, the division chairs comprised the curriculum committee, which gave them more decision-making power in the curriculum process. Also, $\mathrm{C} 3$ is highly unionized which creates a natural distance between faculty and administration. One previous union leader said he was working more closely with the other union leader to try to bring the groups closer together and eliminate some of the tension between faculty members in both unions. Strong leadership in the administration and the two unions is necessary for this vision to become a reality. These leaders are looking for ways to bring the groups together to create a better working environment. At $\mathrm{C} 3$, the administration really has no authority over the work of faculty, but a leader who is open to communication, and leads in a way to work together as a team, may have more influence than one who feels threatened which creates a greater divide with the unions. These behaviors, mentioned above, fall under Levin's (2006) analysis category for economic behaviors, labor behaviors, and oppositional cultures. 
Research Question 4: Have or how have the administrative processes related to curriculum changed and what tensions surround curriculum discussions since the merger between community and technical colleges?

Finding. Interviews with faculty members and academic deans revealed that they understand that college accrediting agencies require that faculty control the curriculum. After the merger, one study participant said that their system office tried to make curriculum bodies "recommending bodies" only, which would allow for a quicker turnaround in curriculum decisions. This attempt would support Levin's analysis that the attempt to reduce faculty resistance to curriculum changes and produce and offer a curriculum quicker demonstrates a motivation toward economic behaviors. Although the process is said to be faculty driven, many faculty members perceived it as top-down. One college academic dean, at $\mathrm{C} 2$, suggested the process is passive due to the historical background of faculty members coming from a secondary teaching experience. The two other colleges had faculty members suggest that there is faculty apathy toward the process and the tendency to rubber stamp what the dean wanted. The reasons could be because the amount of work is overwhelming and faculty members, who feel overburdened with the teaching loads and extra activities their position requires, may be less vested in the curriculum process due to the amount of attention and time it demands. These findings suggest that administrators may approach curriculum decisions from a more economic point of view, leading to tensions and conflict between faculty members and administration.

Finding. The researcher identified two dominant themes reflecting an oppositional culture between academic and technical/occupational faculty. The most prevalent form of 
academic and technical/occupational curriculum integration after merger was to add general education courses to the program curricula. This finding supports Brewer's (1996) study findings which indicated that including required general education courses in the occupational curriculum was the most common method of integration. Just as Cohen and Brawer (2003) predicted about future community college issues and trends, the integration of general education has been difficult. Even though program directors and faculty members see the value in the general education courses, they are under the watchful eye of their discipline accrediting bodies who require that they meet the program content competencies. When making a choice about where to cut, they will cut the general education courses because they cannot cut their program content. The study results indicated that this is happening in the Associate of Applied Sciences programs where English II and communication are removed as requirements. This finding supports Levin's (2006) work on faculty values in the community college. He suggested that the emphasis on workforce development brings about tension between vocational and academic faculty about the quality of the education when more liberal arts classes are removed from program curriculum.

Finding. Another issue regarding academic and technical curriculum integration is the lack of relevancy of the general education courses for the program students. As noted in one of the interviews, students want practical knowledge that will help them in their careers. If this is so, then program faculty members are seeking methods of integrating the general education content into their program curriculums through modularization or contextualizing the general education and technical curriculums. The contextualization represents a step backwards to reflect these programs' original structure under the 
technical college system. At that time, the program faculty member taught all aspects of the curriculum, including the general education portion. Of course, general education faculty members resist this movement because they feel the program faculty members are not as knowledgeable about the general education course as someone with a Master's degree in the discipline. This remains a source of tension between the two disciplines. The need to streamline and limit program hours in the AAS program could be due to economic motivations to get the graduate into the workforce sooner. Ultimately, this is an economic benefit to the local community in the short-term, but the long-term economic benefits may be questionable if the graduate is not a contributing member in a democratic society or they become unemployed after their skills become obsolete.

Finding. While most academic faculty members feel a push toward more workforce development since the merger, technical/occupational program faculty members feel a push toward transfer. Many of these program faculty members are changing their curriculums to include transferable courses to area four-year colleges. This finding supports what Cohen and Brawer (2003) found that the flagship universities accepted fewer occupational courses than the four-year colleges that offered more career-related programs. Students seeking admission from community colleges may be limited by the contents of their community college program curriculum.

\section{Implications for Future Research}

This study demonstrates that changes are occurring in the liberal arts curriculum in community colleges that have merged with technical colleges. The study findings indicated that course variety in English and communication is shrinking and technical/occupational program faculty members are removing general education courses 
from their program curriculums. A study analyzing transcripts of freshmen at four-year colleges compared to community college freshmen could provide insight into the differences in their academic preparation. Related to the finding that the curriculum is shrinking was another finding that general education faculty members are concerned about the shrinking teaching variety. Fear of burn-out was one concern for the faculty members who were experiencing this shrinking liberal arts trend. If this shrinking teaching variety persists, a study seeking the implications of this trend on faculty motivation and persistence could inform community college leaders about the impact the shrinking teaching variety is having on faculty members in community colleges.

Also, the study findings indicated that more program faculty members are advising their students toward transfer; consequently, they are including general education courses that more easily transfer to regional four-year colleges. The literature review revealed that education scholars debate whether these students are at a disadvantage regarding degree completion over students who start at the four-year colleges. As general education courses are limited in the community college curriculums, these students may start their Bachelor's degrees behind students who started their education at the four-year college in terms of their general education exposure. A future study investigating the attrition rates of community college technical/occupational program transfers would be a logical extension to this research study. A qualitative study investigating the role that their academic preparedness played in their decision to quit could inform state education policymakers who drive the decision to limit program hours, which often results in the removal of general education courses. 
Other study findings indicated that academic and technical/occupational program curriculum integration is still creating tension between academic and technical/occupational faculty members. The program faculty members feel the students need more practical application of the general education content and academic faculty feel that the current trend to modularize or contextualize curriculums minimizes the scope of the students' exposure to the liberal arts. Future studies might further this finding by studying how community colleges are dealing with the curriculum integration issue.

Since there are community colleges in the country that merged before the colleges in this study merged, these colleges might provide greater insight about effective curriculum integration strategies.

Many of the overriding issues of conflict around the merger involved initial fears that faculty members on both sides of the merger experienced. Future research could seek information on the role the college leadership played in the successful integration of the two faculties. Through identifying merger strategies that leaders from institutions considered "successful" in the merger process utilized, the information could assist current community and technical college leaders who experience a merger.

\section{Implications for Practice}

Since the trend to merge community and technical colleges continues throughout the United States, community college leadership could benefit from knowing the positive and negatives associated with mergers. This study revealed that the cultural differences between faculty members on both sides of the merger can slow down successful integration. Based on the interview data from this study, faculty members experience suspicion and fear about what the future holds for them in an organization undergoing a 
radical change such as merger. Many of the fears are there because faculty members and staff feel their future is uncertain. Before, and during, the merger is the time that faculty members are seeking out information to ease their fears. Community college leaders must keep communication flowing during this time through combined meetings with faculties from both sides of the merger. Perhaps meeting in small groups with a combination of faculty and staff from both sides of the merger to provide information directly to them could reduce some fears and help to facilitate the integration of the two faculties.

Faculty members in this study revealed a desire for administration to understand what they are going through as the "front line" of the organization. They feel the administration is largely removed from their work. More effort to eliminate organizational hierarchy and open lines of communication to flow in both directions (up and down) could illuminate some fears that community college personnel experience during a significant change.

Also, leaders must emphasize the positives of the merger rather than the negatives. This study finding revealed that enrollment at all three colleges grew significantly since the mergers occurred. Strong enrollment means job security to community college personnel. Also, since the mergers, there is a stronger relationship with the regional colleges. The chief academic officer at one college said that before the merger, a community college president would never pick up the phone and call a president of a regional university, but that is not the case now. The development of career pathways indicates that the regional universities, seeking higher enrollment numbers, see the benefit of establishing a closer relationship with community colleges. State policymakers, community and technical college leaders, and university leaders must work together to 
ensure that the community college graduate has an adequate academic foundation before transferring to a regional or state university to provide every opportunity for success at the university. General education decisions at the regional and state colleges, significantly impact the curriculum at the community colleges; therefore, more communication between the institutions could improve the curriculum situation for students who wish to transfer.

Negatives of merger revealed in this study were that faculty members are frustrated with their workloads increasing through committee work, technology, and the additional attention to student remediation. Many faculty members expressed a concern that too much attention to "other" aspects of their job is taking their attention away from teaching activities. Community college leaders must "hear", "acknowledge" and "respond" to these concerns so that faculty members feel valued for the most important aspect of their job, which is teaching. If community college leaders do not listen to what the faculty members are saying, the divide between administration and faculty could continue to grow.

Another dominant theme throughout this study was the impact that the budget constraints have on faculty work. Some colleges are experiencing more of an impact than other colleges. These budget constraints certainly lead to more discontent from community college faculty. After several years with no raise faculty morale is affected and this poor morale tends to create more tension between faculty and administration. Although administrators have little control over the budget scenario, leaders must insure that there is an equitable distribution of resources between the academic and technical faculty. When one program (general education vs. technical education) is emphasized 
over the other, tensions between the groups are heightened. Also, at times when the budget constraints are high and morale is low, it is especially important for college administrators to communicate with faculty members and acknowledge their work on a personal level.

Another significant study finding was that the demographics of the student body at community colleges have changed. Students are more culturally diverse, younger, more immature, and less academically and socially prepared for college. These characteristics seem to present challenges for faculty members. Community college leaders need to ensure that they remain cognizant of the implications of these changing demographics and the impact the changes have on instruction. Although most colleges include diversity as a general education component, more direct training is needed for the instructor to know how to effectively manage today's community college classroom. Providing professional development to faculty members in the area of diversity, and the new generation of college students, is an important consideration for community college leaders. 


\section{REFERENCES}

American Association of Community Colleges. The Knowledge Net. Washington, D.C: Community College Press, 2000.

Ballinger, P. (2007). Why and how socioeconomic factors should be used in selective college admissions. New Directions for Student Services, 118, 3-17.

Barr, R.A., \& Rossett, A. (1994). Community college curriculum change: Its relationship to faculty discipline affiliation and years of teaching. Community College Review, 22, 45-67.

Bogdan, R. C., \& Biklen, S. K. (2003). Qualitative research for education: An introduction to theories and methods $\left(4^{\text {th }}\right.$ ed.). Boston: Pearson.

Bourke, B., Bray, N. J., \& Horton, C.C. (2009). Approaches to the core curriculum: An exploratory analysis of top liberal arts and doctoral-granting institutions. The Journal of General Education, 58(4), 219-240.

Bragg, D. D. (2001). Opportunities and challenges for the new vocationalism. In D. Bragg (Ed.), The New Vocationalism in Community Colleges. New Directions for Community Colleges, San Francisco: The Jossey-Bass Higher and Adult Education Series.

Bragg, D. D., \& Reger, W. M. (2000). Toward a more unified education: Academic and vocational integration in Illinois community colleges. Journal of Vocational Education Research, 25, 237-272. 
Brawer, F. B. (1999). The liberal arts. In G. Schuyler (Ed.), Trends in Community College Curriculum. New Directions for Community Colleges, San Francisco: The Jossey-Bass Higher and Adult Education Series.

Brewer, J. A. (1996). Integrating academic and vocational education: An investigation of the attitudes and values of administrators and faculty in the Wisconsin Technical College System. Journal of Vocational Education Research, 21, 5-33.

Brint, S., Proctor, K., Murphy, S. P., Turk-Bicakci, L., \& Hanneman, R. A. (2009). General education models: Continuity and change in the U.S. undergraduate curriculum, 1975-2000. Journal of Higher Education, 80(6), 605-642.

Brint, S., Riddle, M., Turk-B. L., \& Levy, C. S. (2005). From the liberal to the practical arts in American colleges and universities: Organizational analysis and curricular change. The Journal of Higher Education, 76, 151-180.

Brown, G. W. (2008). Globalization is what we make of it: Contemporary globalization theory and the future construction of global interconnection. Political Studies Review, 6, 42-53.

Burke, J.(ed.). (1995). Outcomes, learning, and the curriculum: Implications for NVQs, GNVQs, and other qualifications. The Falmer Press: Bristol, PA.

Campbell, D., \& Williams, K. (2005). Futures focus: Proposed solutions for the cyclic workforce. Community College Journal of Research and Practice, 29, 663-669.

Clark, B. R. (1980). The 'cooling out' function revisited. New Directions for Community Colleges, 32, 15-31.

Cohen, A. M., \& Brawer, F. B. (1996). The American community college. (3rd ed.). 
San Francisco: Jossey-Bass.

Cohen, A. M., \& Brawer, F. B. (2003). The American community college. (4 $\left.{ }^{\text {th }} \mathrm{ed}.\right)$. San Francisco: Jossey-Bass.

Cohen, A. M., \& Ignash, J. M. (1992). Trends in liberal arts curriculum. Community College Review, 20, 50-60.

Connecticut State Library. Retrieved August 18, 2010 from http://www.cslib.org/agencies/communitytechnicalcolleges.htm.

Cox, M. A. (1999). Community-Technical Colleges of Connecticut. Community College Journal of Research and Practice, 23(3), 325-335.

Diekhoff, J. (1950). Democracy's college: Higher education in the local community. New York: Harper and Brothers.

Dougherty, K. J. (1994). The contradictory college: The conflicting origins, impacts, and futures of the community college. Albany, New York: State University of New York Press.

Dougherty, K. J. (2002). The evolving role of the community college. In J. Smart and W. Tierney (eds.), Higher Education Handbook of Theory and Research. Norwell Massachusetts: Kluwer.

Dubrow, G. (2004). Collegiality and culture: General education curriculum reform at Western Protestant University. The Journal of General Education, 53, 107-134.

Eddy, P. L. (2003). Change in community colleges through strategic alliances: A case study. Community College Review, 30(4), 1-20.

Eisner, E. W. (1998). The enlightened eye: Qualitative inquiry and the enhancement of 
educational practice. New Jersey: Prentice Hall.

Flannery, C. (1998). Liberal arts and liberal education. On Principle, 6(3), John Ashbrook Center for Public Affairs retrieved from http://www.ashland.edu/ashbrook/publicat/onprin/v6n3/flannery.htm.

Gale Encyclopedia of Education. Retrieved November 25, 2010 from http://www.answers.com/topic/community-college.

Giroux, H. A. (1999). Vocationalizing higher education: Schooling and the politics of corporate culture. College Literature, 26(3), 147-160.

Glesne, C. (2006). Becoming a qualitative researcher: An introduction $\left(3^{\mathrm{rd}} \mathrm{ed}.\right)$. Boston: Pearson.

Goyette, K. A., \& Mullens, A. L. (2006). Who studies the arts and sciences? Social background and the choice and consequences of undergraduate field of study. Journal of Higher Education, 77(3), 497-538.

Grubb, N. (2005, June 6). Is the tech vs. liberal arts debate out of date? Two views. Community College Week. Retrieved October 20, 2010 from http://www.ccweek.com.

Guba, E. G., \& Lincoln, Y.S. (1994). Competing paradigms of qualitative inquiry. In Denzin, N., \& Lincoln, Y. (Eds.) ( $1^{\text {st }}$ ed.). Handbook of Qualitative Research. Thousand Oaks: Sage, 105-117.

Harman, K. (2002). Merging divergent campus cultures into coherent educational communities: Challenges for higher education leaders. Higher Education, 44, $91-114$.

Hardy, D. E., \& Laanan, F. S. (2006). Characteristics and perspectives of faculty at 
public 2-year colleges. Community College Journal of Research and Practice, 30, 787-811.

Jacobs, J, \& Dougherty, K. (2006). The uncertain future of the community college workforce development mission. New Directions for Community Colleges, 136, $53-62$.

Johnson, D. K., Ratcliff, J. L., \& Gaff, J. G. (2004). A decade of change in general Education. New Directions for Higher Education, 125, 9-27.

Karabel, J. (1986). Community colleges and social stratification in the 1980s. In L. S. Zwerling (ed.). The community college and its critics. New Directions for Community Colleges, 54, San Francisco: Jossey-Bass Higher Education Series.

KCTCS Mission. (2010). Retrieved August 4, 2010 from http://www.kctcs.edu.

Kentucky Community and Technical College System. Retrieved August 4, 2010 from http://www.kctcs.edu.

Kentucky House Bill 160. (2010). Retrieved August 4, 2010 from http://www.lrc.ky.gov/record/10rs/HB160/bill.doc.

Kentucky Postsecondary Education Improvement Act of 1997: House Bill 1. (1997) Frankfort, KY. Retrieved August 4, 2010 from http://www.state.ky.us/agencies/gov/psbill2.htm.

Killacky, J. \& Wells, A. E. (2004). The emerging Louisiana community and technical college system: Back to basics and down to business. Community College Journal of Research and Practice, 28, 485-488.

King, S. S. (Ed.). (1989). Human communication as a field of study: Selected contemporary views. Albany: State University of New York Press. 
Levin, J. S. (2000). The revised institution: The community college mission at the end of the twentieth century. Community College Review, 28, 1-24.

Levin, J. S. (2001). Globalizing the community college: Strategies for change in the Twenty-first century. New York: Palgrave.

Levin, J. S. (2001). Public policy, community colleges, and the path to globalization. Higher Education, 42, 237-262.

Levin, J. S. (2002). Global culture and the community college. Community College Journal of Research and Practice, 26, 121-145.

Levin, J. S. (2005). The business culture of the community college: Students as consumers; students as commodities. New Directions For Higher Education, 129, 11-26.

Levin, J. S. (2006). Faculty work: Tensions between educational and economic values. The Journal of Higher Education, 77, 62-88.

Lincoln, Y. S. \& Guba, E. G. (1985). Naturalistic Inquiry. Newbury Park, CA: Sage Publications.

Lohman, E.M. \& Dingerson, M.R. (2005). The effectiveness of occupational-technical certificate programs: Assessing student career goals. Community College Journal of Research and Practice, 29: 339-355.

Louisiana Community and Technical College System. Retrieved August 15, 2010 from http://www.lctcs.edu.

Louisiana Transfer Degree. Retrieved December 10, 2010 from http://www.nunez.edu/LATransferDegree/latransferfaqs.htm\#What is the Transfer Associate Degree. 
Lucas, S. E. (2009). The art of public speaking (10 ${ }^{\text {th }}$ ed.). Boston: McGraw Hill.

Madisonville Community College Mission. (2010). Retrieved August 4, 2010, from http://madisonville.kctcs.edu/About/Our_Mission.aspx.

Madisonville Community College Self-Study Report (2000-01).

Manning, C. (2004). The Louisiana community and technical college system: A brief history. Community College Journal of Research and Practice, 28, 489-502.

Marshall, C., \& Rossman, G. B. (1995). Designing qualitative research $\left(2^{\text {nd }}\right.$ ed.). Thousand Oaks: Sage.

Mazzeo, C., Rab, S. Y., Alssid, J. L. (2003). Building bridges to college and careers: contextualized basic skills programs at community colleges. Workforce Strategy Center, Brooklyn: NY.

Miller, M.T., \& Vacik, S. M. (1998). Community college faculty involvement in institutional governance. Community College Journal of Research and Practice, 22, 645-655.

Milliron, M. D. (2007). Trancendence and globalization: our education and workforce development challenge. New Directions for Community Colleges, 138, $31-38$.

Milliron, M. D., \& De los Santos, G. E. (2004). Making the most of community colleges on the road ahead. Community College Journal of Research and Practice, 28, 105-122.

Newton, R. R. (2000). Tensions and models in general education planning. Journal of General Education, 49(3), 165-181.

Nunez Community College Catalog. (2010). Retrieved August 18, 2010 from 
http://www.nunez.edu/2009-2010\%20Catalog.pdf.

Nunez Community College Self-Study (2008).

O'Banion, T. (2010). To what end? Inside Higher Ed. Retrieved December 1, 2010 from http://www.insidehighered.com/news/focus/community_colleges/views/obanion .

Path, B. R., \& Hammons, J. O. (1999). General education in community colleges: A time for reexamination. Community College Journal of Research and Practice, $23,467-480$.

Perin, D. (2001). Academic-occupational integration as a reform strategy for the community college: Classroom perspectives. Teachers College Record, 103, $303-335$.

Pope, M. L., \& Miller, M. T. (2000). Community college faculty governance leaders: Results of a national survey. Community College Journal of Research and Practice, 24, 627-638.

Portman, C. A., \& Stick, S. L. (2003). The association between departmental affiliation and curricular decision making. Community College Journal of Research and Practice, 27, 519-530.

Puyear, D. E. (2001). Community college and technical institute mission convergence study: Phase 2: Study of selected states. Center for Community College Policy Education Commission of the States. 1-58.

Robertson, R. (1991). The Globalization Paradigm: Thinking Globally. Greenwich: JAI Press.

Rowley, G. (1997). Mergers in higher education: A strategic analysis. Higher Education Quarterly, 51, 251-263. 
Sack, P. (2009). Tearing down the gates: confronting the class divide in American education. Liberal Education, 14-20.

Schuyler, G. (1999). A historical and contemporary view of the community college curriculum. New Directions in Community Colleges, 108, 3-15.

Schweiger, D. M., \& Denisi, A. S. (1991). Communication with employees following a merger: A longitudinal field experiment. Academy of Management Journal, 34, 110-135.

Smart, J. C. (2003). Organizational effectiveness of 2-year colleges: The centrality of cultural and leadership complexity. Research in Higher Education, 44, $673-702$.

Spradley, J. P. (1979). The ethnographic interview. New York: Holt, Rhinehart \& Winston.

Stake, R. E. (1995). The art of case study research. Thousand Oaks: Sage.

Stake, R. E. (2006). Multiple case study analysis. New York: The Guilford Press.

Stewart, G. (2003). College mergers: lessons to be learned from other sectors. Research in Post-Compulsory Education, 8(3), 305-327.

Thaxter, L. P., \& Graham, S. W. (1999). Community college faculty involvement in decision-making. Community College Journal of Research and Practice, 23, 655674.

Three Rivers Community College. (2010). Retrieved August 17, 2010 from http://www.trcc.commnet.edu/index.shtml.

Townsend, B. K., \& Wilson, K. B. (2006). The transfer mission: Tried and true, but troubled? New Directions for Community Colleges, 136, 33-41. 
Van Wagoner, R. J. (2004). Influencing the perception of organizational change in community colleges. Community College Journal of Research and Practice, $28,715-727$.

Warner, D. B., \& Koeppel, K. (2009). General education requirements: A comparative analysis. The Journal of General Education, 58(4), 241-258.

Warren, J. (2003). Changing community and technical college curricula to a learning outcomes approach. Community College Journal of Research and Practice, 27, $721-730$.

Washington State Board for Community and Technical Colleges (2010). Retrieved December 1, 2010 from http://www.sbctc.ctc.edu/college/e-kforcecentersofexcellence.aspxs.

Zekeri, A. A. (2004). College curriculum competencies and skills former students found essential to their careers. College Student Journal, 38, 412-422.

Zeszotarski, P. (1999). Dimensions of general education requirements. In G. Schuyler (Ed.),Trends in community college curriculum. New Directions for Community Colleges, San Francisco: The Jossey-Bass Higher and Adult Education Series. 


\section{Appendix A}

\section{Stake Multiple Case Study Model}

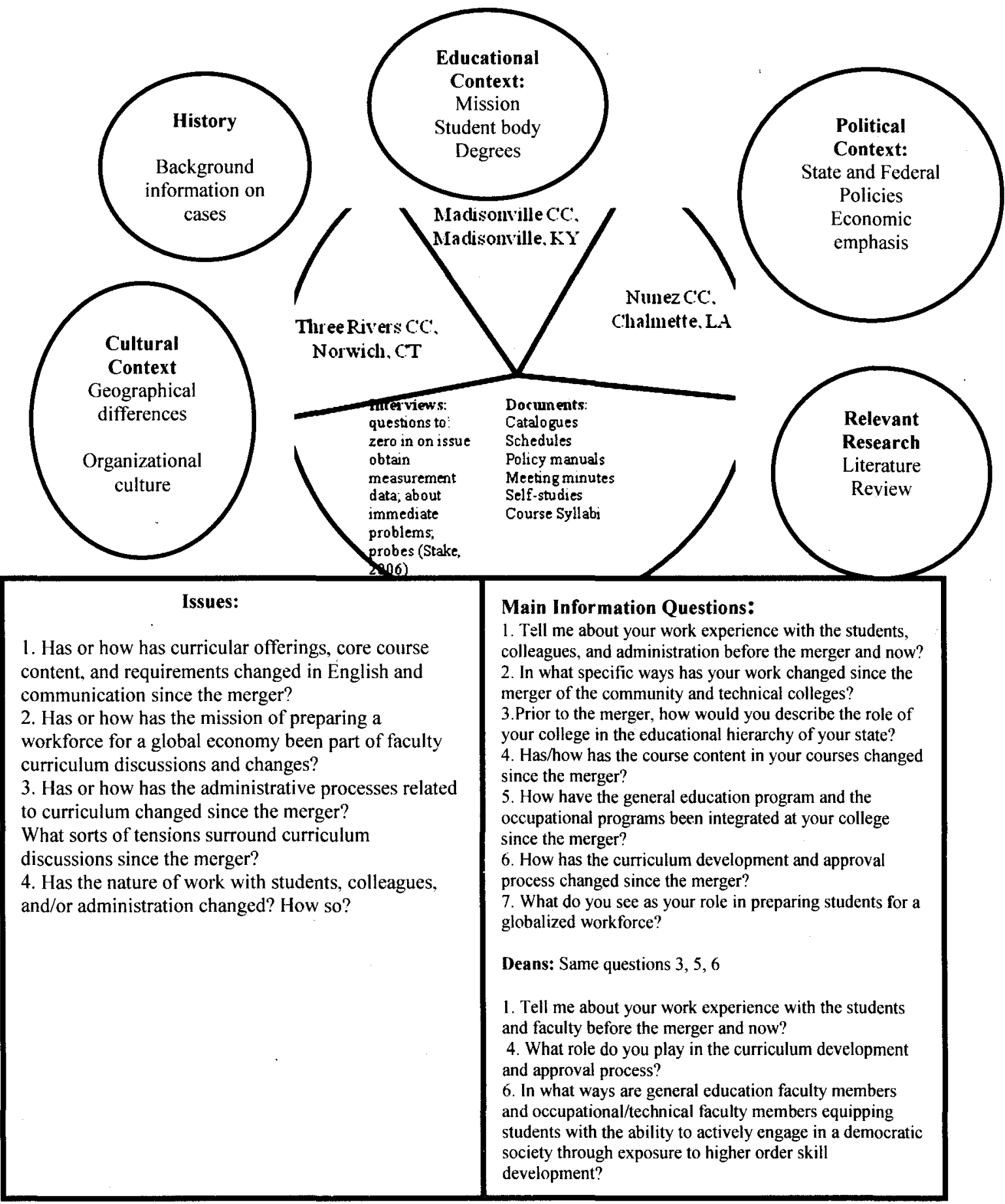

Contexts under study from Multipie Case Study Analysis by Robert Stake. 2006, New York: The Guilford Press

Adapted with permission 


\section{Appendix B}

\section{Research Questions and Documents for Review}

\begin{tabular}{|l|l|l|}
\hline RQ 1 & $\begin{array}{l}\text { Has or how has curricular offerings, course } \\
\text { content, and requirements changed in English } \\
\text { and communication since the merger between } \\
\text { community colleges and technical colleges? }\end{array}$ & $\begin{array}{l}\text { College catalogs } \\
\text { Course enrollment reports } \\
\text { Curriculum guides } \\
\text { Class schedules } \\
\text { Self-study }\end{array}$ \\
\hline RQ 2 & $\begin{array}{l}\text { Has or how has the mission of preparing a } \\
\text { workforce for a global economy been part of } \\
\text { faculty curriculum discussions and changes? }\end{array}$ & $\begin{array}{l}\text { Course syllabi } \\
\text { Curriculum approval } \\
\text { minutes } \\
\text { Discipline meeting minutes }\end{array}$ \\
\hline RQ 3 & $\begin{array}{l}\text { Has or how has the administrative processes } \\
\text { related to curriculum changed since the } \\
\text { merger between community and technical } \\
\text { colleges? What sorts of tensions surround } \\
\text { curriculum discussions since the merger } \\
\text { between community colleges and technical } \\
\text { colleges? }\end{array}$ & $\begin{array}{l}\text { Curriculum committee } \\
\text { minutes } \\
\text { Discipline meeting minutes } \\
\text { Faculty meeting minutes } \\
\text { Policy and procedure } \\
\text { manuals }\end{array}$ \\
\hline RQ 4 & $\begin{array}{l}\text { Has the nature of work with students, } \\
\text { colleagues, and/or administration changed since } \\
\text { the merger? How so? }\end{array}$ & $\begin{array}{l}\text { Faculty policy manuals } \\
\text { Faculty Rules }\end{array}$ \\
\hline
\end{tabular}




\section{Appendix C}

\section{Interview Questions for Liberal Arts/General Education/Occupational/Technical Faculty Members}

The purpose of the interview is to gather data about faculty work and curriculum changes since the merger so that it can be analyzed through Levin's (2006) four categories of behavior in a globalized community college including labor, values, opposition, and economic behaviors.

Study description script: Thank you for taking the time to participate in this interview. First, I would like to give you some background information about the study so you can have a better understanding of the purpose of my study. My interest in curriculum studies grew out of my work as a general education faculty member in a community college that merged with a technical college. Since the merger, changes have occurred in the curriculum development and approval processes. Of particular interest to me is the liberal arts curriculum (general education curriculum) at merged community colleges. Through these interviews I hope to learn about curriculum changes you have experienced since your college merged. Before we begin, do you have any questions?

\section{Can we begin by you telling me about your work experience with the students,} colleagues, and administration before the merger and now?

\section{Prompts:}

Do you feel you interact more with students than before the merger? If so, in what ways. If not, why not?

Would you say you interact more with your colleagues or less since the merger? Why or why not?

What is the extent of your interaction with administrators? How is their role perceived on your campus?

2. In what specific ways has your work changed since the merger of the community and technical colleges?

\section{Prompts:}

Are you teaching more or less since the merger?

Would you say you are teaching a greater variety of classes or less since the merger?

Has your committee work increased or decreased since the merger?

Is professional development emphasized more, less, or remained about the same since the merger? 
3. Prior to the merger, how would you describe the role of your college in the educational hierarchy of your state?

Prompts:

Was the emphasis on transfer education or workforce development?

Was your college mission consistent with what was emphasized?

How has that mission changed since the merger? If any?

Is your current mission consistent with what is emphasized at your college?

4. (For general education faculty member)

As you think about the courses you teach, has/how has the course content in English and communication course requirements changed since the merger?

Prompts:

Do you teach the Toulmin model of argument development? How do you use it?

Do you teach Plato?

How much literature do you cover in your courses? What types?

How do you approach composition? Is it based on essay (descriptive, informative, argumentation?)

Does your discipline use a common syllabus approach? Would you permit me to have a copy of your syllabus for review?

(I may request copies of syllabi before the interview, so some questions will be asked from that document)

When was the last time you, as a discipline, revised your curriculum? Is it more or less since the merger? Why do you think it is more? Less?

Would you say the degree of support for curriculum development/ reform is more, less, or about the same since the merger?

(For occupational/technical faculty member):

5. How have the general education program and the occupational programs been integrated at your college since the merger? 


\section{Prompts:}

As you think about the core curriculum requirements for your program, have/how have

English and communication requirements changed since the merger?

Why do you think these changes occurred?

Do you feel outside agencies, such as accrediting agencies, impact your decision to include or exclude certain general education courses from your curriculum?

When you plan your program curriculum, do you consider that your students may continue their education at a four-year college?

If so, how does this impact your inclusion/ exclusion of general education courses, such as English and communication?

\section{How has the curriculum development and approval process changed since the merger?}

Prompts:

Have you ever served on your local or statewide curriculum committees?

If so, how would you describe the work you did on that committee?

What did this experience mean to you as a faculty member?

Do you recall a particularly controversial curriculum change? If so, what was the nature of the change?

If you want to make a local change, how does that impact other colleges in your state with the same programs?

\section{What do you see as your role in preparing students for a globalized workforce?}

\section{Prompts:}

Do you think of your work in terms of preparing students for job skills at the completion of a certificate AAS or an AA degree?

In what ways do you prepare them for job skills?

Do you see your role as developing their intellectual skills to think critically and engage in problem-solving? If so, how are you doing this in your course/program content? 
7. Do you have any comments you would like to add?

Interview Questions for Chief Academic Officers:

1. Can we begin by you telling me about your work experiences with faculty, students, and colleagues prior to the merger?

\section{Prompts:}

Would you say you are more involved with faculty? If so, how?

Would you say you are more involved with students? If so, how?

Would you say you work more with your colleagues or less?

2. How would you describe the role your college played in the educational hierarchy prior to the merger?

\section{Prompts:}

Do you feel it is the same or has it changed since the merger?

If it has changed, how has it changed?

How have these changes impacted the work of faculty members?

What have these changes meant to students?

3. How would you describe the curriculum development and approval process?

Prompts:

Would you say it has changed from the process before the merger?

If so, how would you describe the process before?

Why do you think these changes have occurred?

What implications do these changes have for faculty? Students?

4. What role do you see yourself playing in the curriculum development and approval process?

\section{Prompts:}

How are curriculum changes initiated?

What are some reasons for those curriculum changes? 
Do you feel faculty members respond differently when you initiate curriculum changes? If so, how?

5. How has the occupational and academic curriculum been integrated at your college since the merger?

\section{Prompts:}

Do you feel this process is working well?

If so, how is it working well?

If not, how could it be improved?

What barriers do you see to academic/occupational integration?

6. In what ways are general education faculty members and occupational/technical faculty members equipping their students with the ability to actively engage in a democratic society through exposure to higher order skill development?

\section{Prompts:}

What components of the curriculum do you think expose students to critical thinking and problem-solving?

What components of the curriculum expose students to the idea of citizenship? What components of the curriculum expose students to the idea of diversity?

\section{Do you have anything you would like to add?}

Thank you very much for your time. If you think of anything else you would like to add, feel free to contact me. 


\section{Appendix D}

\section{Trustworthiness Chart}

\begin{tabular}{|c|c|c|}
\hline Construct & Potential Issues & Strategy \\
\hline Credibility & $\begin{array}{l}\text { whether the inquiry was } \\
\text { conducted accurately }\end{array}$ & $\begin{array}{l}\text { triangulation } \\
\text { peer debriefing } \\
\text { member checking }\end{array}$ \\
\hline Transferability & $\begin{array}{l}\text { whether the study can be } \\
\text { generalized to other } \\
\text { contexts. }\end{array}$ & $\begin{array}{l}\text { document trail for data } \\
\text { review } \\
\text { thick description or a } \\
\text { detailed account of } \\
\text { phenomenon }\end{array}$ \\
\hline Dependability & $\begin{array}{l}\text { whether the researcher } \\
\text { accounts for changing } \\
\text { conditions in the } \\
\text { phenomenon under study } \\
\text { as well as the study } \\
\text { design due to refined } \\
\text { understanding of the } \\
\text { setting (Marshall \& } \\
\text { Rossman, 1995.p. 145). }\end{array}$ & $\begin{array}{l}\text { document trail } \\
\text { peer audit of methods }\end{array}$ \\
\hline Confirmability & $\begin{array}{l}\text { whether the data help } \\
\text { confirm the general } \\
\text { findings and lead to the } \\
\text { implications }\end{array}$ & $\begin{array}{l}\text { keep research findings for } \\
\text { audit } \\
\text { reflexivity } \\
\text { triangulation }\end{array}$ \\
\hline
\end{tabular}


Appendix E

Data Analysis Documents

Table 1

Ratings of Expected Utility of Each Case for Each Theme

\begin{tabular}{|l|c|c|c|}
\hline Original Multi-case Themes & $\mathrm{Cl}$ & $\mathrm{C} 2$ & $\mathrm{C}$ \\
\hline $\begin{array}{l}\text { Theme 1: } \\
\text { Curriculum changes in } \\
\text { English and communication } \\
\text { since merger }\end{array}$ & $\mathrm{H}$ & $\mathrm{H}$ & \\
\hline $\begin{array}{l}\text { Theme 2: } \\
\text { Mission change and } \\
\begin{array}{l}\text { curriculum changes since } \\
\text { merger }\end{array}\end{array}$ & $\mathrm{H}$ & $\mathrm{H}$ & $\mathrm{M}$ \\
\hline $\begin{array}{l}\text { Theme 3: } \\
\text { Curriculum administrative } \\
\text { process change since merger }\end{array}$ & $\mathrm{H}$ & $\mathrm{H}$ & $\mathrm{H}$ \\
\hline $\begin{array}{l}\text { Theme 4: } \\
\text { Conflict }\end{array}$ & & $\mathrm{H}$ & $\mathrm{H}$ \\
\hline $\begin{array}{l}\text { Theme 5: } \\
\text { Faculty work related to } \\
\text { admident, colleague, and }\end{array}$ & $\mathrm{H}$ & $\mathrm{H}$ & $\mathrm{H}$ \\
\hline \begin{tabular}{l} 
Added Themes \\
\hline $\begin{array}{l}\text { Theme 6: } \\
\text { Leadership }\end{array}$
\end{tabular} & & $\mathrm{H}$ & $\mathrm{L}$ \\
\hline
\end{tabular}


Table 2

Ratings of Case Study Findings

\begin{tabular}{|c|c|c|c|c|c|c|}
\hline & \multicolumn{6}{|c|}{ Themes } \\
\hline Case C1 & $\mathbf{1}$ & $\mathbf{2}$ & $\mathbf{3}$ & $\mathbf{4}$ & $\mathbf{5}$ & $\mathbf{6}$ \\
\hline Finding I & $\mathrm{H}$ & $\mathrm{H}$ & $\mathrm{H}$ & $\mathrm{H}$ & $\mathrm{H}$ & \\
\hline Finding II & $\mathrm{H}$ & $\mathrm{H}$ & $\mathrm{H}$ & $\mathrm{H}$ & $\mathrm{H}$ & \\
\hline Finding III & $\mathrm{H}$ & $\mathrm{H}$ & $\mathrm{M}$ & $\mathrm{M}$ & $\mathrm{M}$ & \\
\hline Finding IV & $\mathrm{H}$ & $\mathrm{H}$ & $\mathrm{M}$ & $\mathrm{H}$ & $\mathrm{M}$ & \\
\hline Finding V & $\mathrm{H}$ & $\mathrm{M}$ & $\mathrm{H}$ & $\mathrm{L}$ & $\mathrm{M}$ & \\
\hline Finding VI & & $\mathrm{H}$ & & & & \\
\hline Case C2 & & & & & & \\
\hline Finding I & $\mathrm{H}$ & $\mathrm{H}$ & $\mathrm{H}$ & $\mathrm{H}$ & $\mathrm{M}$ & $\mathrm{M}$ \\
\hline Finding II & $\mathrm{H}$ & $\mathrm{H}$ & $\mathrm{H}$ & $\mathrm{H}$ & $\mathrm{M}$ & \\
\hline Finding III & & $\mathrm{H}$ & $\mathrm{H}$ & $\mathrm{H}$ & $\mathrm{H}$ & \\
\hline Finding IV & & $\mathrm{H}$ & $\mathrm{H}$ & $\mathrm{H}$ & $\mathrm{M}$ & \\
\hline Finding V & & & & $\mathrm{H}$ & & \\
\hline Case C3 & & & & & & \\
\hline Finding I & $\mathrm{H}$ & $\mathrm{H}$ & $\mathrm{H}$ & $\mathrm{H}$ & $\mathrm{H}$ & \\
\hline Finding II & $\mathrm{M}$ & $\mathrm{H}$ & $\mathrm{H}$ & $\mathrm{H}$ & $\mathrm{H}$ & \\
\hline Finding III & $\mathrm{H}$ & $\mathrm{M}$ & $\mathrm{M}$ & $\mathrm{H}$ & $\mathrm{M}$ & \\
\hline Finding IV & $\mathrm{M}$ & & & $\mathrm{M}$ & & \\
\hline Finding V & $\mathrm{H}$ & & & $\mathrm{H}$ & & \\
\hline
\end{tabular}

$\mathrm{H}=$ high importance; $\mathrm{M}=$ middling importance; $\mathrm{L}=$ low importance from Multiple Case Study Analysis by Robert Stake, New York: The Guilford Press

Adapted with permission 


\section{Table 3}

Cross-case themes in order of importance to quintain

\begin{tabular}{|l|c|c|c|}
\hline \multicolumn{1}{|c|}{ Themes } & \multicolumn{2}{c|}{ Colleges } \\
\hline \multicolumn{1}{|c|}{ C1 } & C2 & C3 \\
\hline Diminishing variety of course offerings & $\mathrm{X}$ & $\mathrm{X}$ & \\
\hline Diminishing general education in AAS programs & $\mathrm{X}$ & $\mathrm{X}$ & \\
\hline Curriculum process perceived as top-down & $\mathrm{X}$ & $\mathrm{X}$ & $\mathrm{X}$ \\
\hline Curriculum integration needs work & $\mathrm{X}$ & $\mathrm{X}$ & $\mathrm{X}$ \\
\hline Curriculum revision for more coherence & $\mathrm{X}$ & & $\mathrm{X}$ \\
\hline More focus on critical thinking and problem-solving activities & $\mathrm{X}$ & $\mathrm{X}$ & \\
\hline Student quality declining & $\mathrm{X}$ & $\mathrm{X}$ & $\mathrm{X}$ \\
\hline Discontent with academically and socially underprepared students & $\mathrm{X}$ & $\mathrm{X}$ & $\mathrm{X}$ \\
\hline More classroom management issues & $\mathrm{X}$ & $\mathrm{X}$ & $\mathrm{X}$ \\
\hline More grant writing for faculty professional development & $\mathrm{X}$ & $\mathrm{X}$ & $\mathrm{X}$ \\
\hline Budget constraints impacting work of faculty & $\mathrm{X}$ & $\mathrm{X}$ & $\mathrm{X}$ \\
\hline Faculty value curriculum committee work & $\mathrm{X}$ & $\mathrm{X}$ & $\mathrm{X}$ \\
\hline Mission is more workforce development focused & $\mathrm{X}$ & $\mathrm{X}$ & \\
\hline Distance between administration and faculty & $\mathrm{X}$ & & $\mathrm{X}$ \\
\hline Top-down communication from administration & $\mathrm{X}$ & & $\mathrm{X}$ \\
\hline Cultural differences impacted integration after merger & $\mathrm{X}$ & & $\mathrm{X}$ \\
\hline Physical environments after merger & & $\mathrm{X}$ & $\mathrm{X}$ \\
\hline More diverse student body & & $\mathrm{X}$ & $\mathrm{X}$ \\
\hline
\end{tabular}




\section{CURRICULUM VITAE}

\section{Ann E. Norton}

Madisonville Community College

2000 College Drive

Madisonville, KY 42431

Education \& Training

University of Louisville Louisville, KY

2011

- Ph.D. Educational Leadership and Organizational Development

Western Kentucky University Bowling Green, KY

1988-1990

- M.A. Communication

1983-1988

- B.A. Public Relations

\section{Leadership/Honors}

Golden Key International Honor Society Member 2009-2010

Kentucky Communication Association West Regional Representative 2009-2010

Who's Who in America's Teachers

MCC Advocacy Team

MCC Board of Directors Faculty Representative 2009-12.

MCC Faculty Chair 2002-2006

UKCCS rules committee chair

Glema Mahr Center for the Arts Advisory Board Member 2003-2006

\section{Research/Presentations}

League for Innovation Conference, Reno, NV

Southern States Communication Association Conference, Norfolk, VA Southeastern Association for Community College Research Lexington, KY New Horizons Conference, Lexington, KY

Presentation Title: Implementing Critical Thinking in a Basic Public Speaking Course 